\title{
Lithological Influences on Contemporary and Long-Term Regolith Weathering at the Luquillo Critical Zone Observatory
}

\author{
Heather L. Buss ${ }^{* a}$, María Chapela Lara ${ }^{a}$, Oliver W. Moore ${ }^{\mathrm{a}}$, Andrew C. Kurtz ${ }^{\mathrm{c}}$, Marjorie \\ S. Schulz ${ }^{\mathrm{b}}$, Art F. White ${ }^{\mathrm{b}}$
}
${ }^{a}$ School of Earth Sciences, University of Bristol, Wills Memorial Building, Queens Road, Bristol BS8 1RJ, UK
${ }^{\mathrm{b}}$ U.S. Geological Survey, 325 Middlefield Rd., MS-420, Menlo Park, CA 95025, USA
${ }^{c}$ Department of Earth and Environment, Boston University Boston, MA 02215, USA

* Corresponding author: h.buss@ bristol.ac.uk,

Tel: +44(0)11733 14751, Fax: +44(0)1179253385 
Lithologic differences give rise to the differential weatherability of the Earth's surface and globally variable silicate weathering fluxes, which provide an important negative feedback on climate over geologic timescales. To isolate the influence of lithology on weathering rates and mechanisms, we compare two nearby catchments in the Luquillo Critical Zone Observatory in Puerto Rico, which have similar climate history, relief and vegetation, but differ in bedrock lithology. Regolith and pore water samples with depth were collected from two ridgetops and at three sites along a slope transect in the volcaniclastic Bisley catchment and compared to existing data from the granitic Río Icacos catchment. The depth variations of solid-state and pore water chemistry and quantitative mineralogy were used to calculate mass transfer (tau) and weathering solute profiles, which in turn were used to determine weathering mechanisms and to estimate weathering rates.

Keywords: chemical weathering, critical zone, regolith, saprolite, soil formation 
Silicate mineral weathering in the critical zone is a primary source of solutes and sediments to streams and oceans where they contribute to the sequestration of $\mathrm{CO}_{2}$, providing a negative climate feedback over geologic time (e.g., Berner and Berner, 1997). Therefore, the relative weatherability of Earth's surface (e.g., Kump et al., 2000) is a fundamental constraint on Earth's climate as well as on biogeochemical cycles. Relative weatherability and the lithologic mechanisms that produce silicate weathering products can only be identified and isolated by comparing weathering of different rock types while controlling for climate variability and other parameters (e.g., Berner, 2008). However, many previous studies of silicate weathering fluxes have not controlled for climate in this way (e.g., Bluth and Kump, 1994; White and Blum, 1995; Kump et al., 2000; Dessert et al., 2001).

Silicate weathering also provides mineral nutrients to soils and regolith and is an important factor in the rate of regolith formation and evolution. It is likely that the majority of exported solutes are liberated by weathering processes occurring deep in the critical zone (e.g., Rad et al., 2007; Kurtz et al., 2011; Schopka and Derry, 2012) where weathering-susceptible primary minerals are abundant and exposed to reactive fluids: at rock-regolith interfaces or within bedrock aquifers and fracture networks near the water table. Weathering at rock-regolith interfaces produces porosity and essential mineral nutrients (e.g., $\mathrm{P}, \mathrm{Mg}, \mathrm{Ca}, \mathrm{K}, \mathrm{Fe}$ ), which support terrestrial ecosystems (Walker and Syers, 1976; Buss et al., 2005; 2008; 2010; Graham et al., 2010; Minyard et al., 2011; Hahm et al., 2014). Although near-surface and deep critical zone ecosystems may operate as largely independent nutrient cycles (Buss et al., 2005), especially in deep tropical regolith, they may still affect one another because $i$ ) regolith formed at the rock-regolith interface will effectively move towards the surface as erosion lowers the ground surface over time (e.g., Brantley and White, 2009) and $i$ ) weathering reactions and soil organisms can alter the chemistry and reactivity of infiltrating water. For example, respiration of $\mathrm{O}_{2}$ by soil microorganisms reduces the concentration of $\mathrm{O}_{2}$ in pore water, which can slow down both geochemical and biological oxidation reactions (Fletcher et al., 2006; Buss et al., 2008; Bazilievskaya et al., 2013; Brantley et al., 2014).

In in situ critical zones, the link between the near-surface (classical soil) and deep zones (fractured and disaggregating bedrock) is saprolite. Here we use the term saprolite to refer to friable material weathered in place (not strictly limited to isovolumetrically weathered material), soil for the overlying, bioturbated, rooting zone and regolith as a general term encompassing soil, saprolite and any mobile, weathered, friable material (e.g., Taylor and Eggleton, 2001). Mineral weathering and biogeochemical processes within saprolite determine many characteristics of the overlying soil; indeed, saprolite has traditionally been considered parent material, or C-horizon, in classical soil science (Richter and Markewitz, 1995). Furthermore, as noted above, mineral weathering and 
biogeochemical processes within regolith also determine the reactivity of pore water that reaches the underlying bedrock, with implications for whole-rock weathering rates, regolith formation rates, watershed solute fluxes, and modulation of global $\mathrm{CO}_{2}$. Mineral weathering reactions within regolith also produce nutrients and energy sources for resident microorganisms (e.g., Buss et al., 2005).

Despite the importance of silicate mineral weathering rates to myriad critical zone and global processes, relatively few field-based rates have been measured (see compilation in White and Buss, 2014) and most weathering studies of volcanic materials have focused on basaltic terrains. Different lithologies have different mineral assemblages and different characteristics (e.g., grain size) that may affect mineral weathering mechanisms and rates. Although andesite and basalt make up similar proportions of the global land surface, andesites are more common on tropical and subtropical islands and near active margins while many of the basaltic terrains worldwide are located on continents and at higher latitudes. Tropical watersheds, which cover only about $25 \%$ of the terrestrial surface, produce $65 \%$ of the dissolved silica flux to the oceans via mineral weathering processes (Stallard and Edmond, 1983; Meybeck, 1987). Volcanic islands, globally, contribute about $30 \%$ of the solute flux to the world's oceans despite representing only $9 \%$ of the terrestrial surface (Rad et al., 2007). Therefore, silicate weathering fluxes from low-latitude andesites may be more significant to global $\mathrm{CO}_{2}$ consumption than fluxes from basalts (Goldsmith et al., 2010). However, measured watershed-scale silicate weathering fluxes in andesitic and basaltic watersheds are similar (McDowell and Asbury, 1994; Dessert et al., 2003 and references therein; Rad et al., 2006; Goldsmith et al., 2008; 2010).

The aforementioned andesitic weathering studies determined chemical weathering fluxes from concentration and discharge data for rivers draining catchments of interest, effectively providing watershed-averaged, endpoint views of chemical weathering from which weathering mechanisms and rates are inferred. That approach is complemented by studies that examine chemical weathering processes within weathering profiles, i.e., in situ, which provide mechanistic information enabling determination of mineral-specific reaction rates (Brantley and White, 2009; White and Buss, 2014) as well as providing spatially resolved information about mineral nutrient availability in terrestrial ecosystems (e.g., Buss et al., 2005). Several studies of both types have been done in the Luquillo Mountains of Puerto Rico, in what is now the Luquillo Critical Zone Observatory (LCZO) (McDowell and Asbury, 1994; Murphy et al., 1998; White et al., 1998; Schulz and White, 1999; Buss et al., 2008; 2010; Stallard, 2012; Buss et al., 2013), mostly within the granitic Río Icacos watershed. Here we present weathering profile data from the andesitic, meta-volcaniclastic Bisley catchment as a comparison to the neighboring granitic Río Icacos catchment to investigate the influence of lithology on regolith weathering processes and rates, and on mineral nutrient 
availability. Solid-state elemental and mineral abundances with depth in the regolith were used to estimate mineral weathering rates and elemental fluxes over the timescale of regolith development (long-term rates). Such calculations, from White (2002), assume that a linear approximation of the gradient of the weathering front (depth-dependent depletion of a mobile element or weathering mineral) represents the sum of two vectors: the whole-rock weathering advance rate and the element- or mineral-specific weathering rate. Similarly, solute profiles were used to estimate elemental weathering fluxes on the timescale of water infiltration into the regolith (contemporary rates); in this case the gradient results from vectors representing the hydraulic flux and the elementspecific weathering flux.

\section{FIELD SITE}

The Luquillo Mountains in northeastern Puerto Rico are characterized by steep, rugged topography, highly dissected valleys, a hot and humid climate, thick regolith, and dense, tropical vegetation. The Luquillo Mountains host the $113 \mathrm{~km}^{2}$ Luquillo Experimental Forest (LEF), a forest preserve administered by the U.S. Forest Service that has been designated an International Biosphere Reserve by UNESCO and hosts the U.S. Geological Survey (USGS) Luquillo Water Energy and Biogeochemical Budgets (WEBB) project, a National Science Foundation (NSF) long-term ecological research site (Luq-LTER) and a NSF critical zone observatory (LCZO). Several large river systems drain the Luquillo Mountains north to the Atlantic Ocean (Río Mameyes, Río Sabana, Río Espíritu Santo, and Río Fajardo) or south to the Caribbean Sea (Río Blanco).

The Bisley experimental watersheds are a sequence of 5 adjacent, small catchments (numbered 1-5, from east to west) that feed the Río Mameyes. Elevation in the $44 \mathrm{~km}^{2}\left(17.8 \mathrm{~km}^{2}\right.$ gaged area) Río Mameyes watershed ranges from 80 to $1050 \mathrm{~m}$. In the Bisley watersheds, elevation ranges from 260-400 m. Mean monthly temperatures in the Bisley watersheds are relatively constant, fluctuating seasonally by about $3-4^{\circ} \mathrm{C}$, with winters averaging about $24^{\circ} \mathrm{C}$ and summers about $27.5^{\circ} \mathrm{C}$ (Schellekens, et al., 2004; NWS, 2007). Rainfall increases with altitude in the Luquillo Mountains, from about 2500 to $4500 \mathrm{~mm} \mathrm{y}^{-1}$ over $1200 \mathrm{~m}$ of altitude (Garcia-Martino et al., 1996). The Bisley watersheds typically receive 3000-4000 $\mathrm{mm} \mathrm{y}^{-1}$ of rainfall (Scatena, 1989), largely delivered in short, but intense, storm events. Mean annual runoff from 1991-2005 was 3760 $\mathrm{mm} \mathrm{y}^{-1}$ in the Río Icacos and $2750 \mathrm{~mm} \mathrm{y}^{-1}$ in the Río Mameyes (Murphy and Stallard, 2012). Mineral aerosol dust from Africa contributes significant nutrients to the Caribbean islands; P flux from dust was estimated at $210 \pm 70 \mathrm{~kg} \mathrm{ha}^{-1} \mathrm{y}^{-1}$ to the Río Icacos watershed (Pett-Ridge, 2009) and dust is estimated to account for 0-8\% of shallow ridgetop soils across the LCZO (McClintock et al., 2015). 
The Bisley watersheds are underlain by the $\sim 100 \mathrm{Ma}$, basaltic to andesitic, marine-bedded meta-volcaniclastic Fajardo Formation (Jolly et al., 1998), formed from a near-sea level volcanic complex that produced pyroclastic debris that was deposited in the sea after transport and reworking

141 (Seiders 1971). The Fajardo Formation underwent contact metamorphism during the intrusion of the nearby Río Blanco Quartz Diorite stock (actually a tonalite according to the current IUGS classification scheme), as evidenced by the mineral assemblages (Buss et al., 2013), and is comprised of several units including an upper thin-bedded tuffaceous siltstone and sandstone, an upper thick-bedded tuff, a lower thin-bedded tuffaceous sandstone and siltstone, a lower thickbedded tuff, and an undivided unit (Briggs, 1973; Briggs and Aguilar-Cortes, 1980). Bed thicknesses vary and coarse tuff, breccias, and cherty or calcareous siltstone beds are found in some units. Although the bedrock exposures in the Bisley watersheds appear homogeneous, the catchment is underlain by the upper thick-bedded tuff unit, which includes some breccias, lithic andesitic clasts, calcareous siltstone, and some pumice and red scoria (Briggs and Aguilar-Cortes, 1980). The grain size and color of bedrock samples vary slightly within the Bisley watershed, but the elemental composition is not highly variable (Buss et al., 2013). For simplicity and consistency with other published studies from this site, we refer to the Bisley bedrock as "volcaniclastic" and the intrusion bedrock as "granitic" throughout the manuscript.

Ridges in the Bisley watersheds are mantled by thick (9 to $15+\mathrm{m}$ ), highly cohesive regolith. Landslides, soil creep, and tree throws incise and sharpen the ridges, and leave high angle slopes (in Bisley 1 and 2, over $50 \%$ of the area has slopes $>45^{\circ}$ and $15 \%$ of the slopes are $>70^{\circ}$; Scatena, 1989) with thinner regolith ( 1 to $3 \mathrm{~m}$ ). By area, Bisley 1 and 2 are about $17 \%$ ridges and $65 \%$ slopes (Scatena et al., 1993). Some slopes, lower elevation ridges, and valleys are riddled with boulders. The Bisley 1 ridgetop soils are Ultisols of the Humatas Series, which are 0.8-1.0 m deep, moderately well-drained, very-fine, parasesquic, isohyperthermic Typic Haplohumults (Scatena, 1989; Silver et al., 1994; USDA NCRS, 2002). Biomass in the Bisley watersheds (Scatena et al., 1993 ) is dominated by Tabonuco trees (Dacryodes excelsa), which make up $45.7 \%$ of the aboveground biomass in the Bisley 1 and 2 watersheds. Non-seedling trees $(>2.5 \mathrm{~cm}$ diameter at 1.3 $\mathrm{m}$ height) and coarse roots $(>0.5 \mathrm{~cm})$ make up 73.5 and $24.1 \%$ of vegetation biomass, respectively, in Bisley 1 and 2. Ridges contain the highest aboveground biomass per unit area compared to other topographic categories (Scatena et al., 1993). Sierra palm trees (Prestoea acuminata) and ferns are also common, particularly in the valleys. Soil is mantled by a thin layer of leaf litter in most areas.

\section{METHODS}


Regolith cores, approximately $10 \mathrm{~cm}$ diameter, were collected by hand-augering to the point of refusal at 5 sites (Fig. 1) in the Bisley 1 catchment. Two of the sites, B1R and B1S1, are located on cuchillos (knife-edge ridges). Site B1R is located at N18 $18.831, \mathrm{~W}^{\circ} 44.567$ (NAD83), at about 400 masl (near the top of a north-south striking ridge), along the drainage divide between the Bisley 1 stream (a tributary of the Río Mameyes) and the Río Sabana. Both of these river (río) systems drain north to the Atlantic Ocean. Site B1S1 is located at N18 $18.956, \mathrm{~W}^{\circ} 5^{\circ} 44.700$, at about 285 masl and is $330 \mathrm{~m}$ northwest of site B1R on a ridge about $55 \mathrm{~m}$ northeast and $50 \mathrm{~m}$ above the Bisley 1 stream gage. Sites B1S2, B1S3, and B1S4 are located along the slope (approximate elevations: 280, 275, and 268 masl, respectively) between ridgetop site B1S1 and the Bisley 1 stream (Fig. 1). Site B1S4 $\left(\mathrm{N} 18^{\circ} 18.937, \mathrm{~W}^{\circ} 5^{\circ} 44.711\right)$ is located within the floodplain of the Bisley 1 stream. The deepest regolith core from each site was collected for analysis, but numerous holes were augered in the course of installing pore water and gas samplers. Additional holes were augered at several points along the length of the B1R ridge, between the top (where the site is located) and about 440 $\mathrm{m}$ north. Partially weathered rock fragments were collected during augering and from saprolite outcrops along the road. Soil pits were dug at sites B1R and B1S1 to examine the soil texture and appearance. Bedrock samples were collected from exposed corestones and from two boreholes drilled to 27.0 and $37.2 \mathrm{~m}$ depth near the Bisley 1 stream gage as reported in Buss et al. (2013). refusal. Pore water samplers were left under approximately 80 cbars vacuum and the pore waters were collected approximately monthly from January 2007 - September 2008 at site B1R and from January 2008 - November 2009 at sites B1S(1-4). Openfall precipitation (wet + dry deposition) was measured and sampled monthly from a collector situated on an observation tower near site B1R, above the forest canopy.

Regolith gas samplers (3.2 mm stainless steel tubing tipped with stainless steel mesh) were bundled and installed in hand augered holes at sites B1R and B1S1 in Bisley and site LG1 in Río Icacos. Although gas samplers were installed and sampled by the USGS at LG1 in the 1990's (White et al., 1998), degradation of those samplers and later improvements to the sampler design and collection methodology prompted us to install new equipment. The screened openings were packed in quartz sand at depth intervals separated by bentonite plugs and native regolith. Gas tubes were purged using a plastic syringe prior to sampling. Samples were taken with a gas-tight apparatus attached to a needle and collected in septa-sealed gas canisters under vacuum, which were 
shipped to the USGS in Menlo Park for measurement of $\mathrm{O}_{2}$ and $\mathrm{CO}_{2}$ by gas chromatography (GC). Sampling canisters were deemed airtight as standards were also transported to and from Puerto Rico in sampling canisters and were still accurate when analysed by GC upon return.

Gravimetric water content of the regolith was measured by weighing augered samples, stored in airtight containers, before and after air-drying. Bulk densities were determined from samples collected with a hand soil corer with removable internal rings of known volume (Soil Moisture, Santa Barbara) to depths of 5.0 and $6.7 \mathrm{~m}$ at sites B1R and B1S1, respectively. Density measurements excluded samples with cobbles and large pebble-sized rock fragments.

Bulk solid-state chemical analysis was performed on pulverized and sieved $(150 \mu \mathrm{m})$ rock, weathered rock fragments, and regolith samples. Regolith samples were sieved to $2 \mathrm{~mm}$ prior to pulverization. Solid samples were digested by lithium metaborate fusion and major and minor elements (Al, Ca, Cr, Fe, K, Mg, Mn, Na, P, Si, Ti, Ba, Sr, Zn, Zr) were determined by ICP-AES, and $\mathrm{FeO}$ was determined by titration after multi-acid digest (SGS Mineral Laboratories, Ontario, Canada). Splits of some solid samples were dissolved in a multi-acid digest ( $\left.\mathrm{HF}, \mathrm{HCl}, \mathrm{HNO}_{3}\right)$ and also analyzed via ICP-MS at the USGS (Menlo Park, CA) for comparison. Exchangeable cations were estimated by ICP-MS analysis (USGS, Menlo Park, CA) of $\mathrm{NH}_{4}$-acetate extracts of regolith samples. Briefly, regolith samples $(5 \mathrm{~g})$ were extracted in $100 \mathrm{ml}$ of un-buffered $0.1 \mathrm{~N} \mathrm{NH}_{4}$-acetate. Samples were shaken for one hour and allowed to settle overnight. Supernatants were removed with a syringe and filtered to $0.45 \mu \mathrm{m}$ (SFCA-membrane, Cole-Parmer).

Pore waters from the suction samplers and precipitation samples were filtered in the laboratory and the $\mathrm{pH}$ and alkalinity were measured on some pore waters. Water samples were analyzed by ion chromatography (IC) for anions and ICP-MS for cations (both at the USGS in Menlo Park, CA). Elemental concentrations in precipitation samples were volume-averaged.

Thin sections were prepared from rock, weathered rock fragments, and regolith samples (Vancouver Petrographics, Canada and Spectrum Petrographics, Vancouver, WA, USA). Scanning electron microscopy (SEM) in backscattered electron mode with energy dispersive spectrometry (EDS) were performed on thin sections at the USGS (Menlo Park, CA, USA) and at the University of Bristol. Powder X-ray diffraction was performed at the USGS (Boulder, CO, USA), using a Siemens D500 diffractometer. Quantitative mineral abundances were determined from powder Xray diffraction data by whole-pattern fitting using the computer program ROCKJOCK (Eberl, 2003) and compared to bulk chemical abundances using HANDLENS (Eberl, 2008). Sample preparation for quantitative analysis was performed as described in Eberl (2003). 
Solid and solute data for the ridgetop site LG1 in the granitic Río Icacos watershed from Buss et al. (2005), White (2002), White et al. (1998) and Schulz and White (1999) are presented as comparison to the ridgetop sites $\mathrm{B} 1 \mathrm{~S} 1$ and $\mathrm{B} 1 \mathrm{R}$ in the volcaniclastic Bisley watershed. Uncertainties presented for all data were estimated as either the detection limits of the analytical method (mineralogy by XRD, elemental chemistry by ICP-AES, ICP-MS or IC), laboratory repeatability (moisture content, bulk density) or the standard error (SE) of the means for the averaged datasets (compositions of rainfall, pore waters and pore gases sampled over time and of bedrock sampled at different locations). We present SE for all averaged data to indicate the statistical accuracy of the averages, because we later use these averages to calculate average mass transfer, average elemental fluxes and average mineral weathering rates over annual (or longer) timescales. Therefore, in this context, SE is more appropriate than standard deviations (SD), which reflect the scatter in the data used in the averages (e.g., month-to-month pore water chemistry). Uncertainties presented for all calculated values were fully propagated from the aforementioned uncertainties on the contributing datasets using standard error propagation rules.

\section{RESULTS}

\subsection{Physical Observations and Measurements}

Visibly unweathered rock samples recovered from the boreholes and the stream beds are fine- to medium fine-grained, dark blueish or greenish grey. Augered cores and soil pits reveal hydraulically unsaturated, fine-grained regolith that is red to orange in color except for some grey mottling at $\sim 1.0$ to $1.5 \mathrm{~m}$ depth. An exception is site B1S4, located in the floodplain of the Bisley 1 stream, which was saturated and entirely grey in color. We were unable to reach bedrock by handaugering at site B1R and stopped at $16 \mathrm{~m}$ after 4 days. Site B1S3 is located on a narrow flat produced by the roots of a fallen tree and as such should be regarded as physically disturbed. Occasional, small weathered clasts were recovered from the auger at all sites. Relict mineral grains and thin, linear, black Mn-oxide and white clay zones are visible in the regolith.

Bedrock density is $2.3 \mathrm{~g} \mathrm{~cm}^{-3}$, measured by volume displacement. Dry bulk density of the regolith generally increases with depth in the soil, then decreases slightly in the underlying regolith (Table 1). B1R soils and regolith are slightly denser than B1S1. Porosity is estimated from dry bulk density $\rho$ and specific density $\rho_{\mathrm{s}}$ (the density of soil solids, commonly assumed to be $2.65 \mathrm{~g} \mathrm{~cm}^{-1}$ ) as shown:

$$
\theta=100\left(1-\frac{\rho}{\rho_{s}}\right)
$$


Average estimated porosity and \% water content by mass (Table 1) are higher in B1S1 regolith (60\% and $30 \%$ respectively) than in B1R regolith (46\% and $20 \%$, respectively).

\subsection{Chemistry}

272

273

\subsubsection{Solid-State Chemistry}

Regolith samples are significantly depleted in base cations (Table 2). Ferrous iron, measured at site B1R only, was very low ( $\leq 0.2 \mathrm{wt} \%$ ) within the soil (approx. 0-1.0 $\mathrm{m}$ depth) and below detection $(<0.1 \mathrm{wt} \%)$ at all depths below $1 \mathrm{~m}$. Solid state elemental concentrations are more variable with depth at site B1R than at the other sites, with no discernible trend in most elements. In contrast, solid-state concentrations with depth at sites B1S(1-4) generally follow expected trends with mobile cations (e.g., $\mathrm{Mg}, \mathrm{K}$ ) increasing with depth and relatively immobile cations (Al, Si, Fe, Ti, $\mathrm{Zr}$ ) remaining approximately constant or decreasing with depth. $\mathrm{Na}$ and $\mathrm{Ca}$ are very low or below detection in most samples at all sites, but Ca shows an increase with depth at site B1S4. Manganese increases with depth at site B1S1.

Total extractable cation content of the regolith is very low: about $0.5 \mathrm{meq} / 100 \mathrm{~g}$ at the surface of B1S1, increasing with depth to $2.7 \mathrm{meq} / 100 \mathrm{~g}$ at $9.3 \mathrm{~m}$. The B1R regolith extractable cation content is even lower, measuring below about $0.5 \mathrm{meq} / 100 \mathrm{~g}$ except in the upper soil layer. Extractable cations are dominated by $\mathrm{Mg}$ in both profiles and make up $\leq 10 \%$ of the total $\mathrm{Ca}$ in the bulk regolith, $\leq 8 \%$ of the total $\mathrm{Mg}, \leq 4 \%$ of the total $\mathrm{K}$ and $\leq 14 \%$ of the total $\mathrm{Na}$ (Table 3 ).

\subsubsection{Solute Chemistry}

Average pore water compositions for the most abundant elements (and Sr) are shown in Table 4. Pore water solutes were dominated by $\mathrm{Si}$ and $\mathrm{Na}$ at all sites. The predominance of pore water cations at the B1S(1-4) and B1R sites generally decreases in the order $\mathrm{Na}>\mathrm{Si}>\mathrm{Mg}>\mathrm{Ca} \geq \mathrm{K}>\mathrm{Al}$ $>\mathrm{Mn}>\mathrm{Ba} \approx \mathrm{Sr}>\mathrm{Rb}$, with Fe below detection in most samples. Silicon concentrations were high at the surface, decreasing with depth in the soil layer (upper 1.0-1.5 m), then increasing with depth in the saprolite at all Bisley sites (Fig. 2). Average anion concentrations in the pore waters generally decrease in the order $\mathrm{Cl}>>\mathrm{SO}_{4} \approx \mathrm{NO}_{3}>\mathrm{Br}>\mathrm{F}$. Fluoride was below detection in most samples and $\mathrm{NO}_{3}$ exceeds $\mathrm{SO}_{4}$ in a number of samples. Phosphorus was below detection in all pore water samples.

\subsubsection{Soil gas compositions and $\mathrm{pH}$ distributions}

Measured $\mathrm{pH}$ of pore waters (Table 4) ranged from 4.4 to 5.4 in the ridgetop profiles (B1S1, B1R) and the deepest slope site B1S2. Sites B1S(3-4) had slightly higher pHs up to 5.7. However, these values may reflect degassing under vacuum in the suction water samplers (White et al., 2005) and 
we therefore corrected a selection of these values to determine in situ pore water $\mathrm{pH}$ by assuming equilibrium between dissolved inorganic carbonate (as alkalinity) and soil gas $\mathrm{CO}_{2}$ (Table 4, Fig. 3) using PHREEQC (Parkhurst and Appelo, 1999). In situ pH (only determined for B1S1 and B1R) ranged from 3.9 to 4.7 at B1S1, generally slightly lower than measured values, and from 4.6 to 5.3 at B1R, generally slightly higher than measured values.

$\mathrm{CO}_{2}$ partial pressures increased with depth, reaching a maximum of $0.065 \mathrm{~atm}(6.5 \%)$ at $7.3 \mathrm{~m}$ depth in B1S1 (the deepest gas sampling point in that profile) and $0.042 \mathrm{~atm}$ at $1.5 \mathrm{~m}$ depth at B1R, then decreasing to $0.032 \mathrm{~atm}$ at $8.2 \mathrm{~m}$ depth (Fig. 3). Oxygen partial pressures decreased with depth at both sites, reaching a minimum of 0.127 atm at $7.3 \mathrm{~m}$ in B1S1 (Liermann et al., 2015). Site B1S1 exhibited a marked drop in $\mathrm{O}_{2}$ at $3 \mathrm{~m}$ depth, corresponding to a marked increase in $\mathrm{CO}_{2}$ at the same depth. $\mathrm{CO}_{2}$ in the soil layers ( $<1 \mathrm{~m}$ depth) of the Río Icacos regolith is about double compared to both Bisley sites, but increases only slightly with depth to $0.05 \mathrm{~atm}$ at $7.3 \mathrm{~m}$ with a corresponding decrease in $\mathrm{O}_{2}$ to $0.169 \mathrm{~atm}$.

\subsection{Mineralogy}

Optical microscopy of 9 bedrock thin sections taken from corestones of the volcaniclastic bedrock, obtained by continuous core drilling to $37 \mathrm{~m}$ depth (Fig. 1; Buss et al., 2013), reveal tuff breccias with andesitic clasts. Phenocrysts are randomly dispersed in a fine groundmass of volcanic glass that has been largely devitrified to microcrystalline quartz and plagioclase, which in turn has been extensively sericitized, forming fibrous illite, and chloritized. Epidote grains also contribute to the groundmass. Phenocrysts include clinopyroxene (augite), plagioclase and quartz. Orthoclase phenocrysts are present in some thin sections, but not all. Subhedral chlorite grains indicate replacement of biotite or plagioclase and fine, fibrous chlorite grains in coarse clusters make up a large proportion of the groundmass. Magnetite is present as inclusions in augite and plagioclase. Fibrous actinolite pseudomorphs of augite, a hydrothermal alteration product of pyroxenes commonly known as uralite (Deer et al., 2013), surround augite grains and fill cracks.

Quantitative XRD data for 18 drilled bedrock corestone samples is given in Buss et al. (2013), with the average shown in Table 5. In that paper, we identified orthoclase, tourmaline and tentatively identified biotite based on XRD and did not identify amphibole. Subsequent, extensive optical and SEM-EDS analysis of bedrock thin sections has revealed amphibole throughout the rock but no biotite or tourmaline and only very heterogeneously distributed orthoclase (data not shown). The whole-pattern fitting algorithm used to quantify mineral abundance from powder XRD data depends on the standards input to the program (Eberl, 2003) and a tourmaline standard, but not amphibole, was included in analysis of the drilled bedrock. Herein we refer to this phase as 
amphibole (Table 5). Similarly, we attribute the putative biotite to illite as XRD pattern separation of these minerals was not definitive but correlation of the quantitative XRD results with bulk elemental chemistry using HANDLENS (Eberl, 2008) showed that the pattern previously attributed to biotite is consistent with an Fe-rich illite. Other mineral abundances reported in Buss et al. (2013) are broadly consistent with thin section observations.

Mineralogy of the hand-augered regolith cores is dominated by microcrystalline disordered kaolinite, microcrystalline quartz, goethite, hematite and some mixed-phase, dioctahedral clays, consistent with illite (Tables 7-8, Fig. 4). Abundances of hematite and goethite are similar in the two cores, but the proportions of kaolinite and quartz vary, with B1S1 containing more kaolinite (>80\% at some depths) and less quartz than B1R. Site B1S1 also contains additional minerals in saprolite and clasts from 9.0-9.3 m depth including chlorite, other clays, orthoclase and plagioclase. These minerals are not present in any B1R samples. The clasts in the B1S1 core (present at 9.0 and $9.3 \mathrm{~m}$ ) contain more quartz, chlorite and feldspar, but less hematite, goethite, kaolinite and other clays than the saprolite matrix at the same depths. Most of the clasts in the B1R core have slightly less quartz, slightly more kaolinite and similar FeIII-(hydr-)oxide mineral contents than the surrounding saprolite.

\section{DISCUSSION}

\subsection{Elemental distributions and hydrologic flux}

Typical of a coastal watershed, $\mathrm{Cl}$ is the dominant anion in the soil pore waters (Table 4). The variability in pore water $\mathrm{Cl}$ reflects precipitation patterns, evapotranspiration (ET), and possible minor microbial cycling of chlorinated organic compounds (Bastviken et al., 2007). Because $\mathrm{Cl}$ derived from chemical weathering is negligible given the large sea salt inputs and lack of potential Cl-bearing minerals in the regolith, pore water $\mathrm{Cl}$ concentrations can be used to estimate ET and rates of water movement through the regolith. Assuming 1-D vertical flow, the hydraulic flux, also known as the fluid flux density, $q_{h}\left(\mathrm{~m} \mathrm{yr}^{-1}\right)$, is equal to the net difference between the annual precipitation and the ET fluxes, $q_{\text {precip }}\left(\mathrm{m} \mathrm{yr}^{-1}\right)$ and $q_{E T}\left(\mathrm{~m} \mathrm{yr}^{-1}\right)$, respectively, which in turn is equal to the product of the precipitation and the ratio of the volume-weighted $\mathrm{Cl}$ concentration in precipitation, $C_{C l \text {,precip }}(\mu \mathrm{M})$, to that in the pore waters, $C_{C l \text { solute }}(\mu \mathrm{M})$ (Table 6; White et al., 2009):

$$
q_{h}=q_{\text {precip }}-q_{E T}=q_{\text {precip }}\left(\frac{C_{C l, \text { recip }}}{C_{C l, \text { solute }}}\right)
$$

High estimates for ET ( $50-60 \%$ of rainfall, Eq. 2) in the volcaniclastic and granitic sites are consistent with estimates of ET in the LCZO determined using other methods (e.g., Schellekens et 
al., 2000; Wu et al., 2006; see also compilation in Murphy and Stallard, 2012). The average Cl

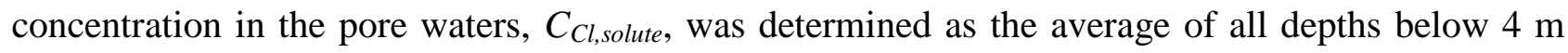
over 2007-2008 and $C_{C l \text {,precip }}$ was determined from the volume-weighted average of monthly openfall samples at site B1R (Table 4). Fluid flux densities were not calculated for slope sites B1S2, B1S3 or B1S4 because 1-D flow may not be a valid assumption at those locations. The resultant fluid flux densities of $q_{h}=1.5 \pm 0.3$ and $1.6 \pm 0.2 \mathrm{~m} \mathrm{yr}^{-1}$ for B1R and B1S1, respectively (Table 6), are the same within error as that reported for the Río Icacos LG1 regolith $\left(q_{h}=1.28 \mathrm{~m} \mathrm{yr}^{-1}\right.$, White et al., 1998). Note that although the units of fluid flux density, $q_{h}$, are here length per unit time, this quantity is intrinsic to the regolith medium and actually represents a volume of water $\left(\mathrm{m}^{3}\right)$ transported across a regolith area $\left(\mathrm{m}^{2}\right)$ over time (s) (Hillel, 1982).

The infiltration rate $\mathrm{I}\left(\mathrm{m} \mathrm{yr}^{-1}\right)$ describes the macroscopic rate of water movement downward through the regolith and is calculated from the fluid flux density divided by the product of the average porosity, $\Phi\left(\mathrm{m}^{3} \mathrm{~m}^{-3}\right)$, and saturation, $\Gamma\left(\mathrm{m}^{3} \mathrm{~m}^{-3}\right)$ :

$$
I=\frac{q_{h}}{\Phi \Gamma}
$$

Porosity, determined from bulk densities and specific gravities, is estimated as $0.47 \pm 0.02$ and 0.60 \pm 0.08 for B1R and B1S1, respectively (Table 1 ). Saturation, determined from water content and porosity, is estimated as $0.62 \pm 0.04$ and $0.55 \pm 0.07$ for B1R and B1S1, respectively (Table 6). The calculated infiltration rates for $\mathrm{B} 1 \mathrm{R}$ and $\mathrm{B} 1 \mathrm{~S} 1$, respectively, are $5.3 \pm 0.3$ and $5.00 \pm 0.01 \mathrm{~m} \mathrm{yr}^{-1}$. The Río Icacos site LG1 has average porosity and saturation values of 0.52 and $0.77 \mathrm{~m}^{3} \mathrm{~m}^{-3}$, respectively (White et al., 1998, based on monthly pore water sampling from 1992-1994), similar to those of the Bisley sites.

Average fluid residence times can be calculated by dividing the profile thicknesses by the infiltration rates (Eq. 3, Table 6). Thus faster infiltration rates yield shorter residence times, $\sim 2$ years in the Luquillo profiles. Therefore, hydrologic fluxes, and by extension, chemical fluxes, can be expected to respond to changing precipitation patterns on an almost annual timescale. This contrasts to other locations such as Santa Cruz, California, where fluid residence times range from 10-24 years, indicating that the hydrologic fluxes are dependent on decadal scale variations in precipitation (White et al., 2009).

White et al. (1998) reported an infiltration rate of $1.07 \mathrm{~m} \mathrm{yr}^{-1}$ and a fluid residence time of 7.93 years for the Río Icacos profile. These values were estimated from hydraulic conductivities and the hydraulic gradient, assuming no ET or lateral flow. To eliminate methodological variation from our comparison between the watersheds, here we recalculated infiltration and residence time in the 
Río Icacos using the $\mathrm{Cl}$ concentration ratio (Eq. 2) and the pore water data from White et al. (1998). We note, however, the assumption of 1-D flow as a potential source of error in estimating $q_{h}$ from $400 \mathrm{Cl}$ concentrations (Eq. 2), because surface runoff or subsurface storm flow would decrease $q_{h}$ (leading to lower infiltration rates) but have little effect on pore water $\mathrm{Cl}$ concentrations.

Contrary to our calculations (Table 6), a previous study determined that the volcaniclastic regolith is less permeable and has lower infiltration rates than the granitic regolith (Simon et al., 1990) based mainly on a more rapid response of piezometers to large rainfall events in the granitic areas. Faster infiltration was implicated in the greater susceptibility to landslides of the granitic regolith relative to the volcaniclastic regolith (Simon et al., 1990). The discrepancy between those relative infiltration rates and ours may stem from the saturation values used in our calculations (Table 6), which were measured on cores taken more than 10 years apart (the granitic cores in the mid 1990's and the volcaniclastic cores in 2006 and 2007), and the timing and size of storms preceding core collection may not be comparable. However, we note that below $0.5 \mathrm{~m}$, regolith porosity at the volcaniclastic site B1S1 is higher than at the granitic site.

For elements such as $\mathrm{Na}$, which are not significantly incorporated into, or sorbed onto, secondary minerals and are not major plant nutrients, input to regolith pore waters is expected to be via precipitation and chemical weathering. Net weathering contributions of such elements to the pore water, $c_{j, n e t}$, are calculated as the difference between the measured concentration of an element $j$ in the pore waters $c_{j, \text { solute }}$, and the ET-corrected concentration of $j$ in precipitation (White et al., 2009). This correction, which accounts for the concentration of elements as water is removed by ET, is made by multiplying $c_{j, \text { precip }}$ by the ratio of pore water $\mathrm{Cl}$ to precipitation $\mathrm{Cl}$ (Eq. 2):

$$
C_{j, \text { net }}=C_{j, \text { solute }}-C_{j, \text { precip }}\left(\frac{C_{\text {Cl,solute }}}{C_{C l, \text { precip }}}\right)
$$

Net solute concentrations (Eq. 4) are zero within error for the majority of the soluble cations at most depths in most of the profiles, including $\mathrm{Na}, \mathrm{Ca}, \mathrm{Sr}, \mathrm{K}, \mathrm{Mg}$, and $\mathrm{Al}$. In contrast, net solute $\mathrm{Si}$ is nearly identical to measured solute $\mathrm{Si}$, because the $\mathrm{Si}$ concentration in precipitation is 2 orders of magnitude lower than $\mathrm{Si}$ in the pore waters (Table 4). Thus, precipitation is not a significant source of Si to the pore water (Fig. 2a-c). Net solute Na concentrations are zero or within error of zero at most depths at most sites, with concentrations $>0$ mainly below the rooting zone of B1S(2-4) and at the soil-saprolite transition of B1R. Due to the close proximity of the ocean, the Luquillo watersheds receive significant inputs of sea salt $\mathrm{Na}$ in precipitation (Gioda et al., 2013), thus it is expected that the majority of $\mathrm{Na}$ in pore water is derived from precipitation. The Bisley regolith is essentially devoid of plagioclase and solid-state concentrations of $\mathrm{Na}$ are below or near detection (Tables 2, 7-8) thus there is no obvious source for weathering-contributed $\mathrm{Na}$ in the regolith. 
Interestingly, the thicker B1R regolith contains measurable solid-state $\mathrm{Na}$ at most depths but no plagioclase or other likely Na-bearing minerals were detected in the XRD patterns of the regolith (Table 76). Net solute $\mathrm{Mg}$ is within error of zero in most of $\mathrm{B} 1 \mathrm{~S}(2-3)$ but is $>0$ below the rooting zone of B1S1, B1S4 and B1R (Fig. 2d, e). Net solute $\mathrm{K}$ is $>0$ at the top and bottom of B1S1 and throughout B1S4.

\subsection{Chemical mobility}

Weathering profiles develop as a combination of open and closed system processes. Open-system contributions include mass transfer, which is described by the mass transfer coefficient commonly known as tau, $\tau_{j, i}$ (Eq. 5; Brimhall and Dietrich, 1987; Anderson et al., 2002), where $j$ represents a mobile element and $i$ represents a relatively immobile element. Closed-system contributions include residual enrichment, reflecting changes in density $(\rho)$, and strain $\left(\varepsilon_{i, w}\right.$, Eq. 6), which reflects volume changes during weathering.

$$
\begin{aligned}
\tau_{j, i}^{*} & =\left(\frac{C_{j, w} C_{i, p}}{C_{j, p} C_{i, w}}\right)-1 \\
\varepsilon_{i, w} & =\frac{\rho_{p} C_{i, p}}{\rho_{w} C_{i, w}}-1
\end{aligned}
$$

The tau equation (5) is equivalent to the negative of the chemical depletion factor (CDF) defined by Riebe et al. (2003) and is a simplification of a longer-form that includes a term for strain:

$$
\tau_{j, i}=\frac{\rho_{w} C_{j, w}}{\rho_{p} C_{j, p}}\left(\varepsilon_{i, w}+1\right)-1
$$

Both versions of tau assess mass transfer of a mobile element, $j$, relative to the concentration, $C$, of an immobile element, $i$, in the parent rock, $p$, and the weathered material, $w$. Following Chadwick et al. (1990), the relationship between tau and strain can be used to evaluate the immobility of low solubility elements and to assess the effect of the variability in concentration, $C_{i, p}$, of these elements in the parent rock. To do this, we use Equation 7 to calculate the mobility (tau) of $\mathrm{Ti}$ using $\mathrm{Zr}$ as immobile and the mobility of $\mathrm{Zr}$ using $\mathrm{Ti}$ as immobile; these are the two elements most commonly considered to be immobile during weathering (e.g., Chadwick et al., 1990; White et al., 1998). We then calculate maximum and minimum values for strain (Eq. 6) using the $1 \sigma$ value for $\mathrm{Zr}$ or $\mathrm{Ti}$ concentrations in the parent rock (protolith composition was assumed to be the average of 18 unweathered samples obtained from drill cores, Table 2; Buss et al., 2013). In a plot of tau versus strain $\left(\tau_{j, i}\right.$ versus $\varepsilon_{i}$, Fig. 5), if the maximum to minimum range in strain values for any given sample overlap with the $\pm 1 \sigma$ zone that reflects the variability in parent rock composition, we can consider the element to be immobile in that sample (Chadwick et al., 1990). If instead $\tau_{j, i}$ versus $\varepsilon_{i}$ plots 
below $(<0)$ the $\pm 1 \sigma$ zone, element $j$ has been leached or the concentration of $j$ in the parent for that particular sample was lower than the concentration represented by the $\pm 1 \sigma$ zone. Similarly, if $\tau_{j, i}$ versus $\varepsilon_{i}$ plots above $(>0)$ the $\pm 1 \sigma$ zone, element $j$ has been added (transported or translocated to the sample location) or the concentration of $j$ in the parent was greater than the concentration represented by the $\pm 1 \sigma$ zone. Strain values $<0$ indicate volume collapse or gain of element $i$, while strain $>0$ indicates dilation or loss of element $i$. If element $i$ is completely immobile and weathering is isovolumetric, $\varepsilon_{i}=0$.

Concentrations of $\mathrm{Ti}$ in the parent rock (volcaniclastic and granitic) for both watersheds (Bisley and Río Icacos) are less variable than $\mathrm{Zr}$, resulting in narrower $\pm 1 \sigma$ zones when $\mathrm{Ti}$ immobility is assessed (Fig. 5d-f) than when Zr immobility is assessed (Fig. 5a-c). For the Bisley sites assessed (B1R, B1S1, Figs. 5a-b,d-e), few samples overlap the $\pm 1 \sigma$ zone for Ti immobility, with most samples showing enrichment in $\mathrm{Zr}$ with respect to $\mathrm{Ti}\left(\tau_{Z r, T i}>0\right)$ and positive strain $\left(\varepsilon_{T i}\right)$, indicating loss of Ti during weathering in Bisley. In contrast, only the shallowest Río Icacos sample does not overlap the $\pm 1 \sigma$ zone for Ti immobility; this sample plots as enriched in Zr relative to Ti, reflecting either dust input of $\mathrm{Zr}$ or leaching of $\mathrm{Ti}$, and strain is strongly positive, reflecting dilation by strong bioturbation (Fig. 5f), consistent with previous findings (White et al., 1998) and our field observations. Therefore, Ti appears to be sufficiently immobile in the Río Icacos weathering profile, but mobile in Bisley.

Most samples in each Bisley profile overlap the $\pm 1 \sigma$ zone for $\mathrm{Zr}$ immobility (Figs. 5a-b) indicating that $\mathrm{Zr}$ is relatively immobile during weathering of the volcaniclastic rocks. Average strain with respect to $\mathrm{Zr}, \varepsilon_{Z r}$, at site B1S1 is near zero, but the range in strain values is $>1$, which likely reflect the variability of $\mathrm{Zr}$ in the parent rock and low $\mathrm{Zr}$ concentrations. The B1S1 samples that do not overlap the $\pm 1 \sigma$ zone come from the upper part of the profile $(<2.5 \mathrm{~m}$ depth $)$ and reflect the loss of $\mathrm{Ti}$ with respect to $\mathrm{Zr}$ and either volume collapse or gain of $\mathrm{Zr}$ from dust with $\mathrm{Zr} / \mathrm{Ti}$ ratio $>$ bedrock, at these depths. In contrast, the two B1R samples that do not overlap the $\pm 1 \sigma$ zone are very deep (14.3 and $15.4 \mathrm{~m}$ ) where density was only estimated. Strain, $\varepsilon_{Z r}$, is more variable in B1R than B1S1, but still within error of zero at most depths (Fig. 6). All Río Icacos samples also overlap the $\pm 1 \sigma$ zone for $\mathrm{Zr}$ immobility (Fig. 5c) indicating that $\mathrm{Zr}$ as well as $\mathrm{Ti}$ is conserved during weathering of the quartz diorite as was shown by White et al. (1998).

Volumetric strain calculations indicate near isovolumetric weathering in B1S1, with slight dilation between 4-8 $\mathrm{m}$ and slight collapse above $2 \mathrm{~m}$ (Fig. 6a). Site B1R has positive strain values for most of the profile, indicating dilation. Weathering in the Río Icacos regolith was shown to be isovolumetric, based on near-zero volumetric strain calculated from a parent rock composition with 
a Ti content that was subsequently found to be anomalously low and the appearance of a visibly unaltered parent rock fabric in the saprolite (White et al., 1998). Our re-calculation of strain for LG1, based on an average of all available chemical analyses of the Río Blanco quartz diorite (Seiders, 1971; Kesler and Sutter, 1979; White et al., 1998; Turner et al., 2003; Buss et al., 2008; Chabaux et al., 2013), indicates dilation throughout the profile (Fig. 6c). Dilation due to bioturbation near the surface is evident in the field, but the deeper saprolite retains the texture of the granitic protolith to the extent that this can be determined visually. Although some expansion of biotite grains during oxidation of $\mathrm{Fe}(\mathrm{II})$ (Buss et al., 2008) and subsequent epitaxial growth of kaolinite (Murphy et al., 1998) are known to occur, it is not clear that these mechanisms are sufficient to produce the modest dilation indicated here and further investigation is merited.

Mass transfer calculations reveal mass loss of mineral nutrient elements (K, P, Mg, Fig. 7; and $\mathrm{Ca}$, not shown) in all Bisley profiles, except for B1R, where $\mathrm{P}$ is enriched at multiple depths throughout the profile (Fig. 7f) and $\mathrm{K}$ is enriched at several depths within the top $4 \mathrm{~m}$ (Fig. 7a). Similarly, Fe, Ti, Al, and Si are enriched at several depths throughout the B1R profile, but these less-mobile elements are depleted by about $\leq 50 \%\left(\tau_{j, Z r}=-0.5\right)$ in the other profiles (Fig. 8), although some enrichment in Fe is seen from about 5 to $8 \mathrm{~m}$ depth in B1S1 (Fig. 8b). These results suggest that depletion-enrichment profiles develop over time in the volcaniclastic regolith such that even relatively immobile elements are mobilized and either leached from, or translocated within, the profiles. The depletion fronts for $\mathrm{K}, \mathrm{P}$, and $\mathrm{Mg}$ in the volcaniclastic profiles, B1S(1-4), reveal progressive loss of these elements via chemical weathering with decreasing depth in the regolith (Fig. 7c-d, g-i, 1-n). However, most of the loss of these elements relative to the parent rock is not directly documented here because it occurs below the deepest samples in each profile, which are about $25-75 \%$ depleted relative to the parent rock (with the exception of the deepest B1S4 sample, which shows no loss of $\mathrm{K}$ relative to the parent rock, Fig. 7d). As with the granitic rock, which loses significant mass during spheroidal weathering of corestones below the augerable regolith (Buss et al., 2008), the volcaniclastics also undergo significant mass loss before the corestones disaggregate into regolith. Spheroidal weathering is rare in the volcaniclastics, with rock weathering largely occurring within mm's-thick weathering rinds (Buss et al., 2013) in comparison to the approximately $50 \mathrm{~cm}$ spheroidal weathering rindlet sequences in the granitic rock (Buss et al., 2008). The high density of fractures in the volcaniclastic rock (Buss et al., 2013), coupled with the sharp weathering fronts across rinds and the lack of weatherable minerals in the volcaniclastic regolith, highlights the primary importance of weathering of rock surfaces relative to weathering in the regolith. Therefore, solute exports from the watershed are expected to be overwhelmingly dominated by rock weathering rather than regolith weathering in the volcaniclastics. Indeed, $\mathrm{S}$ and 
$\mathrm{Mg}$ isotope ratios in the Bisley 1 stream during baseflow are consistent with dominant bedrocksources of these elements (Chapela Lara et al., 2014; Yi-Balan et al., 2014). Similarly, Ge/Si ratios in the Río Icacos during baseflow reflect weathering reactions that only occur in the spheroidally weathering bedrock (Kurtz et al., 2011).

Near-zero net solute concentrations for most soluble cations throughout most of the volcaniclastic regolith profiles demonstrate that contemporary chemical weathering of minerals in the regolith does not, generally, produce significant solutes. The notable exception is Si, which has high net concentrations in the pore water throughout all of the profiles, reflecting contemporary release of Si during weathering (Fig. 2). Net concentrations of $\mathrm{Mg}$ and $\mathrm{K}$ at the bottom of some of the profiles likely reflect contemporary weathering of primary minerals near the rock-regolith interfaces.

\subsection{Mineral weathering reactions}

\subsubsection{Mineral weathering fronts}

A weathering front is the zone over which a weathering reaction (e.g., plagioclase dissolution) occurs; in a 1-D profile (e.g., a ridgetop), it extends from the depth at which the reaction begins to the depth at which the reaction is complete or, in the case of an incompletely developed weathering profile, to the land surface. When a tau or net solute profile can be associated with a specific mineral weathering reaction, it describes the weathering front of that reaction over the timescale of regolith development or the timescale of water infiltration, respectively (White, 2002). We identify weathering fronts in the Bisley and Río Icacos depth profiles (solid-state and solute) based on linear regressions (Figs. 2, 7-8; Table 9). Where more than one front may be identified in a depth profile, we opt for the most inclusive front (extending over a greater regolith thickness), providing a greater number of data points. An exception is where elemental fronts can be directly attributed to an individual mineral as identified in quantitative XRD depth profiles (Fig. 4h, Tables 7-8). We focus only on the ridgetop profiles B1R, B1S1 and LG1 when discussing solute weathering fronts because possible lateral solute transport cannot reasonably be ignored in the slope profiles (B1S2-4).

Weathering fronts for primary minerals (with the exception of some illite) in the solid Bisley regolith profiles (excluding the few weathered clasts) are located only at the corestone-regolith interfaces at the bottom of sites B1S(1-4). The XRD data (Table 8), shows that the Bisley regolith is devoid of primary minerals other than quartz and illite except at the bottom of B1S1 (XRD analysis was only done on B1R and B1S1 samples). No weathering fronts were identified in the B1R solid profiles and those tau plots likely reflect significant chemical redistribution. Near-total depletion of $\mathrm{Na}$ and $\mathrm{Ca}$ in all profiles indicates that the weathering fronts for the minerals containing these 
elements (i.e., plagioclase, pyroxene, amphibole, epidote, prehnite) occur below the depth of augering. In the disturbed site, B1S3 (sited on a tree throw), no weathering fronts were detected and this site was not used for further investigation or calculations. At sites B1S1, B1S2, B1S4 and LG1 tau profiles for $\mathrm{Mg}$ indicate mineral weathering fronts over, approximately, the deepest 1-2 meters of the profiles (Fig. 7). As these tau profiles do not reach parent composition at depth, the fronts likely begin within the weathering rinds, which were not retrievable by hand-augering. Similarly, sites B1S1 and LG1 show P weathering fronts at the bottom of the profiles Figs. $7 \mathrm{~g}$ and $7 \mathrm{j}$ ). In contrast, $\mathrm{K}$ weathering fronts are evident in sites B1S1, B1S4 and LG1 that span most of the regolith thickness (Figs.7b and 7d-e). Site B1S1 also has a slight, but significant, $\mathrm{Mg}$ front that spans about $8 \mathrm{~m}$ of regolith (Fig. 7l).

Based on the mineralogical composition of the weathering rinds (Buss et al., 2013), it is likely that $\mathrm{Mg}$ is largely lost from chlorite, pyroxene and amphibole and $\mathrm{K}$ is lost mainly from illite during rind formation. The absence of pyroxene and amphibole in the regolith means we can attribute the $\mathrm{Mg}$ front here to chlorite dissolution, where chlorite is detected (>9 m depth, Fig. 4). Above $9 \mathrm{~m}$ depth, the source of $\mathrm{Mg}$ is less obvious. Illite dissolution could release both $\mathrm{Mg}$ and $\mathrm{K}$, but net solute profiles for these elements appear unrelated (e.g., $\mathrm{R}^{2}=0.00$ in B1S1). However, net solute $\mathrm{Mg}$ and $\mathrm{Si}$ concentrations both correlate to $\mathrm{NH}_{4}$-acetate extractable $\mathrm{Mg}$ at site $\mathrm{B} 1 \mathrm{R}$ (there are insufficient matching depths to determine this for $\mathrm{B} 1 \mathrm{~S} 1$ ), both with $\mathrm{R}^{2}$ of 0.78 , consistent with dissolution of a silicate phase containing exchangeable $\mathrm{Mg}$ (Fig. 9). Indeed, in the B1S1 regolith, about $61 \mathrm{~mol} \%$ of total extractable cations are $\mathrm{Mg}$ (44\% in B1R), although these could be present in the regolith sorbed to oxides or organics as well as to silicates. In contrast, extractable $\mathrm{K}$ and net solute $\mathrm{Si}$ do not correlate $\left(\mathrm{R}^{2}=0.02\right)$ and net solute $\mathrm{K}$ is below detection at all but the two shallowest depths. Illite is also the only K-containing mineral phase identified by XRD in the regolith profile above $9 \mathrm{~m}$ depth (Table 8). Therefore, although illite dissolves in the upper portion of the B1S1 regolith (above $7.6 \mathrm{~m}$ ) as evident in the depletion profile calculated from mineral abundance (Fig. 10), the small amount of $\mathrm{K}$ this dissolution releases to pore water is insignificant. Below these depths, the tau values for illite and kaolinite form addition profiles, reflecting clay formation (Fig. 10). Interestingly, this clay formation coincides with a solid-state depletion profile in $\mathrm{K}$ below about $8 \mathrm{~m}$ depth in B1S1 (Fig. 7b), which is consistent with loss of $\mathrm{K}$ ions during oxidation of $\mathrm{Fe}(\mathrm{II})$ in the clays to maintain charge balance, and/or removal of $\mathrm{K}$ as dioctahedral clays weather into simpler phases (e.g., kaolinite). The volcaniclastic bedrock contains only minor apatite $(<0.5 \mathrm{vol} \%)$, which is unlikely to survive the intensive weathering at the rock-regolith interface. Thus we tentatively attribute the B1S1 P tau profile (Fig. $7 \mathrm{~g}$ ) to the release of sorbed or organic $\mathrm{P}$ of atmospheric origin, although further investigation is needed. 
Solute weathering fronts are determined from net solute concentrations (Fig. 2), which are measured pore water concentrations corrected for rainfall inputs and ET (Eq. 4). A decrease in a net solute with decreasing depth reflects progressive release of that solute from the solid phase, generally attributed to dissolution (e.g., White, 2002). Solute weathering fronts for $\mathrm{Mg}$ and $\mathrm{Si}$ are apparent in the three ridgetop regolith profiles: B1R, B1S1 and LG1 below the rooting depth (Fig. 2). In site B1S1, we attribute the $\mathrm{Mg}$ front to chlorite dissolution below $9 \mathrm{~m}$ depth, where chlorite was identified by XRD (Table 8, Fig. 4h). The B1S1 Mg front above this depth may represent dissolution of some combination of trace residual chlorite, illite and impure kaolinite and/or the release of sorbed $\mathrm{Mg}$.

Above $\sim 1 \mathrm{~m}$ depth at these sites, net solute Mg increases, which we attribute to throughfall and decomposition inputs of $\mathrm{Mg}$ not accounted for in Equation 4. Over the timescale of regolith formation, these inputs represent internal fluxes expected to be at steady state, which may not hold true on the timescale of water infiltration. As the chemistry of throughfall varies significantly in space and time here (Heartsill-Scalley et al., 2007), we will only use fronts identified below rooting depth to calculate rates (Section 5.3.2).

Net Si solute concentrations below $2 \mathrm{~m}$ depth in the three ridgetop sites indicate dissolution of silicate minerals (Fig. 2). Above this depth in B1S1 and B1R, net Si increases towards the surface, which may reflect more rapid weathering (i.e., Si release by weathering is not in steady state over the thickness of the profile) and/or an additional source of non-rainfall Si such as the dissolution of phytoliths, as was identified in the upper $30 \mathrm{~cm}$ of ridgetop soils in the LG1 profile based on $\mathrm{Si}$ isotopes (Ziegler et al., 2005) and Ge/Si ratios (Lugolobi et al., 2010). Dissolution of both biotite and quartz have been documented in the LG1 regolith (Murphy et al., 1998; Schulz and White, 1999).

\subsubsection{Long-term weathering rates and fluxes}

Solid-state weathering fronts reflect cumulative weathering over the timescale of regolith development. Using a 1-D, linear approximation, we estimate long-term, average mineral reaction rates, $R_{L T}\left(\mathrm{~mol} \mathrm{~m} \mathrm{~m}^{-2} \mathrm{~s}^{-1}\right.$, normalized to mineral surface area, from the gradients of these fronts (White, 2002):

$$
R_{L T}=10^{-3} \frac{\omega}{\varphi \beta s b_{s}}
$$

where $\varphi\left(\mathrm{g} \mathrm{g}^{-1}\right)$ is the mass fraction of the mineral in the weathering material, $\beta\left(\mathrm{mol} \mathrm{mol}^{-1}\right)$ is the stoichiometric coefficient of the element in the mineral, $s\left(\mathrm{~m}^{2} \mathrm{~g}^{-1}\right)$ is the specific surface area of the mineral, $b_{s}\left(\mathrm{~m} \mathrm{~kg} \mathrm{~mol}^{-1}\right)$ is the weathering gradient, and $\omega\left(\mathrm{m} \mathrm{s}^{-1}\right)$ is the weathering advance rate. 
627 The weathering advance rate reflects the lowering of the rock-regolith interface, for which we use 628 the average regolith production rate, $334 \pm 46 \mathrm{~mm} \mathrm{ky}^{-1}$, calculated for the Bisley watershed from the 629 U-series regolith age (Dosseto et al., 2012). We estimate a reactive surface area, $s$, for illite and 630 chlorite using the relationship between the spherical geometric surface area and BET surface area 631 (Helgeson et al., 1984; White and Brantley, 2003):

$$
s=\frac{6 \lambda}{\rho D}
$$

633

634

635

636

637

638

639

640

641

642

643

644

645

646

647

648

649

650

651

652

653

654

655

656

657

658

with a surface roughness factor, $\lambda$, of 110 for un-weathered micas, which also accounts for the nonspherical geometry of layered silicate minerals (White and Brantley, 2003). Mineral densities, $\rho$, of 2.65 and $2.75 \mathrm{~g} \mathrm{~cm}^{-3}$ for chlorite and illite, respectively, and the average groundmass grain size diameter, $D$, of $14 \mu \mathrm{m}$ (determined from SEM images), yielded specific surface areas of 18 and 17 $\mathrm{m}^{2} \mathrm{~g}^{-1}$ for chlorite and illite, respectively. Kaolinite surface area was estimated at $35 \mathrm{~m}^{2} \mathrm{~g}^{-1}$, which is typical for soil kaolinites (Singh and Gilkes, 1992). The stoichiometric coefficient, $\beta$, is $4.6 \mathrm{~mol} \mathrm{Mg}$ $\mathrm{mol}^{-1}$ chlorite, based on electron microprobe analysis of bedrock thin sections. The kaolinite and illite dissolution rates are calculated using the quantitative XRD abundances rather than interpreted from elemental profiles, therefore $\beta$ is not included in the calculation for kaolinite or illite. The mass fractions of the minerals in the weathering bedrock, $\varphi$, are $0.23 \mathrm{~g} \mathrm{~g}^{-1}$ chlorite, $0.009 \mathrm{~g} \mathrm{~g}^{-1}$ illite and $0.004 \mathrm{~g} \mathrm{~g}^{-1}$ kaolinite (Buss et al., 2013). Finally, the weathering gradients (Table 9) are $6 \pm 1 \mathrm{~m} \mathrm{~kg}$ $\mathrm{mol}^{-1} \mathrm{Mg}$ for chlorite (over 8.2-9.3 m depth, $\mathrm{R}^{2}=0.69$ ), $30 \pm 10 \mathrm{~m} \mathrm{~kg} \mathrm{~mol}^{-1}$ illite (over 0-7.6 m depth, $\mathrm{R}^{2}=0.95$ ) and $7.5 \pm 0.6 \mathrm{~m} \mathrm{~kg} \mathrm{~mol}^{-1}$ kaolinite (over 0-4.9 $\mathrm{m}$ depth, $\mathrm{R}^{2}=0.76$ ). The resulting long-term mineral weathering rates are: $8.9 \times 10^{-14}$ mol chlorite $\mathrm{m}^{-2} \mathrm{~s}^{-1}, 2.1 \times 10^{-14}$ mol illite $\mathrm{m}^{-2} \mathrm{~s}^{-1}$ and $4.0 \times 10^{-14} \mathrm{~mol}$ kaolinite $\mathrm{m}^{-2} \mathrm{~s}^{-1}$ (Table 10). This kaolinite dissolution rate $(\log \mathrm{R}=-13.5$ to 13.3, with uncertainty) is within range of laboratory rates ( $\log R=-14.1$ to -12.4$)$ for experiments conducted at ambient temperatures within the $\mathrm{pH}$ range of the B1S1 pore waters in the kaolinite dissolution zone ( $\mathrm{pH} 4-5)$, but with lower specific surface areas $\left(7.5-18 \mathrm{~m}^{2} \mathrm{~g}^{-1}\right)$ than assumed here $\left(35 \mathrm{~m}^{2} \mathrm{~g}^{-1}\right)$, as compiled by Bandstra et al. (2008). The chlorite dissolution rate at the bottom of the saprolite in Bisley ( $\log \mathrm{R}=-13.2$ to -13.0 ) is nearly as fast as laboratory rates at $\mathrm{pH} 4-5$ and ambient temperatures ( $\log \mathrm{R} \sim-13$ to -11 ) as compiled by Alekseyev (2007) and faster than field rates: $\log \mathrm{R}$ $=-17$ to -16.3 in shale at the Susquehanna/Shale Hills CZO (SSHCZO) in Pennsylvania, USA (Jin et al., 2010) and $\log \mathrm{R}=-13.9$ to -15.8 in Amazonian ultramafic schists (Freyssinet and Farah, 2000). There are fewer published rates available for illite dissolution, but the Bisley illite dissolution rate $(\log \mathrm{R}=-13.5$ to -13.9$)$ is also consistent with laboratory rates $(\log \mathrm{R}=-14$ to 13.7) measured at pH 3.0-4.7 and $25^{\circ} \mathrm{C}$ (Köhler et al., 2003; Allan et al., 2011; Bibi et al., 2011) 
659

660

661

662

663

664

665

666

667

668

669

670

671

672

673

674

675

676

677

678

679

680

681

682

683

684

685

686

and orders of magnitude faster than field rates $(\log R=-16.7$ to -16$)$ for the SSHCZO shale (Jin et al., 2010).

Not all gradients can be easily, or solely, attributed to a specific mineral. In this case we can use them to calculate long-term elemental fluxes per unit area of weathering regolith, $Q_{L T}\left(\mathrm{~mol} \mathrm{~m}^{-2}\right.$ $\left.\mathrm{s}^{-1}\right)$ :

where $\Delta z$ is the depth $(\mathrm{m})$ over which the gradient $b_{s}$ is calculated; that is, the mass of the element is only integrated over the vertical distance in which the element increases with depth in the augered regolith. Here we calculate the long-term elemental fluxes through the volcaniclastic B1S1, B1S2, and B1S4 regolith profiles and the granitic LG1 regolith profile, the latter using regolith data from Buss (2006) (Table 2). Note that these fluxes (and the mineral weathering rates calculated above) only reflect weathering within the augered regolith as our profiles do not extend into the nonaugerable bedrock, where substantial weathering occurs along fractures (Buss et al., 2013). As noted previously, profile B1R does not contain any clear solid-state weathering fronts (Figs. 7-8). The resultant long-term Si fluxes (Table 10) are identical within uncertainty for the three other Bisley sites (a Si gradient was not apparent in the Rio Icacos profile, consistent with retention of Si in secondary phases and with previous studies, White et al., 1998; White, 2002). Solid-state fluxes of $\mathrm{Mg}, \mathrm{K}$ and $\mathrm{P}$ are several orders of magnitude lower in Río Icacos than in Bisley (Table 10), despite similar abundances of $\mathrm{P}$ and higher $\mathrm{Mg}$ and $\mathrm{K}$ abundance in the Río Icacos regolith.

\subsubsection{Contemporary weathering}

Absolute mass change with depth per unit volume is significantly greater in solid profiles than in solute profiles, because while solid-state gradients reflect cumulative weathering over the age of regolith, typically $\sim 10^{4}-10^{6}$ years, solute gradients reflect contemporary weathering, typically over 1-100 years, the timescale of water infiltration into regolith. The rates of these reactions can be compared to determine whether or not a reaction is in steady-state. Similar to the long-term fluxes calculated above, short-term weathering solute fluxes, $Q_{S T}\left(\mathrm{~mol} \mathrm{~m}^{-2} \mathrm{~s}^{-1}\right)$, can be calculated from the net solute gradients and the fluid flux density, $q_{h}\left(\mathrm{~m} \mathrm{~s}^{-1}\right)$ (White, 2002):

$$
Q_{S T}=10^{3} \frac{q_{h} \Gamma \Delta z}{b_{f}}
$$


687

688

689

690

691

692

693

694

695

696

697

698

699

700

701

702

703

704

705

706

707

708

709

710

711

712

713

714

715

716

717

718

719

where $b_{f}$ is the weathering gradient in the fluid phase $\left(\mathrm{m} \mathrm{L} \mathrm{mol}^{-1}\right), \Gamma$ is the saturation $\left(\mathrm{m}^{3} \mathrm{~m}^{-3}\right), \Delta z$ is the depth $(\mathrm{m})$ over which the gradient is measured and $10^{3}$ is a unit conversion factor (Tables 6 and 9).

Solute gradients in the volcaniclastic watershed were only determined for the ridgetop sites B1R and B1S1 (Table 9). The resulting fluxes (Table 10) represent only solute production occurring within the regolith profiles, not catchment fluxes, which may include weathering products from other parts of the critical zone. The regolith Mg and Si solute fluxes (Eq. 11) in B1R and B1S1 are about an order of magnitude lower than the Si fluxes (Table 10). The solute flux in the granitic ridgetop (LG1) regolith was calculated from weathering gradients previously measured (Tables 910; Schulz and White, 1999; White, 2002) and $q_{h}$ and $\Gamma$ values calculated here (Table 6). The Mg and $\mathrm{K}$ solute fluxes in the granitic regolith are faster than those in the volcaniclastic regolith (K was below detection in most volcaniclastic pore waters; Table 10), reflecting biotite dissolution in the granitic regolith (Murphy et al., 1998) - and mostly secondary mineral dissolution in the volcaniclastic regolith. Although contemporary weathering fluxes in the volcaniclastic Bisley regolith are apparently slow (Table 10), contemporary whole-watershed weathering fluxes are likely faster due to the rapid weathering of primary minerals in fractured bedrock below the augerable regolith (Buss et al., 2013). Indeed, solute weathering fluxes of $\mathrm{Mg}, \mathrm{K}$ and Si averaged over 1991-2005 (Stallard, 2012) were faster in the river that drains the Bisley catchments (Río Mameyes) than in the Bisley regolith and nearly identical to those in the Río Icacos (Table 10).

The long-term fluxes calculated from solid-state profiles are several orders of magnitude larger than the contemporary fluxes calculated from solute profiles in the volcaniclastic regolith, consistent with faster regolith weathering in the past (Table 10). In contrast, the granitic regolith of site LG1 has similar long-term and contemporary weathering fluxes. The granitic watershed has slower ridgetop weathering advance rates than the volcaniclastic watershed $\left(\sim 50 \mathrm{~m} \mathrm{Ma}^{-1}\right.$ versus $\sim 330 \mathrm{~m} \mathrm{Ma}^{-1}$, respectively; Brown et al., 1995; Dosseto et al., 2012). Therefore, a $10 \mathrm{~m}$ granitic regolith is older than a $10 \mathrm{~m}$ volcaniclastic regolith in this $\mathrm{CZO}$, yet the older granitic regolith retains more primary minerals, namely biotite, which produces the faster contemporary $\mathrm{Mg}$ and $\mathrm{K}$ weathering fluxes as compared to the volcaniclastic regolith. In contrast, the primary minerals in the volcaniclastic regolith dissolve almost completely at the rock-regolith interface (Tables 5, 7-8; Buss et al., 2013).

\subsection{Importance of lithology to weathering profiles and rates}

Lithology is arguably the primary difference between the two catchments discussed here (Bisley and Río Icacos); these two rock types (andesitic meta-volcaniclastic and tonalite) differ in 
mineralogy, grain size and porosity. Other differences between the catchments, of potential importance to weathering, are mean annual precipitation (slightly higher in Río Icacos) and bedrock age (much older in Bisley). Weathering of the bedrock has produced thick regolith profiles on both rock types. The augerable, ridgetop regolith in Bisley is thicker than in Río Icacos: 9-16 $\mathrm{m}$ and 5-9 $\mathrm{m}$, respectively, as evidenced by observations of high-elevation landslides in both watersheds and by augering to refusal at 8 ridgetop locations in Bisley for this study and roughly 30 times by us and other groups in the Río Icacos (e.g., White et al., 1998; Schellekens et al., 2004; Buss et al., 2005). The thicker regolith on the relatively stable Bisley ridgetops likely reflects the faster regolith production rate $\left(334 \pm 46 \mathrm{~mm} \mathrm{ky}^{-1}\right)$ relative to Río Icacos $\left(45 \pm 12 \mathrm{~mm} \mathrm{ky}^{-1}\right)$, as estimated from Useries analysis of these regolith and weathering rock (saprock) profiles (Dosseto et al., 2012; Chabaux et al., 2013). The U-series rates for Río Icacos corroborate earlier denudation rates estimated from elemental and isotopic mass balances in water (stream or pore water) and saprolite profiles (McDowell and Asbury, 1994; White et al., 1998; Turner et al., 2003; Pett-Ridge et al., 2009), and cosmogenic ${ }^{10}$ Be nuclides in stream sediments (Brown et al., 1995; Riebe et al., 2003). The regolith production rates indicate that the Bisley regolith is younger than the Río Icacos regolith (40-60 ky at site B1R versus 100-200 ky in Río Icacos; Dosseto et al., 2012; Chabaux et al., 2013) despite the higher erosion rate in the Río Icacos compared to the Bisley watershed (0.58 and $0.40 \mathrm{~mm} \mathrm{y}^{-1}$, respectively; Larsen, 2012) and despite the older age of the volcaniclastic Bisley bedrock compared to the granitic intrusion of the Río Icacos ( 100 Ma versus $47 \mathrm{Ma}$, respectively; Jolly et al., 1998; Smith et al., 1998).

Regolith production rates are contingent upon weathering reactions at the bedrock-regolith interface and work is ongoing to identify and quantify the earliest reactions in the Bisley bedrock. Incipient chemical weathering reactions may be either dissolution or oxidation reactions and as such are dependent on the supply of acid (primarily $\mathrm{CO}_{2}$ ) or $\mathrm{O}_{2}$, respectively (Brantley et al., 2014). Consequently, processes that affect the gradients of these gases in regolith may thereby influence the weathering fronts that control regolith formation, even if these fronts are located in bedrock. Regolith gradients in $\mathrm{O}_{2}$ and $\mathrm{CO}_{2}$ often mirror one another due to heterotrophic microbial respiration, which consumes $\mathrm{O}_{2}$ and produces $\mathrm{CO}_{2}$; as a result, regolith microorganisms may either enhance or retard the bedrock weathering rate, depending on whether the weathering front is controlled by dissolution or oxidation reactions, respectively. Of the three LCZO sites where gas profiles were measured (B1S1, B1R and LG1), only B1S1 contains an "elbow", or bend, in the gas profiles, characteristic of strong biotic influence (Fig. 3; Brantley et al., 2014). The elbow at $\sim 2 \mathrm{~m}$ depth coincides with a change in the makeup of the microbial community and a drop in heterotrophic cell numbers that persists to the bottom of the augered regolith (Liermann et al., 2015). Total microbial cell numbers in the Río Icacos profile, LG1, are roughly an order of 
magnitude larger than in B1S1 throughout the profile, with large changes at about 1 and $4 \mathrm{~m}$ depth (Buss et al., 2005). Although the limited pore gas data presented here does not capture the full temporal variability, the relatively high $\mathrm{O}_{2}$ content throughout LG1 (and B1R) suggests that microbial reduction of $\mathrm{O}_{2}$ may be less significant than abiotic processes over the measured depths than in the B1S1 profile. Alternatively, microbial elbows in gas concentrations may occur deeper than the sampled depths.

Brantley et al. (2014) proposed that dissolution versus oxidation control of weathering fronts may be contingent upon the amount of $\mathrm{FeO}$ in the bedrock, such that $\mathrm{Fe}$ (II)-oxidation reactions use up $\mathrm{O}_{2}$ quickly in $\mathrm{Fe}(\mathrm{II})$-rich rock, allowing the $\mathrm{CO}_{2}$-driven dissolution front to extend deeper, whereas $\mathrm{O}_{2}$ is able to penetrate deeper in $\mathrm{Fe}(\mathrm{II})$-poor lithologies. The initiation of chemical weathering by $\mathrm{Fe}(\mathrm{II})$-oxidation has been identified in the Río Icacos tonalite (Buss et al., 2008), in high-grade metamorphic charnokite in Sri Lanka (Behrens et al., 2015), granite in the Virginia Piedmont, USA (Bazilevskaya et al., 2013) and shale in Pennsylvania, USA (Brantley et al., 2013). The Bisley andesitic volcaniclastic rock has significantly more $\mathrm{FeO}(6.1 \mathrm{wt} \%)$ compared to the granitic rock in the Río Icacos catchment (2.7\%, Fletcher et al., 2006; Buss et al., 2008). In the Río Icacos catchment, regolith formation is initiated by reaction-driven fracturing of the bedrock, in which $\mathrm{O}_{2}$ diffuses into the rock and oxidizes $\mathrm{Fe}(\mathrm{II})$ in biotite, which leads to a build-up of elastic strain energy, ultimately causing a spheroidal fracture (Fletcher et al., 2006; Buss et al., 2008). Evidence for spheroidal weathering is rare in Bisley rocks and biotite is not present. However, unlike the granitic bedrock, the volcaniclastic bedrock may not require physical fracturing to initiate dissolution of primary minerals as porosity in the un-weathered bedrock is significantly greater: $8 \pm$ $4 \%$ in the volcaniclastic versus $1 \pm 1 \%$ for the granitic rock (Buss et al., 2013; Navarre-Sitchler et al., 2013). The volcaniclastic rocks also contain veins and bedding planes that may provide reactive fluids with additional access to weatherable minerals. In addition, the minerals in the volcaniclastic bedrock have higher surface area owing to smaller grain size and a higher proportion of weatherable minerals (i.e., non-quartz silicates). These lithological characteristics contribute to a faster chemical weathering at the volcaniclastic rock-regolith interfaces (Buss et al., 2013) than at the granitic interfaces. These interfaces represent weathering hotspots such that weathering export to the rivers is likely dominated by fluxes from the fractured bedrock in the deep critical zone (e.g., Kurtz et al., 2011; Chapela Lara et al., 2014) and thus contemporary regolith weathering fluxes may only be of significance to the local ecosystem.

\section{CONCLUSIONS}


We compared solid and solute weathering profile data from an andesitic, meta-volcaniclastic catchment (Bisley) to a nearby granitic (tonalite) catchment (Río Icacos) to assess the influence of lithology on weathering mechanisms and rates, and on mineral nutrient availability. We determined that $\mathrm{Ti}$ is not conserved in the volcaniclastic profiles, but that $\mathrm{Zr}$ is effectively immobile, except near the surface where dust likely contributes additional Zr. Similarly, Zr is effectively immobile in the granitic regolith although $\mathrm{Ti}$ is also immobile at all but the shallowest depth. Volumetric strain was recalculated and found to be positive in the granitic profile (LG1), indicating dilation, but nearly zero at most depths in the volcaniclastic profiles, indicating largely isovolumetric weathering.

Solid-state weathering fronts for primary minerals in the volcaniclastic regolith exist only near the corestone-regolith interfaces at the bottom of the augered profiles, although weathering fronts for dissolving clay minerals are evident at shallower depths. Solute weathering fronts in the volcaniclastic profiles, determined from pore water concentrations corrected for rainfall and ET, were only detected for $\mathrm{Si}$ and $\mathrm{Mg}$. The solute $\mathrm{Mg}$ front is attributed to chlorite dissolution below 9 $\mathrm{m}$ depth and to dissolution of residual phases or release of sorbed $\mathrm{Mg}$ above this depth.

Long-term $\mathrm{K}$ and $\mathrm{P}$ fluxes are several orders of magnitude higher in the volcaniclastic regolith than in the granitic regolith, despite solid-state concentrations of $\mathrm{P}$ that are nearly the same and of $\mathrm{K}$ that are greater in the granitic regolith. Contemporary (net solute) $\mathrm{Mg}$ and $\mathrm{Si}$ fluxes are similar in the two lithologies, despite arising from different mineral weathering reactions. This similarity does not carry over to the riverine solute concentrations, which vary with lithology and are likely fed by weathering reactions occurring along bedrock fractures, deeper in the critical zone. The long-term ( 40 kyrs) elemental fluxes are larger than the contemporary ( 2 yrs) fluxes in the volcaniclastic catchment, indicating faster weathering in the regolith in the past. Despite the thicker, more depleted regolith, long-term fluxes of $\mathrm{Mg}, \mathrm{Si}, \mathrm{K}$ and $\mathrm{P}$ are also larger in the andesitic volcaniclastic Bisley regolith than in the granitic Río Icacos regolith, highlighting the primary control of lithology on weathering fluxes.

\section{ACKNOWLEDGMENTS}

This article is dedicated to the memory of our friend and analytical chemist Davisson Vivit (USGS). We also thank USGS personnel for field and laboratory support: Manuel Rosario-Torres, James Shanley, Alex Blum, Bill Evans and Mark Huebner as well as Festo Lugolobi (Boston Univ.), Joel Moore (Towson Univ.) and Carlos Estrada (USFS) and University of Bristol students Bethany Rathbone, Jessica Ecott, and Anne Hunt for optical petrography. We also acknowledge the invaluable advice of Fred Scatena (in memoriam) and funding support from the USGS Water 
Energy and Biogeochemical Budgets Project of the National Research Program, the NSF Luquillo CZO (NSF EAR-0722476), and PhD fellowships from NERC (for O.W. Moore) and Conacyt (for M. Chapela Lara). We also thank Associate Editor Christophe Tournassat for helpful review and editorial comments as well as those of 3 anonymous reviewers.

\section{REFERENCES}

Alekseyev, V.A. (2007) Equations for the dissolution reaction rates of montmorillonite, illite, and chlorite. Geochemistry International 45, 770-780.

Allan, M.M., Turner, A. and Yardley, B.W.D. (2011) Relation between the dissolution rates of single minerals and reservoir rocks in acidified pore waters. Appl. Geochem. 26, 1289-1301.

Anderson, S.P., Dietrich, W.E. and Brimhall, G.H. (2002) Weathering profiles, mass-balance analysis, and rates of solute loss: Linkages between weathering and erosion in a small, steep catchment. Geological Society of America Bulletin 114, 1143-1158.

Bandstra, J.Z., Buss, H.L., Campen, R.K., Liermann, L.J., Moore, J., Hausrath, E.M., Navarre-Sitchler, A.K., Jang, J.-H. and Brantley, S.L. (2008) Appendix: Compilation of Mineral Dissolution Rates, in: Brantley, S.L., Kubicki, J.D., White, A.F. (Eds.), Kinetics of Water-Rock Interaction. Springer, New York, pp. 737-823.

Bastviken, D., Thomsen, F., Svensson, T., Karlsson, S., Sanden, P., Shaw, G., Matucha, M. and Oberg, G. (2007) Chloride retention in forest soil by microbial uptake and by natural chlorination of organic matter. Geochim. Cosmochim. Acta 71, 3182-3192.

Bazilevskaya, E., Lebedeva, M., Pavich, M., Rother, G., Parkinson, D.Y., Cole, D. and Brantley, S.L. (2013) Where fast weathering creates thin regolith and slow weathering creates thick regolith. Earth Surface Processes and Landforms 38, 847-858.

Bazilievskaya, E., Lebedeva, M., Pavich, M., Rother, G., Parkinson, D.Y., Cole, D. and Brantley, S.L. (2013) Where fast weathering creates thin regolith and slow weathering creates thick regolith. Earth Surface Processes and Landforms 38, 847-858.

Behrens, R., Bouchez, J., Schuessler, J.A., Dultz, S., Hewawasam, T. and Von Blanckenburg, F. (2015) Mineralogical transformations set slow weathering rates in low-porosity metamorphic bedrock on mountain slopes in a tropical climate. Chem. Geol. 411, 283-298.

Berner, R.A. (2008) Addendum to "Inclusion of the Weathering of Volcanic Rocks in the GEOCARBSULF Model” (R. A. Berner, 2006, V. 306, p. 295-302). Amer. J. Sci. 308, 100-103.

Berner, R.A. and Berner, E.K. (1997) Silicate weathering and climate, in: Ruddiman, W.F. (Ed.), Tectonic Uplift and Climate Change. Plenum Press, New York, pp. 353-364.

Bibi, I., Singh, B. and Silvester, E. (2011) Dissolution of illite in saline-acidic solutions at $25^{\circ} \mathrm{C}$. Geochim. Cosmochim. Acta 75, 3237-3249.

Bluth, G.S. and Kump, L.R. (1994) Lithologic and climatic controls of river chemistry. Geochimica Cosmochimica Acta 58, 2341-2359. 
Brantley, S.L., Holleran, M.E., Jin, L. and Bazilevskaya, E. (2013) Probing deep weathering in the Shale Hills Critical Zone Observatory, Pennsylvania (USA): the hypothesis of nested chemical reaction fronts in the subsurface. Earth Surface Processes and Landforms 38, 1280-1298.

Brantley, S.L., Lebedeva, M. and Bazilevskaya, E. (2014) 6.15 - Relating Weathering Fronts for Acid Neutralization and Oxidation to pCO2 and pO2, in: Turekian, H.D.H.K. (Ed.), Treatise on Geochemistry (Second Edition). Elsevier, Oxford, pp. 327-352.

Brantley, S.L. and White, A.F. (2009) Approaches to modeling regolith, in: Oelkers, E.H., Schott, J. (Eds.), Thermodynamics and Kinetics of Water-Rock Interaction. Mineralogical Society of America, Washington, D.C., pp. 435-484.

Brimhall, G. and Dietrich, W.E. (1987) Constitutive mass balance relations between chemical composition, volume, density, porosity, and strain in metasomatic hydrochemical systems: results on weathering and pedogenisis. Geochim. Cosmochim. Acta 51, 567-587.

Brown, E.T., Stallard, R., Larsen, M.C., Raisbeck, G.M. and Yiou, F. (1995) Denudation rates determined from the accumulation of in situ-produced ${ }^{10} \mathrm{Be}$ in the Luquillo Experimental Forest, Puerto Rico. Earth and Planetary Science Letters 129, 193-202.

Buss, H.L. (2006) Biogeochemical Weathering of Iron-Silicate Minerals, Geosciences. The Pennsylvania State University, University Park, PA, p. 203.

Buss, H.L., Brantley, S.L., Scatena, F.N., Bazilievskaya, E.A., Blum, A., Schulz, M., Jimenez, R., White, A.F., Rother, G. and Cole, D. (2013) Probing the deep critical zone beneath the Luquillo Experimental Forest, Puerto Rico. Earth Surface Processes and Landforms 38, 1170-1186.

Buss, H.L., Bruns, M.A., Schultz, M.J., Moore, J., Mathur, C.F. and Brantley, S.L. (2005) The coupling of biological iron cycling and mineral weathering during saprolite formation, Luquillo Mountains, Puerto Rico. Geobiology 3, 247-260.

Buss, H.L., Mathur, R., White, A.F. and Brantley, S.L. (2010) Phosphorus and iron cycling in deep saprolite, Luquillo Mountains, Puerto Rico. Chem. Geol. 269, 52-61.

Buss, H.L., Sak, P.B., Webb, S.M. and Brantley, S.L. (2008) Weathering of the Rio Blanco quartz diorite, Luquillo Mountains, Puerto Rico: Coupling oxidation, dissolution, and fracturing. Geochim. Cosmoch. Acta 72, 4488-4507.

Chabaux, F., Blaes, E., Stille, P., di Chiara, R.R., Dosseto, A., Pelt, E., Ma, L., Buss, H.L. and Brantley, S.L. (2013) Regolith formation rate from U-series nuclides: Implications from the study of a spheroidal weathering profile in the Rio Icacos watershed (Puerto Rico). Geochim. Cosmochim. Acta 100, $73-$ 95.

Chadwick, O.A., Brimhall, G.H. and Hendricks, D.M. (1990) From black box to a grey box: a mass balance interpretation of pedogenesis. Geomorphology 3, 369-390.

Chapela Lara, M., Buss, H.L., Pogge von Strandmann, P.A.E., Dessert, C. and Gaillardet, J. (2014) Controls ont he mg cycle in the tropics: insights from a case study at the Luquillo Critical Zone Observatory. Procedia Earth and Planeary Science 10, 200-203. 
Deer, W.A., Howie, R.A. and Zussman, J. (2013) An Introduction to the Rock-Forming Minerals, 3 ed. The Mineralogical Society, London.

Dessert, C., Dupre, B., Francois, L., Schott, J., Gaillard, J., Chakrapani, G. and Bajpai, S. (2001) Erosion of Deccan Traps determined by river geochemistry: impact on global climate and the 87Sr86Sr ratioof seawater. Earth Planet. Sci. Lett. 188, 459-474.

Dessert, C., Dupre, B., Gaillardet, J., Francois, L.M. and Allegre, C.J. (2003) Basalt weathering laws and the impact of basalt weathering on the global carbon cycle. Chem. Geol. 202, 257-273.

Dosseto, A., Buss, H.L. and Suresh, P.O. (2012) Rapid regolith formation over volcanic bedrock and implications for landscape evolution. Earth and Planetary Science Letters 337-338, 47-55.

Eberl, D.D. (2003) User guide to RockJock - A program for determining quantitative mineralogy from X-ray diffraction data.

Eberl, D.D. (2008) User's guide to HandLens-A computer program that calculates the chemistry of minerals in mixtures.

Fletcher, R.C., Buss, H.L. and Brantley, S.L. (2006) A spheroidal weathering model coupling porewater chemistry to soil thicknesses during steady-state denudation. Earth and Planetary Science Letters $244,444-457$.

Freyssinet, P. and Farah, A.S. (2000) Geochemical mass balance and weahteirng rates of ultramafic schists in Amazonia. Chem. Geol. 170, 133-151.

Gioda, A., Mayol-Bracero, O.L., Scatena, F.N., Weathers, K.C., Mateus, V.L. and McDowell, W.H. (2013) Chemical constituents in clouds and rainwater in the Puerto Rican rainforest: Potential sources and seasonal drivers. Atmospheric Environment 68, 208-220.

Goldsmith, S.T., Carey, A.E., Johnson, B.M., Welch, S.A., Lyons, W.B., McDowell, W.H. and Pigott, J.S. (2010) Stream geochemistry, chemical weathering and CO (sub 2) consumption potential of andesitic terrains, Dominica, Lesser Antilles. Geochim. Cosmochim. Acta 74, 85-103.

Goldsmith, S.T., Carey, A.E., Lyons, W.B. and Hicks, D.M. (2008) Geochemical fluxes and weathering of volcanic terrains on high standing islands; Taranaki and Manawatu-Wanganui regions of New Zealand. Geochim. Cosmochim. Acta 72, 2248-2267.

Graham, R.C., Rossi, A.M. and Hubbert, K.R. (2010) Rock to regolith conversion: Producing hospitable substrates for terrestrial ecosystems. GSA Today 20, 4-9.

Hahm, W.J., Riebe, C.S., Lukens, C.E. and Araki, S. (2014) Bedrock composition regulates mountain ecosystems and landscape evolution. Proc. Natl. Acad. Sci. U. S. A. 111, 3338-3343.

Heartsill-Scalley, T., Scatena, F.N., Estrada, C., McDowell, W.H. and Lugo, A.E. (2007) Disturbance and long-term patterns of rainfall and throughfall nutrient fluxes in a subtropical wet forest in Puerto Rico. Journal of Hydrology 333, 472-485.

Helgeson, H.C., Murphy, W.M. and Aagard, P. (1984) Thermodynamic and kinetic constraints on reaction rates among minerals and aqueous solutions II. Rate constants, effective surface area, and the hydrolysis of feldspar. Geochim. Cosmochim. Acta 48, 2405-2432.

Hillel, D. (1982) Introduction to Soil Physics. Academic Press, San Diego. 
Jin, L., Ravella, R., Ketchum, B., Bierman, P.R., Heaney, P., White, T. and Brantley, S.L. (2010) Mineral weathering and elemental transport during hillslope evolution at the Susquehanna/Shale Hills Critical Zone Observatory. Geochim. Cosmochim. Acta 74, 3669-3691.

Jolly, W.T., Lidiak, E.G., Dickin, A.P. and Wu, T.-W. (1998) Geochemical diversity of Mesozoic island arc tectonic blocks in eastern Puerto Rico. Geol. Soc. Am. Spec. Pap. 322, 67-98.

Kesler, S.E. and Sutter, J.F. (1979) Chemical analysis of intrusive rocks from Puerto Rico. Geological Society of America Suppl. Mater. 79-5, 2 pp.

Köhler, S.J., Dufaud, F. and Oelkers, E.H. (2003) An experimental study of illite dissolution kinetics as a function of ph from 1.4 to 12.4 and temperature from 5 to $50^{\circ} \mathrm{C}$. Geochim. Cosmochim. Acta 67, 3583-3594.

Kump, L.R., Brantley, S.L. and Arthur, M.A. (2000) Chemical weathering, atmospheric CO2 and climate. Ann. Rev of Earth and Planetary Sciences 28, 611-667.

Kurtz, A.C., Lugolobi, F. and Salvucci, G. (2011) Germanium-silicon as a flowpath tracer: Application to the Rio Icacos watershed. Water Resour. Res. 47, W06516.

Larsen, M.C. (2012) Landslides and Sediment Budgets in Four Watersheds in Eastern Puerto Rico, in: Murphy, S.F., Stallard, R.F. (Eds.), Water Quality and Landscape Processes of Four Watersheds in Eastern Puerto Rico: U.S. Geological Survey Professional Paper 1789, pp. 153-178.

Liermann, L.J., Albert, I., Buss, H.L., Minyard, M. and Brantley, S.L. (2015) Relating Microbial Community Structure and Geochemistry in Deep Regolith Developed on Volcaniclastic Rock in the Luquillo Mountains, Puerto Rico. Geomicrobiology 32, 494-510.

Lugolobi, F., Kurtz, A.C. and Derry, L.A. (2010) Germanium-silicon fractionation in a tropical, granitic weathering environment. Geochim. Cosmochim. Acta 74, 1294-1308.

McClintock, M.A., Brocard, G., Willenbring, J., Tamayo, C., Porder, S. and Pett-Ridge, J.C. (2015) Spatial variability of African dust in soils in a montane tropical landscape in Puerto Rico. Chem. Geol. 412, 69-81.

McDowell, W.H. and Asbury, C.E. (1994) Export of carbon, nitrogen, and major ions from three tropical montane watersheds. Limnology and Oceanography 39, 111-125.

Meybeck, M. (1987) Global chemical weathering of surficial rocks estimated from dissolved river loads. Amer. J. Sci. 287, 401-428.

Minyard, M.L., Bruns, M.A., Martinez, C.E., Liermann, L.J., Buss, H.L. and Brantley, S.L. (2011) Halloysite nanotubes and bacteria at the saprolite-bedrock interface, Rio Icacos Watershed, Puerto Rico. Soil Sci Soc Am J 75, 348-356.

Murphy, S.F., Brantley, S.L., Blum, A.E., White, A.F. and Dong, H. (1998) Chemical weathering in a tropical watershed, Luquillo Mountains, Puerto Rico; II. Rate and mechanism of biotite weathering. Geochim. Cosmochim. Acta 62, 227-243.

Murphy, S.F. and Stallard, R.F. (2012) Hydrology and climate of four watersheds in eastern Puerto Rico, in: Murphy, S.F., Stallard, R.F. (Eds.), Water Quality and Landscape Processes of Four Watersheds in Eastern Puerto Rico: U.S. Geological Survey Professional Paper 1789, pp. 43-83. 
Navarre-Sitchler, A.K., Cole, D., Rother, G., Jin, L., Buss, H.L. and Brantley, S.L. (2013) Porosity and surface area evolution during weathering of two igneous rocks. Geochim. Cosmochim. Acta 109, 400-413.

Parkhurst, D.L. and Appelo, C.A.J. (1999) User's guide to PHREEQC (Version 2)—A computer program for speciation, batch-reaction, one-dimensional transport, and inverse geochemical calculations, U.S. Geological Survey Water-Resources Investigations Report 99-4259, p. 310.

Pett-Ridge, J. (2009) Contributions of dust to phosphorus cycling in tropical forests of the Luquillo Mountains, Puerto Rico. Biogeochemistry 94, 63-80.

Pett-Ridge, J.C., Derry, L.A. and Kurtz, A.C. (2009) Sr isotopes as a tracer of weathering processes and dust inputs in a tropical granitoid watershed, Luquillo Mountains, Puerto Rico. Geochim. Cosmochim. Acta $73,25-43$.

Rad, S., Louvat, P., Gorge, C., Gaillardet, J. and Allègre, C.J. (2006) River dissolved and solid loads in the Lesser Antilles: New insight into basalt weathering processes. Journal of Geochemical Exploration 88, 308-312.

Rad, S.D., Allegre, C.J. and Louvat, P. (2007) Hidden erosion on volcanic islands. Earth Planet. Sci. Lett. $262,109-124$.

Richter, D.D. and Markewitz, D. (1995) How deep is soil? Bioscience 45, 600-609.

Riebe, C.S., Kirchner, J.W. and Finkel, R.C. (2003) Long-term rates of chemical weathering and physical erosion from cosmogenic nuclides and geochemical mass balance. Geochim. Cosmochim. Acta 67, 4411-4427.

Scatena, F.N. (1989) An introduction to the physiography and history of the Bisley Experimental Watersheds in the Luquillo Mountains of Puerto Rico. USDA Forest Service, General Technical Report SO-72, p. 22.

Scatena, F.N., Silver, W., Siccama, T., Johnson, A. and Sanchez, M.J. (1993) Biomass and Nutrient Content of the Bisley Experimental Watersheds, Luquillo Experimental Forest, Puerto Rico, Before and After Hurricane Hugo. Biotropica 25, 15-27.

Schellekens, J., Bruijnzeel, L.A., Scatena, F.N., Bink, N.J. and Holwerda, F. (2000) Evaporation from a tropical rain forest, Luquillo Experimental Forest, eastern Puerto Rico. Water Resour. Res. 36, 2183 2196.

Schellekens, J.H., Scatena, F.N., Bruijnzeel, L.A., van Dijk, A.I.J.M., Groen, M.M.A. and van Hogezand, R.J.P. (2004) Stormflow generation in a small rainforest catchment in the Luquillo Experimental Forest, Puerto Rico. Hydrol. Process. 18, 505-530.

Schopka, H.H. and Derry, L.A. (2012) Chemical weathering fluxes from volcanic islands and the importance of groundwater: The Hawaiian example. Earth and Planetary Science Letters 339-340, 67-78.

Schulz, M.S. and White, A.F. (1999) Chemical weathering in a tropical watershed, Luquillo Mountains, Puerto Rico; III. Quartz dissolution rates. Geochim. Cosmochim. Acta 63, 337-350.

Seiders, V.M. (1971) Geologic map of the El Yunque quadrangle, Puerto Rico. U.S. Geological Survey. 
Silver, W.L., Scatena, F.N., Johnson, A.H., Siccama, T.G. and Sanchez, M.J. (1994) Nutrient availability in a montane wet tropical forest: Spatial patterns and methodological considerations. Plant Soil 164, 129145.

Simon, A., Larsen, M.C. and Hupp, C.R. (1990) The role of soil processes in determining mechanisms of slope failure and hillslope development in a humid-tropical forest, eastern Puerto Rico. Geomorphology 3, 263-286.

Singh, R. and Gilkes, R.J. (1992) Properties of soil kaolinites from south-western Australia. J. Soil. Sci. 43, 645-667.

Smith, A.L., Schellekens, J.H. and Diaz, A.M. (1998) Batholiths as markers of tectonic change in the northeastern Caribbean. Geol. Soc. Am. Spec. Pap. 322, 99-122.

Stallard, R.F. (2012) Weathering, Landscape Equilibrium, and Carbon in Four Watersheds in Eastern Puerto Rico, in: Murphy, S.F., Stallard, R.F. (Eds.), Water Quality and Landscape Processes of Four Watersheds in Eastern Puerto Rico. U.S. Geological Survey Professional Paper 1789-H, pp. 199247.

Stallard, R.F. and Edmond, J.M. (1983) Geochemistry of the Amazon: 2. The influence of the geology and weathering environment on the load. Journal of Geophysical Research 88, 9671-9688.

Taylor, G. and Eggleton, R.A. (2001) Regolith Geology and Geomorphology. Wiley.

Turner, B.F., Stallard, R.F. and Brantley, S.L. (2003) Investigation of in situ weathering of quartz diorite bedrock in the Rio Icacos basin, Luquillo Experimental Forest, Puerto Rico. Chem. Geol. 202, 313 341.

USDA NCRS (2002) Soil Survey of Caribbean National Forest and Luquillo Experimental Forest, Commonwealth of Puerto Rico. USDA, Natural Resources Conservation Service, Washington D.C., p. 181.

Walker, T.W. and Syers, J.K. (1976) Fate of phosphorus during pedogenesis. Geoderma 15, 1-19.

White, A.F. (2002) Determining mineral weathering rates based on solid and solute weathering gradients and velocities: application to biotite weathering in saprolites. Chem. Geol. 190, 69-89.

White, A.F. and Blum, A.E. (1995) Effects of climate on chemical weathering rates in watersheds. Geochim. Cosmochim. Acta 59, 1729-1747.

White, A.F., Blum, A.E., Schulz, M.S., Vivit, D.V., Stonestrom, D.A., Larsen, M., Murphy, S.F. and Eberl, D. (1998) Chemical weathering in a tropical watershed, Luquillo Mountains, Puerto Rico: I. Longterm versus short-term weathering fluxes. Geochim. Cosmochim. Acta 62, 209-226.

White, A.F. and Brantley, S.L. (2003) The effect of time on the experimental and natural weathering rates of silicate minerals. Chem. Geol. 202, 479-506.

White, A.F. and Buss, H.L. (2014) 7.4 - Natural Weathering Rates of Silicate Minerals, in: Drever, J.I. (Ed.), Treatise on Geochemistry (Second Edition). Elsevier, Oxford, pp. 115-155.

White, A.F., Schulz, M.S., Lowenstern, J.B., Vivit, D. and Bullen, T.D. (2005) The ubiquitous nature of accessory calcite in granitoid rocks: Implications for weathering and solute evolution, and petrogenesis. Geochim. Cosmochim. Acta 69, 1455-1471. 
White, A.F., Schulz, M.S., Stonestrom, D.A., Vivit, D.V., Fitzpatrick, J., Bullen, T.D., Maher, K. and Blum, A.E. (2009) Chemical weathering of a marine terrace chronosequence, Santa Cruz, California. Part II: Solute profiles, gradients and the comparisons of contemporary and long-term weathering rates. Geochim. Cosmochim. Acta 73, 2769-2803.

Wu, W., Hall, C.A.S., Scatena, F.N. and Quackenbush, L.J. (2006) Spatial modelling of evapotranspiration in the Luquillo experimental forest of Puerto Rico using remotely-sensed data. Journal of Hydrology $328,733-752$.

Yi-Balan, S.A., Amundson, R. and Buss, H.L. (2014) Decoupling of sulfur and nitrogen cycling due to biotic processes in a tropical rainforest. Geochim. Cosmochim. Acta 142, 411-428.

Ziegler, K., Chadwick, O.A., White, A. and Brzezinski, M.A. (2005) $\delta^{30}$ Si systematics in a granitic saprolite, Puerto Rico. Geology 33, 817-820. 


\section{Figure Captions}

Figure 1. Map of the Luquillo Critical Zone Observatory (LCZO) indicating the key lithological units. The approximate areas of the Río Icacos and Bisley 1 watersheds are shown as boxes on the large map as well as the site of the Río Icacos regolith profile LG1. The inset shows the watershed boundaries of the Bisley 1 and the hand-augered profile sites B1R, B1S(1-4), the borehole drilling sites B1W1 and B1W2 (Buss et al., 2013) and the USGS stream gage.

Figure 2. Si and Mg pore water solute concentrations with depth in the LCZO ridgetop sites. (a) and (b) Measured Si concentrations (open symbols) in Bisley pore waters, with net weathering concentrations (closed symbols) calculated from the averages of the study period (Eq. 4). (c) Average net Si weathering concentrations for site LG1, taken from Schulz and White (1999). (d) and (e) Measured Mg concentrations (open symbols) in Bisley pore waters, with net weathering concentrations (closed symbols) calculated from the averages over the study period (Eqn. 4). (f) Average net Mg weathering concentrations for site LG1, taken from Schulz and White (1999). Note different scale on depth axis for site B1R ( $a$ and d). Dashed lines indicate linear gradients used to calculate short-term solute fluxes (Eq. 11, Tables 9-10). The LG1 gradients were determined by (c) Schulz and White (1999) and (f) White (2002). Error bars on Bisley data indicate the standard error of the average for the measured concentrations, which was propagated for the net concentrations. Only mean values were available for the LG1 site (Schulz and White, 1999; White, 2002).

Figure 3. Average pore space concentrations of gaseous (a) $\mathrm{CO}_{2}$ and (b) $\mathrm{O}_{2}$. For comparison, average atmospheric concentrations are: $\mathrm{O}_{2} 20.9 \%$ and $\mathrm{CO}_{2} 0.039 \%$. Error bars are the standard error of the average of 2-4 sampling dates during different seasons (B1S1 and B1R). LG1 gas samplers were installed last and data reflect only one sampling date, with error bars representing standard error of the mean of repeat measurements on the same samples.

Figure 4. Oxide wt.\% (symbols) and major mineralogy (shaded areas) for site B1R (a-d) and B1S1 (e-h). Note different scales for different oxides and minerals. Chlorite was not detected in site B1R. $\mathrm{Al}$ content corresponds to kaolinite (a, e) except between 1-4 m depth at site B1R where the trends diverge. $\mathrm{Si}, \mathrm{Fe}$ (total), and $\mathrm{Mg}$ can be correlated with quartz (b, f), Fe-(hydr)oxides (goethite and hematite, $\mathbf{c}, \mathbf{g})$, and chlorite (d, h), respectively.

Figure 5. Assessment of $\mathrm{Zr}$ (a-c) and $\mathrm{Ti}$ (d-f) immobility. The horizontal line is the mean of the range of bedrock composition values $\pm 1 \sigma$ (dotted lines). Open circles $=$ samples that overlap the $\pm 1 \sigma$ zones, closed circles $=$ samples that do not overlap the $\pm 1 \sigma$ zones. (a) B1R: Samples that do not 
overlap the $\pm 1 \sigma$ zone: 14.9 and $15.4 \mathrm{~m}$. (b) B1S1: Samples that do not overlap the $\pm 1 \sigma$ zone: 0.6 , 1.2-2.4, and $9.0 \mathrm{~m}$. Samples that do overlap the $\pm 1 \sigma$ zone: $0.9,3.3-8.5$, and $9.3 \mathrm{~m}$. (c) LG1: All samples overlap the $\pm 1 \sigma$ zone. (d) B1R: Samples that do not overlap the $\pm 1 \sigma$ zone: $0.6,0.8,2.3-6.9$, 8.9-10.1, 13.1-14.9, 15.7-15.9 m. Samples that do overlap the $\pm 1 \sigma$ zone: $0.04-0.35,1.3,7.4-8.5$, 11.3-12.2, $15.4 \mathrm{~m}$. (e) B1S1: Most samples do not overlap the $\pm 1 \sigma$ zone; those that do overlap: 4.9 and $7.6 \mathrm{~m}$. (f) LG1: Samples that do not overlap the $\pm 1 \sigma$ zone: $0.25 \mathrm{~m}$.

Figure 6. Volumetric strain with depth in the ridgetop sites. Error bars reflect estimated 3\% error on bulk density measurements, detection limits of elemental analyses and SE of the mean parent $\mathrm{Zr}$ concentrations, propagated through the calculation. (a) Strain values near zero indicate near isovolumetric weathering at Bisley site B1R with slight dilation in B1R, particularly near 2.5 and 7 $\mathrm{m}$ depth.and (b) near isovolumetric weathering throughout Bisley site B1S1. (c) Strain in Rio Icacos site LG1 indicates modest dilation at most depths.

Figure 7. Rigetop mass transfer (tau) profiles for inorganic nutrient elements: K (a-e), P (f-j), and Mg (k-o). Sites are arranged in columns, from left to right: B1R, B1S1, B1S2, B1S4, LG1 for each row and exclude the weathered clasts recovered in some profiles. Note different depth (y-axis) scale for B1R (first column) and different tau (x-axis) scales for (a, e, and f). $\mathrm{Na}$ and $\mathrm{Ca}$ (not shown) are completely depeleted $\left(\tau_{j, Z r}=-1\right)$ in almost every sample of every profile, with the exception of B1S4, where $\tau_{N a, Z r}=-0.5$ at the bottom $(0.9 \mathrm{~m}$ depth). Vertical solid lines (a, e, f) indicate tau $=0$. Dashed lines in some profiles indicate linear gradients used to calculate long-term elemental fluxes (Eq. 10, Table 9). The gradient used to calculate the long-term chlorite weathering rate (Eq. 8, Tables 9-10) is not shown, but determined from data in (1) from 8.2-9.3 $\mathrm{m}$ depth only.

Figure 8. Mass transfer (tau) profiles of less-mobile elements: $j=\mathrm{Si}$ (circles) or Fe (triangles). Note different depth and tau scales were used to show key features. Solid vertical lines indicate tau $=0$. (a-d) All Bisley profiles are depleted in Si and Fe reflecting extreme mass loss due to chemical weathering. However, the deeper ridgetop profiles (a-b, B1R and B1S1) indicate some enrichment of Fe, suggesting redistribution occurs over time. Dashed lines in B1S1, B1S2 and B1S4 profiles (b, c, d) indicate linear gradients used to calculate long-term Si fluxes (Eq. 10, Table 9). Weathered clasts are excluded from these profiles. (e) Si enrichment occurs at the surface of Río Icacos site LG1, which may reflect biogenic input of Si as phytoliths (Ziegler et al., 2005; Lugolobi et al., 2010). Error was calculated from the analytical detection limits and standard errors of the mean parent rock compositions (Table 2) and propagated through the calculations. Error bars for Si are smaller than the symbols and Fe error bars are not shown for clarity. 
1123 Figure 9. Net solute concentrations in B1R pore waters versus ammonium-acetate extractable Mg. 1124 (a) Net $\mathrm{Mg}$ concentrations and (b) net $\mathrm{Si}$ concentrations both correlate well with extractable $\mathrm{Mg}$ 1125 below the shallowest depths, where extractable $\mathrm{Mg}$ is much higher than in the remainder of the 1126 profile.

1127 Figure 10. Mass transfer (tau) profiles of clay minerals in the B1S1 profile. (a) Kaolinite increases 1128 from the bottom of the profile to about $4.9 \mathrm{~m}$ depth, above which a depletion trend is evident. (b) 1129 Illite increases from the bottom only to about $7.6 \mathrm{~m}$ depth; a depletion trend extends from this depth 1130 to the surface. Both profiles are consistent with secondary clay formation during earlier stages of 1131 weathering followed by dissolution in the upper meters of the regolith. Dashed lines indicate linear 1132 gradients used for calculating long-term mineral dissolution rates (Eq. 8, Tables 9-10). Error bars 1133 reflect XRD detection limits and standard error of the mean parent rock compositions, propagated 1134 through the calculations. 
Table 1. Regolith physical properties

\begin{tabular}{|c|c|c|c|}
\hline $\begin{array}{l}\text { Depth } \\
\text { (m) }\end{array}$ & $\begin{array}{c}\text { Water } \\
\text { Content }^{\mathrm{a}} \\
(\text { vol \%) }\end{array}$ & $\begin{array}{c}\text { Bulk } \\
\text { Density } \\
\left(\mathrm{g} \mathrm{cm}^{-3}\right)\end{array}$ & $\begin{array}{c}\text { Porosity } \\
(\%)\end{array}$ \\
\hline \multicolumn{4}{|c|}{ B1R (Upper Ridge) } \\
\hline 0.05 & 31.7 & 0.89 & 66 \\
\hline 0.29 & 25.5 & 1.25 & 53 \\
\hline 0.36 & 15.8 & 1.38 & 48 \\
\hline 0.58 & 19.2 & 1.47 & 45 \\
\hline 0.79 & 16.5 & 1.67 & 37 \\
\hline 1.42 & 21.3 & 1.55 & 42 \\
\hline 2.43 & 20.7 & 1.48 & 44 \\
\hline 3.06 & 19.7 & 1.49 & 44 \\
\hline 3.80 & 17.5 & 1.57 & 41 \\
\hline 5.00 & 15.3 & 1.42 & 46 \\
\hline \multicolumn{4}{|c|}{ B1S1 (Lower Ridge) } \\
\hline 0.30 & 35.2 & 0.95 & 64 \\
\hline 0.61 & 25.8 & 1.19 & 55 \\
\hline 0.91 & 27.4 & 1.18 & 56 \\
\hline 1.22 & 26.6 & 1.18 & 55 \\
\hline 1.52 & 28.4 & 1.13 & 57 \\
\hline 1.83 & 29.4 & 1.11 & 58 \\
\hline 2.44 & 32.0 & 1.05 & 60 \\
\hline 3.30 & 29.9 & 1.07 & 60 \\
\hline 3.66 & 32.2 & 1.05 & 61 \\
\hline 4.27 & 33.3 & 0.99 & 63 \\
\hline 4.88 & 32.2 & 1.01 & 62 \\
\hline 5.49 & 30.4 & 1.00 & 62 \\
\hline 6.10 & 32.5 & 1.01 & 62 \\
\hline 6.71 & 32.1 & 1.06 & 60 \\
\hline
\end{tabular}




\begin{tabular}{|c|c|c|c|c|c|c|c|c|c|c|c|c|c|c|c|}
\hline $\begin{array}{c}\text { Depth } \\
\text { (m) }\end{array}$ & $\begin{array}{r}\mathrm{Al}_{2} \mathrm{O}_{3} \\
\text { (wt. \%) } \\
\end{array}$ & $\mathrm{CaO}$ & $\begin{array}{c}\mathrm{Fe}_{2} \mathrm{O}_{3} \\
\text { total Fe }\end{array}$ & $\mathrm{FeO}^{\mathrm{b}}$ & $\mathrm{K}_{2} \mathrm{O}$ & $\mathrm{MgO}$ & $\mathrm{MnO}$ & $\mathrm{Na}_{2} \mathrm{O}$ & $\mathrm{P}_{2} \mathrm{O}_{5}$ & $\mathrm{SiO}_{2}$ & $\mathrm{TiO}_{2}$ & $\begin{array}{l}\mathrm{Nb} \\
(\mathrm{ppm})\end{array}$ & $\mathrm{Sr}$ & $\mathrm{Zn}$ & $\mathrm{Zr}$ \\
\hline \multicolumn{16}{|c|}{ Bisley Bedrock $^{c}$} \\
\hline & 16.8 & 7.9 & 8.6 & 6.1 & 0.8 & 5.5 & 0.15 & 2.8 & 0.11 & 53.1 & 0.65 & $<10$ & 540 & 77 & 82 \\
\hline & \pm 0.3 & \pm 0.5 & \pm 0.2 & \pm 0.3 & \pm 0.1 & \pm 0.3 & \pm 0.02 & \pm 0.2 & \pm 0.01 & \pm 0.7 & \pm 0.02 & & \pm 40 & \pm 4 & \pm 4 \\
\hline \multicolumn{16}{|c|}{ Rio Icacos Bedrock $^{c}$} \\
\hline & 17.0 & 7.32 & 8.5 & 4.6 & 0.86 & 2.9 & 0.17 & 3.0 & 0.12 & 55.3 & 0.58 & $<10$ & 247 & - & 85 \\
\hline & \pm 0.6 & \pm 0.06 & \pm 0.7 & \pm 0.4 & \pm 0.03 & \pm 0.3 & \pm 0.02 & \pm 0.1 & \pm 0.01 & \pm 0.5 & \pm 0.04 & & \pm 9 & - & \pm 3 \\
\hline \multicolumn{16}{|c|}{ B1R Regolith } \\
\hline 0.04 & 16.2 & 0.11 & 8.32 & 0.20 & 0.30 & 0.18 & $<0.01$ & 0.14 & 0.07 & 53.6 & 0.87 & 40 & 40 & 28 & 120 \\
\hline 0.2 & 17.5 & 0.09 & 9.66 & 0.20 & 0.33 & 0.17 & $<0.01$ & 0.24 & 0.06 & 56.6 & 0.92 & 40 & 30 & 35 & 130 \\
\hline 0.4 & 18.0 & 0.03 & 10.4 & 0.10 & 0.42 & 0.18 & $<0.01$ & 0.20 & 0.05 & 57.7 & 0.94 & 50 & 30 & 27 & 130 \\
\hline 0.6 & 13.7 & 0.02 & 6.29 & 0.20 & 1.34 & 0.33 & $<0.01$ & 0.24 & 0.05 & 65.0 & 0.61 & 70 & 30 & 23 & 90 \\
\hline 0.8 & 13.1 & 0.03 & 28.9 & 0.10 & 1.21 & 0.30 & 0.03 & 0.22 & 0.65 & 40.5 & 0.52 & 70 & 20 & 197 & 90 \\
\hline 1.3 & 18.7 & 0.03 & 10.8 & $<0.1$ & 0.48 & 0.11 & 0.02 & 0.17 & 0.22 & 59.4 & 0.81 & 50 & 30 & 86 & 110 \\
\hline 2.3 & 19.6 & 0.03 & 9.16 & $<0.1$ & 0.71 & 0.15 & 0.02 & 0.17 & 0.21 & 60.5 & 0.79 & 40 & 30 & 59 & 70 \\
\hline 3.1 & 20.4 & 0.02 & 9.43 & $<0.1$ & 0.55 & 0.13 & 0.04 & 0.22 & 0.16 & 60.4 & 0.90 & 30 & 40 & 51 & 150 \\
\hline 3.5 & 14.7 & 0.03 & 18.0 & $<0.1$ & 1.29 & 0.26 & 0.08 & 0.20 & 0.52 & 55.6 & 0.47 & 30 & 30 & 84 & 90 \\
\hline 3.7 & 14.1 & 0.03 & 5.51 & $<0.1$ & 1.55 & 0.33 & 0.02 & 0.19 & 0.20 & 71.5 & 0.64 & 30 & 110 & 37 & 110 \\
\hline 5.0 & 17.6 & 0.02 & 8.42 & $<0.1$ & 0.91 & 0.18 & 0.03 & 0.17 & 0.25 & 63.6 & 0.89 & 20 & 30 & 52 & 200 \\
\hline 5.6 & 18.6 & 0.03 & 7.09 & $<0.1$ & 0.73 & 0.18 & 0.08 & 0.06 & 0.21 & 63.3 & 0.75 & 10 & 60 & 30 & 140 \\
\hline 6.2 & 22.1 & 0.01 & 9.98 & $<0.1$ & 0.31 & 0.10 & 0.11 & 0.04 & 0.17 & 53.9 & 0.83 & 20 & 20 & 35 & 130 \\
\hline 6.9 & 11.5 & 0.04 & 4.60 & $<0.1$ & 0.41 & 0.10 & 0.03 & 0.08 & 0.08 & 75.5 & 0.39 & $<10$ & 10 & 22 & 70 \\
\hline 7.4 & 8.74 & 0.02 & 7.51 & $<0.1$ & 0.46 & 0.10 & 0.14 & 0.20 & 0.13 & 76.9 & 0.37 & 40 & 20 & 31 & 50 \\
\hline 7.6 & 11.0 & 0.05 & 5.07 & $<0.1$ & 0.60 & 0.16 & 0.03 & 0.04 & 0.09 & 75.4 & 0.51 & 10 & 30 & 14 & 70 \\
\hline 8.5 & 19.2 & 0.17 & 9.43 & $<0.1$ & 0.16 & 0.15 & 0.07 & 0.11 & 0.10 & 60.6 & 0.70 & $<10$ & 10 & 23 & 80 \\
\hline 8.9 & 24.2 & 0.02 & 12.1 & $<0.1$ & 0.14 & 0.08 & 0.46 & 0.12 & 0.13 & 51.5 & 0.84 & 40 & $<10$ & 55 & 80 \\
\hline 9.3 & 24.5 & 0.02 & 13.7 & $<0.1$ & 0.15 & 0.12 & 0.70 & 0.02 & 0.16 & 45.3 & 0.92 & 20 & $<10$ & 69 & 90 \\
\hline 10.1 & 22.8 & 0.02 & 11.3 & $<0.1$ & 0.18 & 0.08 & 0.14 & 0.12 & 0.14 & 51.3 & 0.91 & 40 & $<10$ & 37 & 90 \\
\hline 11.3 & 17.8 & 0.02 & 8.88 & $<0.1$ & 0.58 & 0.15 & 0.10 & 0.14 & 0.18 & 64.5 & 0.88 & 50 & 20 & 41 & 110 \\
\hline 12.2 & 18.7 & 0.10 & 19.5 & $<0.1$ & 0.41 & 0.15 & 0.51 & 0.03 & 0.25 & 48.2 & 0.83 & 20 & $<10$ & 73 & 110 \\
\hline 13.1 & 15.5 & 0.02 & 8.57 & $<0.1$ & 0.53 & 0.15 & 0.10 & 0.12 & 0.15 & 66.0 & 0.75 & 40 & 10 & 30 & 120 \\
\hline 14.3 & 22.6 & 0.02 & 13.8 & $<0.1$ & 0.32 & 0.11 & 0.19 & 0.13 & 0.15 & 51.3 & 0.86 & 40 & $<10$ & 37 & 130 \\
\hline 14.9 & 24.8 & 0.02 & 11.3 & $<0.1$ & 0.45 & 0.11 & 0.17 & $<0.01$ & 0.14 & 49.5 & 0.93 & 30 & 40 & 55 & 280 \\
\hline
\end{tabular}




\begin{tabular}{|c|c|c|c|c|c|c|c|c|c|c|c|c|c|c|c|}
\hline 15.4 & 17.7 & 0.03 & 13.5 & $<0.1$ & 0.82 & 0.17 & 0.53 & 0.13 & 0.20 & 55.7 & 0.62 & 50 & 30 & 79 & 120 \\
\hline 15.5 & 16.7 & 0.03 & 13.8 & $<0.1$ & 0.46 & 0.11 & 0.59 & 0.12 & 0.23 & 53.8 & 0.54 & 40 & 30 & 94 & 100 \\
\hline 15.7 & 22.5 & 0.01 & 8.69 & $<0.1$ & 0.36 & 0.10 & 0.57 & $<0.01$ & 0.13 & 54.9 & 0.90 & 30 & 30 & 66 & 180 \\
\hline 15.8 & 21.3 & 0.02 & 9.47 & $<0.1$ & 0.30 & 0.07 & 0.41 & 0.15 & 0.13 & 54.9 & 0.80 & 30 & 20 & 67 & 140 \\
\hline 15.9 & 19.3 & 0.05 & 11.4 & $<0.1$ & 0.22 & 0.09 & 0.24 & $<0.01$ & 0.17 & 56.8 & 0.94 & 20 & 10 & 51 & 160 \\
\hline \multicolumn{16}{|c|}{ B1R Augered Clasts } \\
\hline 5.6 & 16.7 & 0.07 & 5.89 & - & 0.59 & 0.15 & 0.05 & 0.01 & 0.16 & 67.2 & 0.51 & 20 & 40 & 28 & 80 \\
\hline 6.2 & 23.2 & 0.01 & 8.23 & - & 0.29 & 0.09 & 0.10 & 0.01 & 0.15 & 55.3 & 0.91 & 30 & 20 & 32 & 130 \\
\hline 6.9 & 5.47 & 0.05 & 2.89 & - & 0.30 & 0.07 & $<0.01$ & $<0.01$ & 0.05 & 76.4 & 0.28 & 20 & 30 & 7 & 60 \\
\hline 7.6 & 8.27 & $<0.01$ & 3.69 & - & 0.53 & 0.13 & 0.02 & $<0.01$ & 0.07 & 76.5 & 0.39 & $<10$ & 20 & 7 & 60 \\
\hline 8.5 & 20.5 & 0.02 & 9.50 & - & 0.08 & 0.06 & 0.10 & $<0.01$ & 0.11 & 58.5 & 0.74 & 10 & $<10$ & 34 & 90 \\
\hline 9.3 & 25.3 & $<0.01$ & 12.4 & - & 0.22 & 0.12 & 1.04 & $<0.01$ & 0.19 & 46.2 & 0.86 & 20 & $<10$ & 73 & 90 \\
\hline 12.2 & 24.4 & 0.01 & 11.6 & - & 0.17 & 0.07 & 0.05 & $<0.01$ & 0.21 & 48.5 & 1.11 & 30 & $<10$ & 28 & 150 \\
\hline 14.9 & 25.7 & $<0.01$ & 10.8 & - & 0.56 & 0.12 & 0.02 & 0.02 & 0.14 & 46.5 & 0.99 & 30 & 40 & 45 & 390 \\
\hline 15.9 & 22.3 & 0.01 & 9.51 & - & 0.24 & 0.06 & 0.14 & 0.05 & 0.15 & 54.2 & 0.78 & 20 & 10 & 62 & 130 \\
\hline 15.7 & 23.2 & 0.01 & 8.73 & - & 0.39 & 0.10 & 0.74 & $<0.01$ & 0.15 & 52.8 & 0.97 & 20 & 30 & 67 & 180 \\
\hline \multicolumn{16}{|c|}{ B1S1 Regolith } \\
\hline 0.6 & 22.9 & 0.02 & 11.3 & - & 0.07 & 0.29 & 0.02 & $<0.1$ & 0.08 & 46.5 & 1.03 & 20 & 4.0 & 53 & 210 \\
\hline 0.9 & 22.0 & 0.03 & 11.1 & - & 0.06 & 0.29 & 0.03 & $<0.1$ & 0.09 & 57.2 & 0.92 & 10 & 2.1 & 41 & 170 \\
\hline 1.2 & 22.5 & 0.01 & 11.2 & - & 0.07 & 0.23 & 0.02 & $<0.1$ & 0.10 & 54.7 & 0.89 & 20 & 2.4 & 39 & 170 \\
\hline 1.5 & 21.8 & 0.01 & 9.83 & - & 0.05 & 0.24 & 0.02 & $<0.1$ & 0.10 & 55.5 & 0.84 & 10 & 2.2 & 37 & 170 \\
\hline 1.8 & 23.7 & 0.02 & 10.7 & - & 0.04 & 0.45 & 0.03 & $<0.1$ & 0.06 & 46.5 & 0.93 & 10 & 1.0 & 38 & 180 \\
\hline 2.7 & 23.6 & 0.02 & 11.1 & - & 0.12 & 0.48 & 0.04 & $<0.1$ & 0.09 & 48.3 & 0.95 & 20 & 1.0 & 45 & 180 \\
\hline 3.1 & 26.0 & $<0.01$ & 11.8 & - & 0.12 & 0.53 & 0.05 & $<0.1$ & 0.09 & 45.9 & 1.03 & 10 & $<10$ & 63 & 170 \\
\hline 3.7 & 24.0 & 0.01 & 11.2 & - & 0.17 & 0.51 & 0.08 & $<0.1$ & 0.08 & 49.5 & 0.95 & $<10$ & $<10$ & 48 & 160 \\
\hline 4.3 & 22.1 & 0.03 & 10.8 & - & 0.10 & 0.54 & 0.21 & $<0.1$ & 0.07 & 52.3 & 0.85 & $<10$ & 1.4 & 59 & 150 \\
\hline 4.9 & 23.8 & 0.02 & 12.2 & - & 0.08 & 0.62 & 0.40 & $<0.1$ & 0.08 & 49.7 & 0.91 & 10 & $<10$ & 67 & 130 \\
\hline 5.5 & 23.1 & 0.02 & 11.6 & - & 0.07 & 0.60 & 0.46 & $<0.1$ & 0.06 & 48.9 & 0.87 & 10 & $<10$ & 72 & 130 \\
\hline 6.4 & 22.0 & 0.01 & 11.1 & - & 0.15 & 0.61 & 0.24 & $<0.1$ & 0.07 & 47.2 & 0.84 & $<10$ & 1.9 & 62 & 130 \\
\hline 7.0 & 23.2 & 0.03 & 11.6 & - & 0.24 & 0.81 & 0.42 & $<0.1$ & 0.07 & 48.1 & 0.87 & $<10$ & $<10$ & 78 & 130 \\
\hline 7.6 & 22.1 & 0.01 & 10.9 & - & 0.32 & 0.77 & 0.38 & $<0.1$ & 0.07 & 47.6 & 0.82 & $<10$ & $<10$ & 71 & 120 \\
\hline 8.2 & 24.1 & 0.01 & 11.4 & - & 0.17 & 0.80 & 0.24 & $<0.1$ & 0.05 & 46.0 & 0.93 & 10 & 2.2 & 79 & 150 \\
\hline 8.5 & 21.1 & 0.02 & 8.36 & - & 0.22 & 0.66 & 0.25 & $<0.1$ & 0.06 & 52.9 & 0.73 & $<10$ & $<10$ & 79 & 130 \\
\hline 9.0 & 19.1 & 0.02 & 8.85 & - & 0.44 & 0.89 & 0.26 & $<0.1$ & 0.09 & 57.9 & 0.74 & $<10$ & $<10$ & 123 & 140 \\
\hline 9.3 & 20.7 & 0.03 & 9.85 & - & 0.69 & 1.42 & 0.37 & $<0.1$ & 0.12 & 51.4 & 0.73 & 10 & 17 & 172 & 120 \\
\hline
\end{tabular}


B1S1 Augered Clasts

\begin{tabular}{|c|c|c|c|c|c|c|c|c|c|c|c|c|c|c|c|}
\hline \\
\hline 0.6 & 5.47 & 0.02 & 9.57 & - & 0.04 & 0.04 & $<0.01$ & $<0.1$ & 0.09 & 74.3 & 0.74 & $<10$ & $<10$ & 37 & 150 \\
\hline 4.3 & 6.40 & 0.05 & 4.79 & - & 0.19 & 0.10 & 0.02 & $<0.1$ & 0.09 & 76.7 & 0.33 & $<10$ & $<10$ & 16 & 80 \\
\hline 9.0 & 6.32 & 0.09 & 3.36 & - & 0.76 & 0.88 & 0.06 & 0.1 & 0.07 & 83.1 & 0.37 & $<10$ & 30 & 51 & 80 \\
\hline 9.3 & 7.49 & 0.03 & 4.99 & - & 0.92 & 1.16 & 0.06 & $<0.1$ & 0.06 & 75.4 & 0.59 & $<10$ & 34.5 & 84 & 100 \\
\hline
\end{tabular}

\begin{tabular}{|c|c|c|c|c|c|c|c|c|c|c|c|c|c|c|c|}
\hline 0.15 & 19.7 & 0.02 & 10.4 & - & 0.07 & 0.41 & 0.02 & $<0.1$ & 0.07 & 48.5 & 0.99 & 20 & $<10$ & 41 & 150 \\
\hline 0.6 & 21.7 & 0.01 & 10.8 & - & 0.59 & 0.99 & 0.43 & 0.1 & 0.09 & 49.0 & 0.88 & 20 & 10 & 92 & 120 \\
\hline 0.9 & 23.1 & 0.01 & 11.6 & - & 0.11 & 0.41 & 0.04 & $<0.1$ & 0.12 & 46.6 & 1.06 & 20 & $<10$ & 57 & 180 \\
\hline 1.5 & 23.5 & 0.03 & 10.5 & - & 0.19 & 1.41 & 0.40 & $<0.1$ & 0.10 & 47.1 & 0.94 & 20 & $<10$ & 153 & 140 \\
\hline 1.8 & 23.4 & $<0.01$ & 11.5 & - & 0.24 & 0.95 & 0.65 & $<0.1$ & 0.09 & 46.1 & 0.98 & 20 & $<10$ & 101 & 150 \\
\hline 2.7 & 22.6 & 0.02 & 11.0 & - & 0.36 & 2.22 & 0.31 & 0.2 & 0.12 & 46.2 & 0.97 & 20 & 10 & 297 & 140 \\
\hline
\end{tabular}

\begin{tabular}{|c|c|c|c|c|c|c|c|c|c|c|c|c|c|c|c|}
\hline \multicolumn{16}{|c|}{ 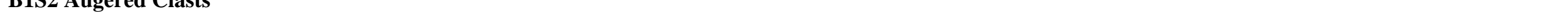 } \\
\hline 0.6 & 7.74 & 0.04 & 6.05 & - & 0.21 & 1.84 & 0.06 & $<0.1$ & 0.10 & 76.5 & 0.76 & 20 & 20 & 75 & 140 \\
\hline \multicolumn{16}{|c|}{ B1S3 Regolith } \\
\hline 0.15 & 22.5 & 0.02 & 11.2 & - & 0.16 & 0.81 & 0.25 & $<0.1$ & 0.08 & 47.7 & 0.93 & 20 & $<10$ & 77 & 130 \\
\hline 1.2 & 21.7 & 0.01 & 11.1 & - & 0.48 & 1.32 & 0.39 & 0.1 & 0.10 & 48.3 & 0.89 & 20 & 10 & 166 & 120 \\
\hline \multicolumn{16}{|c|}{ B1S4 Regolith } \\
\hline 0.15 & 20.2 & 0.09 & 11.0 & - & 0.16 & 0.79 & 0.25 & $<0.1$ & 0.09 & 45.9 & 0.91 & 20 & 10 & 89 & 130 \\
\hline 0.3 & 19.3 & 0.13 & 9.60 & - & 0.67 & 1.66 & 0.21 & 1.0 & 0.09 & 51.9 & 0.83 & 20 & 50 & 120 & 130 \\
\hline 0.9 & 15.4 & 0.53 & 6.99 & - & 1.29 & 1.77 & 0.10 & 1.4 & 0.09 & 62.1 & 0.67 & 20 & 90 & 97 & 120 \\
\hline \multicolumn{16}{|c|}{ LG1 Regolith } \\
\hline 0.15 & 13.2 & 0.03 & 4.74 & - & 0.27 & 0.13 & 0.02 & $<0.01$ & 0.01 & 68.3 & 0.36 & $<10$ & $<10$ & - & 138 \\
\hline 0.3 & 12.7 & 0.03 & 4.30 & - & 0.27 & 0.11 & 0.02 & 0.02 & $<0.01$ & 69.0 & 0.34 & $<10$ & $<10$ & - & 189 \\
\hline 0.5 & 15.7 & 0.02 & 5.12 & - & 0.34 & 0.19 & 0.02 & $<0.01$ & $<0.01$ & 65.1 & 0.43 & $<10$ & $<10$ & - & 145 \\
\hline 0.6 & 19.4 & 0.06 & 6.46 & - & 0.60 & 0.48 & 0.07 & 0.03 & 0.01 & 60.9 & 0.47 & $<10$ & $<10$ & - & 167 \\
\hline 0.8 & 17.1 & 0.03 & 5.79 & - & 0.56 & 0.44 & 0.07 & 0.03 & 0.01 & 62.4 & 0.42 & $<10$ & $<10$ & - & 99 \\
\hline 0.9 & 20.6 & 0.02 & 6.75 & - & 0.74 & 0.53 & 0.31 & 0.02 & 0.04 & 57.2 & 0.44 & $<10$ & $<10$ & - & 107 \\
\hline 1.1 & 20.6 & 0.02 & 6.67 & - & 0.92 & 0.72 & 0.08 & 0.02 & 0.02 & 57.6 & 0.46 & $<10$ & $<10$ & - & 183 \\
\hline 1.2 & 18.3 & 0.03 & 6.31 & - & 0.84 & 0.64 & 0.08 & 0.02 & 0.04 & 58.7 & 0.45 & $<10$ & $<10$ & - & 94 \\
\hline 1.4 & 20.2 & 0.02 & 7.23 & - & 0.84 & 0.67 & 0.17 & 0.02 & 0.04 & 57.7 & 0.47 & $<10$ & $<10$ & - & 97 \\
\hline 1.5 & 20.6 & 0.03 & 7.39 & - & 0.82 & 0.67 & 0.08 & $<0.01$ & 0.03 & 58.5 & 0.50 & $<10$ & $<10$ & - & 103 \\
\hline 1.8 & 19.7 & 0.07 & 6.63 & - & 0.90 & 0.53 & 0.05 & 0.04 & 0.04 & 61.5 & 0.42 & $<10$ & $<10$ & - & 101 \\
\hline 2.1 & 21.0 & 0.02 & 6.47 & - & 0.91 & 0.46 & 0.06 & $<0.01$ & 0.03 & 58.5 & 0.48 & $<10$ & $<10$ & - & 106 \\
\hline 2.4 & 24.4 & 0.02 & 5.66 & - & 0.77 & 0.51 & 0.46 & $<0.01$ & 0.05 & 54.6 & 0.39 & $<10$ & $<10$ & - & 80 \\
\hline
\end{tabular}




\begin{tabular}{|c|c|c|c|c|c|c|c|c|c|c|c|c|c|c|c|}
\hline 2.7 & 22.5 & 0.02 & 6.91 & - & 0.91 & 0.66 & 0.13 & 0.01 & 0.07 & 57.9 & 0.46 & $<10$ & $<10$ & - & 113 \\
\hline 3.0 & 23.8 & 0.05 & 7.43 & - & 1.03 & 0.74 & 0.06 & 0.07 & 0.06 & 57.3 & 0.49 & $<10$ & $<10$ & - & 132 \\
\hline 3.4 & 20.4 & 0.02 & 6.66 & - & 1.09 & 0.70 & 0.09 & 0.06 & 0.04 & 59.2 & 0.45 & $<10$ & $<10$ & - & 120 \\
\hline 3.7 & 20.4 & 0.02 & 6.99 & - & 1.00 & 0.61 & 0.12 & 0.03 & 0.03 & 57.8 & 0.46 & $<10$ & $<10$ & - & 103 \\
\hline 4.0 & 19.4 & 0.02 & 7.23 & - & 1.07 & 0.63 & 0.12 & 0.03 & 0.02 & 58.5 & 0.47 & $<10$ & $<10$ & - & 129 \\
\hline 4.3 & 18.2 & 0.03 & 6.90 & - & 1.03 & 0.55 & 0.26 & 0.07 & 0.02 & 59.4 & 0.44 & $<10$ & $<10$ & - & 128 \\
\hline 4.6 & 20.6 & 0.04 & 8.26 & - & 0.98 & 0.61 & 0.295 & 0.05 & 0.04 & 55.4 & 0.56 & $<10$ & $<10$ & - & 101 \\
\hline 4.9 & 18.7 & 0.89 & 6.78 & - & 1.41 & 1.29 & 0.255 & 0.61 & 0.09 & 60.1 & 0.43 & $<10$ & 28 & - & 97 \\
\hline 5.2 & 16.6 & 2.52 & 6.13 & - & 1.34 & 1.52 & 0.17 & 1.67 & 0.08 & 61.3 & 0.39 & $<10$ & 92 & - & 138 \\
\hline 5.5 & 16.7 & 2.59 & 6.32 & - & 1.45 & 1.95 & 1.03 & 1.74 & 0.07 & 60.0 & 0.42 & $<10$ & 85 & - & 98 \\
\hline 5.8 & 15.7 & 3.74 & 5.42 & - & 1.47 & 1.73 & 0.13 & 2.43 & 0.08 & 63.3 & 0.37 & $<10$ & 143 & - & 75 \\
\hline 6.1 & 15.4 & 3.55 & 5.09 & - & 1.45 & 1.57 & 0.14 & 2.36 & 0.08 & 60.5 & 0.36 & $<10$ & 140 & - & 115 \\
\hline 6.4 & 16.3 & 4.02 & 4.90 & - & 1.47 & 1.59 & 0.13 & 2.69 & 0.08 & 63.7 & 0.34 & $<10$ & 159 & - & 66 \\
\hline 6.7 & 15.4 & 4.06 & 5.52 & - & 1.50 & 1.84 & 0.15 & 2.53 & 0.08 & 63.7 & 0.38 & $<10$ & 153 & - & 62 \\
\hline 7.0 & 15.2 & 3.94 & 5.52 & - & 1.53 & 1.79 & 0.15 & 2.54 & 0.07 & 65.2 & 0.37 & $<10$ & 150 & - & 81 \\
\hline 7.3 & 16.6 & 4.48 & 5.57 & - & 1.35 & 1.92 & 0.18 & 2.67 & 0.10 & 59.9 & 0.36 & $<10$ & 162 & - & 111 \\
\hline
\end{tabular}

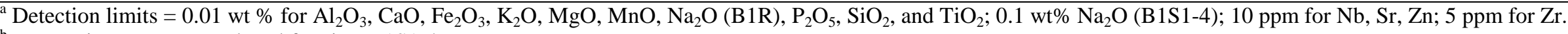

${ }^{\mathrm{b}}$ Ferrous iron was not analysed for sites B1S1-4.

${ }^{\mathrm{c}}$ Averaged bedrock data includes $\pm \mathrm{SE}$ of the mean. 
Table 3. Concentrations of cations in $\mathrm{NH}_{4}$-acetate extracts

\begin{tabular}{|c|c|c|c|c|c|c|}
\hline $\begin{array}{c}\text { Depth } \\
(\mathrm{m})\end{array}$ & $\begin{array}{c}\mathrm{Al} \\
(\mathrm{mmol} \mathrm{kg}\end{array}$ & )$^{\mathrm{Ca}}$ & K & $\mathrm{Mg}$ & $\mathrm{Na}$ & $\mathrm{Sr}$ \\
\hline $\mathrm{DL}^{\mathrm{a}}$ & 0.0025 & 0.05 & 0.1 & 0.03 & 0.01 & $4 \times 10^{-6}$ \\
\hline \multicolumn{7}{|c|}{ B1R regolith } \\
\hline 0.04 & 0.069 & 4.61 & 1.0 & 3.52 & 2.49 & 0.0176 \\
\hline 0.2 & 0.023 & 1.58 & 0.7 & 1.63 & 1.34 & 0.0088 \\
\hline 0.4 & 0.013 & 0.84 & 0.4 & 1.47 & 0.88 & 0.0053 \\
\hline 0.8 & 0.008 & 0.38 & 0.3 & 0.37 & 0.40 & 0.0020 \\
\hline 1.3 & 0.206 & 0.27 & bd & 0.33 & 0.61 & 0.0025 \\
\hline 2.3 & 0.010 & 0.20 & 0.1 & 0.41 & 0.94 & 0.0022 \\
\hline 3.1 & 0.008 & 0.14 & 0.1 & 0.66 & 1.34 & 0.0034 \\
\hline 3.7 & 0.015 & 0.21 & 0.4 & 0.46 & 0.60 & 0.0010 \\
\hline 5.0 & 0.010 & 0.27 & 0.2 & 0.48 & 1.78 & 0.0027 \\
\hline 5.6 & 0.004 & 0.04 & 0.1 & 0.45 & 1.00 & 0.0013 \\
\hline 6.2 & 0.001 & 0.08 & 0.2 & 0.65 & 0.88 & 0.0013 \\
\hline 6.7 & bd & 0.05 & bd & 0.42 & 0.62 & 0.0011 \\
\hline 6.9 & 0.016 & 0.10 & 0.1 & 0.22 & 0.40 & 0.0030 \\
\hline 7.4 & bd & 0.10 & 0.1 & 0.16 & 0.36 & 0.0011 \\
\hline 7.6 & bd & 0.14 & 0.1 & 0.27 & 0.48 & 0.0018 \\
\hline 7.7 & bd & 0.05 & bd & 0.21 & 5.00 & 0.0012 \\
\hline 8.4 & 0.005 & 0.10 & bd & 0.41 & 0.47 & 0.0017 \\
\hline 8.9 & 0.000 & 0.05 & 0.1 & 0.78 & 0.64 & 0.0026 \\
\hline 9.2 & 0.024 & 0.16 & 0.5 & 1.28 & 0.92 & 0.0036 \\
\hline 10.1 & 0.007 & 0.13 & bd & 0.71 & 0.76 & 0.0020 \\
\hline 11.3 & 0.013 & 0.14 & 0.3 & 0.60 & 0.51 & 0.0015 \\
\hline 12.2 & 0.000 & 0.21 & 0.3 & 0.78 & 0.66 & 0.0017 \\
\hline 13.1 & bd & 0.09 & 0.2 & 0.53 & 0.32 & 0.0010 \\
\hline 14.3 & 0.006 & 0.11 & 0.2 & 0.99 & 0.50 & 0.0014 \\
\hline 14.9 & bd & 0.09 & 0.1 & 0.56 & 1.01 & 0.0026 \\
\hline 15.4 & 0.006 & 0.17 & 0.1 & 0.72 & 0.70 & 0.0016 \\
\hline 15.5 & 0.001 & 0.04 & 0.2 & 0.72 & 0.89 & 0.0016 \\
\hline 15.7 & 0.002 & 0.13 & 0.1 & 0.65 & 0.98 & 0.0015 \\
\hline 15.8 & bd & 0.08 & 0.1 & 0.62 & 1.29 & 0.0019 \\
\hline 15.9 & 0.012 & 0.11 & 0.1 & 0.70 & 1.59 & 0.0024 \\
\hline \multicolumn{7}{|c|}{ B1S1 regolith } \\
\hline 0.6 & 0.03 & 0.41 & 0.2 & 1.47 & 0.60 & 0.0024 \\
\hline 1.8 & 0.05 & 0.32 & 0.4 & 1.19 & 0.53 & 0.0011 \\
\hline 3.1 & 0.06 & 0.37 & 0.7 & 1.30 & 0.84 & 0.0013 \\
\hline 4.3 & 0.09 & 0.38 & 0.5 & 1.48 & 0.72 & 0.0011 \\
\hline 4.9 & 0.05 & 0.36 & 0.7 & 1.66 & 0.76 & 0.0011 \\
\hline 5.5 & 0.07 & 0.42 & 0.3 & 1.91 & 0.78 & 0.0016 \\
\hline 6.4 & 0.05 & 0.37 & 0.6 & 2.69 & 0.88 & 0.0017 \\
\hline 7.0 & 0.17 & 0.37 & 1.0 & 3.88 & 0.97 & 0.0020 \\
\hline 7.6 & 0.19 & 0.38 & 1.1 & 4.13 & 1.03 & 0.0020 \\
\hline 8.2 & 0.17 & 0.34 & 1.2 & 6.65 & 1.31 & 0.0033 \\
\hline 8.5 & 0.06 & 0.38 & 1.0 & 7.13 & 1.35 & 0.0046 \\
\hline 9.0 & 0.06 & 0.57 & 1.2 & 6.87 & 1.17 & 0.0048 \\
\hline 9.3 & 0.06 & 0.61 & 1.3 & 10.1 & 1.27 & 0.0088 \\
\hline
\end{tabular}


Table 4. Average pore water concentrations ${ }^{\mathrm{a}}$

\begin{tabular}{|c|c|c|c|c|c|c|c|c|c|c|c|}
\hline $\begin{array}{c}\text { Depth } \\
(\mathrm{m})\end{array}$ & $\mathrm{pH}(\text { calc })^{\mathrm{b}}$ & $\begin{array}{r}\mathrm{Na} \\
(\mathrm{uM}) \\
\end{array}$ & $\mathrm{Mg}$ & $\mathrm{Al}$ & $\mathrm{Si}$ & $\mathrm{K}$ & $\mathrm{Ca}$ & $\mathrm{Sr}$ & $\mathrm{Cl}$ & $\mathrm{SO} 4$ & NO3 \\
\hline \multicolumn{12}{|c|}{ B1R pore water } \\
\hline 0.15 & 4.5 & $285 \pm 8$ & $36 \pm 6$ & $2.3 \pm 0.5$ & $240 \pm 10$ & $11 \pm 1$ & $36 \pm 6$ & $0.19 \pm 0.03$ & $320 \pm 10$ & $7 \pm 1$ & $130 \pm 40$ \\
\hline 0.3 & $4.6(5.3)$ & $390 \pm 20$ & $30 \pm 3$ & $3.3 \pm 0.6$ & $180 \pm 10$ & $11 \pm 1$ & $14 \pm 2$ & $0.108 \pm 0.006$ & $400 \pm 20$ & $13 \pm 45$ & $100 \pm 20$ \\
\hline 0.6 & $4.5(4.7)$ & $280 \pm 10$ & $25 \pm 1$ & $2.6 \pm 0.5$ & $166 \pm 7$ & $5 \pm 1$ & $12 \pm 2$ & $0.060 \pm 0.005$ & $260 \pm 10$ & $19 \pm 4$ & $80 \pm 20$ \\
\hline 0.9 & $4.4(4.6)$ & $245 \pm 5$ & $30 \pm 1$ & $4.2 \pm 1.0$ & $144 \pm 6$ & $5 \pm 1$ & $9 \pm 2$ & $0.050 \pm 0.003$ & $227 \pm 8$ & $22 \pm 4$ & $84 \pm 8$ \\
\hline 1.2 & 4.4 & $223 \pm 3$ & $30 \pm 1$ & $4.4 \pm 0.7$ & $128 \pm 6$ & $5 \pm 1$ & $14 \pm 1$ & $0.072 \pm 0.004$ & $233 \pm 5$ & $23.9 \pm 0.3$ & $63 \pm 4$ \\
\hline 1.5 & $4.5(4.6)$ & $207 \pm 5$ & $34.3 \pm 0.5$ & $6 \pm 1$ & $121 \pm 6$ & $3.9 \pm 0.7$ & $13 \pm 1$ & $0.075 \pm 0.003$ & $229 \pm 1$ & $29.6 \pm 0.7$ & $56 \pm 2$ \\
\hline 1.8 & & $196 \pm 7$ & $29.7 \pm 0.7$ & $5.9 \pm 0.9$ & $131 \pm 1$ & $4 \pm 1$ & $12 \pm 1$ & $0.057 \pm 0.003$ & $209 \pm 8$ & $22 \pm 1$ & $63 \pm 9$ \\
\hline 2.4 & 4.8 & $191 \pm 6$ & $32 \pm 1$ & $3.6 \pm 0.8$ & $174 \pm 8$ & $1.4 \pm 0.5$ & $19 \pm 2$ & $0.104 \pm 0.009$ & $231 \pm 9$ & $21 \pm 2$ & $31 \pm 4$ \\
\hline 3.4 & $4.6(4.6)$ & $200 \pm 10$ & $30 \pm 2$ & $4 \pm 1$ & $170 \pm 9$ & $3.2 \pm 0.7$ & $11 \pm 2$ & $0.063 \pm 0.002$ & $230 \pm 20$ & $20 \pm 2$ & $33 \pm 4$ \\
\hline 4.9 & & $260 \pm 30$ & $36 \pm 2$ & $3.4 \pm 0.8$ & $170 \pm 20$ & $2.3 \pm 0.6$ & $23 \pm 2$ & $0.057 \pm 0.008$ & $290 \pm 40$ & $22 \pm 2$ & $60 \pm 30$ \\
\hline 5.8 & & $290 \pm 40$ & $37 \pm 3$ & $3 \pm 1$ & $180 \pm 20$ & $2.8 \pm 0.6$ & $18 \pm 2$ & $0.060 \pm 0.006$ & $330 \pm 50$ & $20 \pm 3$ & $17 \pm 2$ \\
\hline 6.4 & $4.7(4.6)$ & $260 \pm 5$ & $41.2 \pm 0.6$ & $6 \pm 1$ & $191 \pm 6$ & $2.4 \pm 0.4$ & $12 \pm 2$ & $0.073 \pm 0.004$ & $318 \pm 9$ & $16 \pm 1$ & $37 \pm 3$ \\
\hline 16.0 & & $280 \pm 20$ & $50 \pm 1$ & $4 \pm 1$ & $210 \pm 5$ & $7 \pm 3$ & $12 \pm 1$ & $0.060 \pm 0.005$ & $370 \pm 20$ & $17.6 \pm 0.4$ & $24 \pm 3$ \\
\hline \multicolumn{12}{|c|}{ B1R openfall (volume weighted average) } \\
\hline & $5.1-7.0$ & $120 \pm 20$ & $11 \pm 2$ & $0.5 \pm 0.2$ & $2.1 \pm 0.3$ & $3.3 \pm 0.6$ & $8 \pm 1$ & $0.029 \pm 0.003$ & $140 \pm 20$ & $17 \pm 2$ & bd \\
\hline \multicolumn{12}{|c|}{ B1S1 pore water } \\
\hline 0.15 & 4.89 & $102 \pm 7$ & $13 \pm 27$ & $0.7 \pm 0.2$ & $170 \pm 20$ & $6.9 \pm 0.7$ & $4 \pm 1$ & $0.074 \pm 0.009$ & $128 \pm 3$ & $12 \pm 2$ & $9 \pm 5$ \\
\hline 0.3 & 4.4 & $185 \pm 2$ & $34 \pm 1$ & $6.3 \pm 0.9$ & $149 \pm 7$ & $6 \pm 2$ & $4.4 \pm 0.9$ & $0.085 \pm 0.002$ & $310 \pm 4$ & $1.0 \pm 0.3$ & $5 \pm 3$ \\
\hline 0.6 & $4.8(4.7)$ & $110 \pm 5$ & $19.8 \pm 0.7$ & $2.9 \pm 0.8$ & $91 \pm 7$ & $6 \pm 3$ & $4.0 \pm 0.7$ & $0.033 \pm 0.002$ & $164 \pm 7$ & $4.3 \pm 0.7$ & $6 \pm 4$ \\
\hline 0.9 & 4.6 & $131 \pm 3$ & $23.5 \pm 0.3$ & $6.5 \pm 0.7$ & $97 \pm 6$ & $4 \pm 1$ & $2.5 \pm 0.9$ & $0.044 \pm 0.001$ & $214 \pm 4$ & $4.6 \pm 0.7$ & $4 \pm 2$ \\
\hline 1.2 & 4.7 & $111 \pm 4$ & $14.8 \pm 0.4$ & $6.0 \pm 0.8$ & $88 \pm 7$ & $4 \pm 1$ & $4 \pm 3$ & $0.033 \pm 0.002$ & $152 \pm 1$ & $10.7 \pm 0.2$ & $3 \pm 1$ \\
\hline 1.5 & 4.5 & $154 \pm 5$ & $32 \pm 1$ & $10 \pm 1$ & $87 \pm 4$ & $5 \pm 2$ & $3 \pm 1$ & $0.047 \pm 0.003$ & $300 \pm 2$ & $2.8 \pm 0.1$ & $1.2 \pm 0.3$ \\
\hline 1.8 & $4.6(3.9)$ & $98 \pm 4$ & $17.2 \pm 0.6$ & $5.8 \pm 0.5$ & $51 \pm 6$ & $4.0 \pm 1.0$ & $4 \pm 1$ & $0.040 \pm 0.001$ & $138 \pm 6$ & $27.5 \pm 0.9$ & $0.7 \pm 0.2$ \\
\hline 4.3 & $4.7(4.5)$ & $196 \pm 9$ & $36 \pm 1$ & $6.7 \pm 0.3$ & $101 \pm 5$ & $0.2 \pm 0.2$ & $3 \pm 1$ & $0.033 \pm 0.001$ & $306 \pm 1$ & $3 \pm 0.4$ & $6.9 \pm 0.5$ \\
\hline 9.3 & 5.4 & $257 \pm 4$ & $36 \pm 1$ & $1.3 \pm 0.4$ & $184 \pm 4$ & $11.9 \pm 0.7$ & $4 \pm 1$ & $0.046 \pm 0.001$ & $297 \pm 3$ & $7.4 \pm 0.8$ & $11.8 \pm 0.6$ \\
\hline \multicolumn{12}{|c|}{ B1S2 pore water } \\
\hline 0.15 & 4.55 & $240 \pm 10$ & $24 \pm 3$ & $2.3 \pm 0.5$ & $250 \pm 20$ & $7.5 \pm 0.6$ & $4.5 \pm 0.8$ & $0.048 \pm 0.006$ & $250 \pm 20$ & $21 \pm 5$ & $12 \pm 4$ \\
\hline 0.3 & 4.7 & $300 \pm 20$ & $19 \pm 2$ & $2.0 \pm 0.8$ & $210 \pm 20$ & $10 \pm 1$ & $5 \pm 2$ & $0.037 \pm 0.004$ & $320 \pm 20$ & $23 \pm 3$ & $4 \pm 2$ \\
\hline 0.9 & 5.2 & $260 \pm 20$ & $12.3 \pm 0.4$ & $0.11 \pm 0.6$ & $113 \pm 5$ & $5.8 \pm 0.7$ & $2 \pm 2$ & $0.028 \pm 0.007$ & $244 \pm 8$ & $14 \pm 4$ & $4 \pm 3$ \\
\hline 1.2 & 5.1 & $280 \pm 10$ & $12.8 \pm 0.4$ & $0.4 \pm 0.1$ & $106 \pm 9$ & $4.2 \pm 0.7$ & $1.2 \pm 0.4$ & $0.019 \pm 0.001$ & $280 \pm 10$ & $14.4 \pm 0.8$ & $5 \pm 3$ \\
\hline 1.5 & 5.3 & $311 \pm 9$ & $12.7 \pm 0.5$ & $0.5 \pm 0.2$ & $110 \pm 10$ & $4.3 \pm 0.9$ & $0.7 \pm 0.4$ & $0.019 \pm 0.001$ & $306 \pm 7$ & $15.7 \pm 0.1$ & $6 \pm 2$ \\
\hline
\end{tabular}




\begin{tabular}{ccllllllllll}
1.8 & 5.3 & $240 \pm 10$ & $16 \pm 3$ & $1 \pm 1$ & $106 \pm 3$ & $5.2 \pm 0.8$ & $4 \pm 1$ & $0.034 \pm 0.004$ & $233 \pm 9$ & $21 \pm 3$ & $10 \pm 1$ \\
2.7 & 5.4 & $225 \pm 5$ & $12.7 \pm 0.2$ & $0.4 \pm 0.1$ & $133 \pm 6$ & $2.4 \pm 0.7$ & $4 \pm 1$ & $0.032 \pm 0.001$ & $217 \pm 2$ & $9 \pm 1$ & $14 \pm 3$ \\
B1S3 pore water & & & & & & & & & & \\
0.15 & 4.6 & $390 \pm 50$ & $90 \pm 10$ & $1.5 \pm 0.6$ & $184 \pm 7$ & $12 \pm 4$ & $39 \pm 5$ & $0.29 \pm 0.04$ & $740 \pm 60$ & $6 \pm 3$ \\
0.3 & 4.8 & $540 \pm 70$ & $110 \pm 20$ & $0.4 \pm 0.2$ & $160 \pm 10$ & $8 \pm 1$ & $40 \pm 6$ & $0.33 \pm 0.05$ & $970 \pm 50$ & $1.3 \pm 0.3$ & $3 \pm 2$ \\
0.6 & 5.6 & $83 \pm 6$ & $4 \pm 1$ & $0.06 \pm 0.03$ & $130 \pm 10$ & $3 \pm 1$ & $1.1 \pm 0.4$ & $0.013 \pm 0.001$ & $25 \pm 6$ & $10 \pm 1$ & $12 \pm 6$ \\
0.9 & 5.2 & $145 \pm 7$ & $18 \pm 3$ & $0.17 \pm 0.6$ & $123 \pm 5$ & $1.2 \pm 0.8$ & $0.3 \pm 0.3$ & $0.019 \pm 0.002$ & $150 \pm 10$ & $12.2 \pm 0.7$ & $2 \pm 1$ \\
1.5 & 5.7 & $123 \pm 6$ & $10 \pm 2$ & $0.9 \pm 0.6$ & $128 \pm 4$ & $4 \pm 1$ & $0.8 \pm 0.5$ & $0.020 \pm 0.001$ & $66 \pm 6$ & $23.3 \pm 0.7$ & $6 \pm 2$ \\
B1S4 pore water & & & & & & & & & \\
0.15 & 5.7 & $175 \pm 6$ & $55 \pm 3$ & $0.2 \pm 0.1$ & $199 \pm 6$ & $17 \pm 2$ & $32 \pm 2$ & $0.216 \pm 0.008$ & $241 \pm 5$ & $15.1 \pm 0.8$ & $2 \pm \pm 1$ \\
0.3 & 5.6 & $176 \pm 5$ & $36 \pm 1$ & $0.13 \pm 0.06$ & $188 \pm 5$ & $9.5 \pm 0.4$ & $19 \pm 1$ & $0.144 \pm 0.006$ & $169 \pm 4$ & $14 \pm 1$ \\
0.6 & 5.7 & $231 \pm 7$ & $43 \pm 2$ & $0.06 \pm 0.05$ & $260 \pm 8$ & $17.2 \pm 0.6$ & $8 \pm 1$ & $0.117 \pm 0.004$ & $193 \pm 1$ & $24.3 \pm 0.7$ & $8 \pm 3$ \\
0.9 & 5.6 & $201 \pm 6$ & $46 \pm 4$ & $0.2 \pm 0.1$ & $179 \pm 7$ & $11.4 \pm 1$ & $14 \pm 1$ & $0.120 \pm 0.005$ & $184 \pm 9$ & $16 \pm 1$ & $29 \pm 6$ \\
\hline
\end{tabular}

${ }^{\mathrm{a}}$ Pore water concentrations for each sample averaged over time \pm SE of the mean.

${ }^{\mathrm{b}} \mathrm{pH}$ values as measured in pore water, $\mathrm{pH}$ in parentheses were calculated from $\mathrm{pCO}_{2}$ using PHREEQCi (Parkhurst and Appelo, 1999). 
Table 5. Average bedrock mineralogy by quantitative $X_{R D}{ }^{a}$

Quartz K-spar ${ }^{\mathrm{b}}$ Plag $^{\mathrm{b}}$ Kaolinite Chlorite Pyroxene Amphibole ${ }^{\mathrm{c}}$ Calcite Epidote Prehnite Illite

(wt. \%)

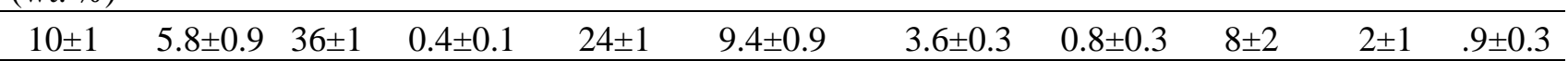

${ }^{\mathrm{a}}$ Bedrock XRD data from Buss et al. (2013) \pm SE of the mean.

${ }^{\mathrm{b}} \mathrm{K}$-spar = orthoclase, Plag = plagioclase

${ }^{c}$ Amphibole was previously identified as tourmaline and illite was previously identified as biotite (Buss et al., 2013). Subsequent extensive thin section analysis (optical and SEM) has identified only amphibole and illite.

Table 6. Precipitation and pore water fluxes $\left(\mathrm{m} \mathrm{yr}^{-1}\right)$, Cl concentrations $(\mu \mathrm{M})$ and hydrologic parameters

\begin{tabular}{ccccccccc}
\hline Site & $\begin{array}{c}\text { Precip. } \\
\mathrm{Cl} \\
(\mu \mathrm{M})\end{array}$ & $\begin{array}{c}\text { Deep pore } \\
\text { water Cl } \\
(\mu \mathrm{M})\end{array}$ & $\begin{array}{c}\text { Precip. Flux, } \\
\text { qprecip } \\
\left(\mathrm{m} \mathrm{y}^{-1}\right)\end{array}$ & $\begin{array}{c}\text { Pore water } \\
\text { flux density, } \\
\mathrm{q}_{\mathrm{h}}\left(\mathrm{m} \mathrm{y}^{-1}\right)\end{array}$ & $\begin{array}{c}\text { Average } \\
\text { porosity, } \\
\Phi\left(\mathrm{m}^{3} \mathrm{~m}^{-3}\right)\end{array}$ & $\begin{array}{c}\text { Average } \\
\text { saturation, } \\
\Gamma\left(\mathrm{m}^{3} \mathrm{~m}^{-3}\right)\end{array}$ & $\begin{array}{c}\text { Infiltration } \\
\text { rate, I } \\
\left(\mathrm{m} \mathrm{yr}^{-1}\right)\end{array}$ & $\begin{array}{c}\text { Fluid } \\
\text { residence } \\
\text { time }(\mathrm{yr})\end{array}$ \\
\hline${\mathrm{B} 1 \mathrm{R}^{\mathrm{a}}}^{\mathrm{a}}$ & $150 \pm 20$ & $320 \pm 17$ & $3.4 \pm 0.2$ & $1.5 \pm 0.3$ & $0.47 \pm 0.02$ & $0.62 \pm 0.04$ & $5.3 \pm 0.3$ & $1.8 \pm 0.1$ \\
$\mathrm{~B} 1 S 1^{\mathrm{a}}$ & $150 \pm 20$ & $303 \pm 2$ & $3.4 \pm 0.2$ & $1.6 \pm 0.2$ & $0.60 \pm 0.08$ & $0.55 \pm 0.07$ & $5.0 \pm 0.01$ & $1.87 \pm 0.02$ \\
$\mathrm{LG}^{\mathrm{b}}$ & 65 & 171 & 4.20 & 1.28 & $0.52 \pm 0.01$ & $0.77 \pm 0.01$ & 3.2 & 2.7 \\
\hline
\end{tabular}

${ }^{\mathrm{a}}$ Errors represent SE of the means, propagated through subsequent calculations.

${ }^{\mathrm{b}}$ LG1 precipitation, $\mathrm{Cl}$, porosity, and saturation data from White et al. (1998); errors represent SE of the means where the complete data was available. 
Table 7. B1R regolith mineralogy by quantitative $X R D^{a}$

\begin{tabular}{|c|c|c|c|c|c|}
\hline $\begin{array}{l}\text { Depth } \\
\text { (m) }\end{array}$ & $\begin{array}{l}\text { Quartz } \\
\text { (wt. \%) }\end{array}$ & Hematite & Goethite & Kaolinite & Illite \\
\hline 0.04 & $36 \pm 2$ & $0.10 \pm 0.01$ & $4.6 \pm 0.2$ & $36 \pm 2$ & $10.6 \pm 0.5$ \\
\hline 0.2 & $38 \pm 2$ & $0.13 \pm 0.01$ & $5.9 \pm 0.3$ & $38 \pm 2$ & $11.9 \pm 0.6$ \\
\hline 0.4 & $37 \pm 2$ & $0.060 \pm 0.003$ & $6.4 \pm 0.3$ & $35 \pm 2$ & $15.4 \pm 0.8$ \\
\hline 0.6 & $54 \pm 3$ & $0.047 \pm 0.002$ & $3.7 \pm 0.2$ & $20 \pm 1$ & $23 \pm 1$ \\
\hline 0.8 & $28 \pm 1$ & $0.43 \pm 0.02$ & $20 \pm 1$ & $20 \pm 1$ & $27 \pm 1$ \\
\hline 1.3 & $40 \pm 2$ & $0.96 \pm 0.05$ & $4.8 \pm 0.2$ & $41 \pm 2$ & $12.5 \pm 0.6$ \\
\hline 2.3 & $40 \pm 2$ & $0.64 \pm 0.03$ & $3.9 \pm 0.2$ & $42 \pm 2$ & $13.6 \pm 0.7$ \\
\hline 3.1 & $37 \pm 2$ & $1.4 \pm 0.1$ & $3.6 \pm 0.2$ & $41 \pm 2$ & $14.0 \pm 0.7$ \\
\hline 3.5 & $40 \pm 2$ & $0.35 \pm 0.02$ & $12.4 \pm 0.6$ & $22 \pm 1$ & $25 \pm 1$ \\
\hline 3.7 & $57 \pm 3$ & $0.096 \pm 0.005$ & $2.5 \pm 0.1$ & $20 \pm 1$ & $20 \pm 1$ \\
\hline 5.0 & $45 \pm 2$ & $0.73 \pm 0.04$ & $3.1 \pm 0.2$ & $34 \pm 2$ & $16.6 \pm 0.8$ \\
\hline 5.6 & $42 \pm 2$ & $1.1 \pm 0.1$ & $3.2 \pm 0.2$ & $38 \pm 2$ & $10.5 \pm 0.5$ \\
\hline $5.6 \mathrm{R}^{\mathrm{b}}$ & $58 \pm 3$ & $0.93 \pm 0.05$ & $3.0 \pm 0.1$ & $26 \pm 1$ & $7.4 \pm 0.4$ \\
\hline 6.2 & $31 \pm 2$ & $2.1 \pm 0.1$ & $4.0 \pm 0.2$ & $52 \pm 3$ & $5.1 \pm 0.3$ \\
\hline $6.2 \mathrm{R}$ & $22 \pm 1$ & $2.0 \pm 0.1$ & $3.9 \pm 0.2$ & $62 \pm 3$ & $4.9 \pm 0.2$ \\
\hline 6.7 & $33 \pm 2$ & $1.9 \pm 0.1$ & $2.5 \pm 0.1$ & $54 \pm 3$ & $8.9 \pm 0.4$ \\
\hline 6.9 & $64 \pm 3$ & $0.90 \pm 0.05$ & $1.5 \pm 0.1$ & $23 \pm 1$ & $6.2 \pm 0.3$ \\
\hline $6.9 \mathrm{R}$ & $79 \pm 4$ & $0.41 \pm 0.02$ & $1.8 \pm 0.1$ & $11.0 \pm 0.6$ & $5.6 \pm 0.3$ \\
\hline 7.4 & $69 \pm 3$ & $0.71 \pm 0.04$ & $3.6 \pm 0.2$ & $15.2 \pm 0.8$ & $10.3 \pm 0.5$ \\
\hline 7.6 & $63 \pm 3$ & $1.2 \pm 0.1$ & $1.7 \pm 0.1$ & $21 \pm 1$ & $7.7 \pm 0.4$ \\
\hline 7.6R & $69 \pm 3$ & $1.2 \pm 0.1$ & $1.6 \pm 0.1$ & $15.6 \pm 0.8$ & $7.9 \pm 0.4$ \\
\hline 7.7 & $54 \pm 3$ & $1.2 \pm 0.1$ & $5.3 \pm 0.3$ & $27 \pm 1$ & $10.2 \pm 0.5$ \\
\hline 8.5 & $40 \pm 2$ & $2.7 \pm 0.1$ & $2.7 \pm 0.1$ & $45 \pm 2$ & $3.8 \pm 0.2$ \\
\hline $8.5 \mathrm{R}$ & $31 \pm 2$ & $2.9 \pm 0.1$ & $2.1 \pm 0.1$ & $54 \pm 3$ & $4.5 \pm 0.2$ \\
\hline 8.9 & $21 \pm 1$ & $3.6 \pm 0.2$ & $3.0 \pm 0.1$ & $61 \pm 3$ & $7.5 \pm 0.4$ \\
\hline 9.3 & $14.0 \pm 0.7$ & $3.3 \pm 0.2$ & $4.1 \pm 0.2$ & $65 \pm 3$ & $5.1 \pm 0.3$ \\
\hline $9.3 \mathrm{R}$ & $12.6 \pm 0.6$ & $2.5 \pm 0.1$ & $5.1 \pm 0.3$ & $68 \pm 3$ & $5.7 \pm 0.3$ \\
\hline 10.1 & $27 \pm 1$ & $2.7 \pm 0.1$ & $3.4 \pm 0.2$ & $56 \pm 3$ & $7.9 \pm 0.4$ \\
\hline 11.3 & $45 \pm 2$ & $1.5 \pm 0.1$ & $2.8 \pm 0.1$ & $36 \pm 2$ & $13.8 \pm 0.7$ \\
\hline 12.2 & $28 \pm 1$ & $2.7 \pm 0.1$ & $9.5 \pm 0.5$ & $44 \pm 2$ & $8.6 \pm 0.4$ \\
\hline $12.2 \mathrm{R}$ & $22 \pm 1$ & $3.3 \pm 0.2$ & $3.6 \pm 0.2$ & $62 \pm 3$ & $4.7 \pm 0.2$ \\
\hline 13.1 & $50 \pm 3$ & $2.0 \pm 0.1$ & $2.5 \pm 0.1$ & $31 \pm 2$ & $11.9 \pm 0.6$ \\
\hline 14.3 & $25 \pm 1$ & $2.9 \pm 0.1$ & $5.1 \pm 0.3$ & $52 \pm 3$ & $13.7 \pm 0.7$ \\
\hline 14.9 & $24 \pm 1$ & $3.8 \pm 0.2$ & $3.7 \pm 0.2$ & $56 \pm 3$ & $8.2 \pm 0.4$ \\
\hline $14.9 \mathrm{R}$ & $21 \pm 1$ & $3.2 \pm 0.2$ & $2.6 \pm 0.1$ & $61 \pm 3$ & $8.7 \pm 0.4$ \\
\hline 15.4 & $35 \pm 2$ & $1.2 \pm 0.1$ & $8.5 \pm 0.4$ & $32 \pm 2$ & $21 \pm 1$ \\
\hline 15.5 & $37 \pm 2$ & $0.95 \pm 0.05$ & $7.9 \pm 0.4$ & $33 \pm 2$ & $16.0 \pm 0.8$ \\
\hline 15.7 & $32 \pm 2$ & $1.9 \pm 0.1$ & $3.2 \pm 0.2$ & $49 \pm 2$ & $6.8 \pm 0.3$ \\
\hline $15.7 \mathrm{R}$ & $19 \pm 1$ & $2.0 \pm 0.1$ & $3.4 \pm 0.2$ & $64 \pm 3$ & $5.6 \pm 0.3$ \\
\hline 15.8 & $33 \pm 2$ & $2.6 \pm 0.1$ & $2.9 \pm 0.1$ & $48 \pm 2$ & $11.0 \pm 0.5$ \\
\hline 15.9 & $37 \pm 2$ & $3.3 \pm 0.2$ & $3.5 \pm 0.2$ & $41 \pm 2$ & $5.3 \pm 0.3$ \\
\hline $15.9 \mathrm{R}$ & $26 \pm 1$ & $2.8 \pm 0.1$ & $3.3 \pm 0.2$ & $56 \pm 3$ & $5.4 \pm 0.3$ \\
\hline
\end{tabular}

${ }^{\mathrm{a}}$ Error estimated at $\pm 5 \%$ of the measured value.

${ }^{\mathrm{b}}$ Depths labeled R (shaded) are weathered clasts. 
Table 8. B1S1 regolith mineralogy by quantitative $X_{R D}^{a}$

\begin{tabular}{ccccccccc}
\hline $\begin{array}{c}\text { Depth } \\
(\mathrm{m})\end{array}$ & $\begin{array}{c}\text { Quartz } \\
(\text { wt. \%) }\end{array}$ & Hematite & Goethite & Kaolinite & Illite & Chlorite $^{\text {K-spar }}$ & Plag $^{\mathrm{b}}$ \\
\hline 0.6 & $21 \pm 1$ & $1.6 \pm 0.1$ & $5.2 \pm 0.3$ & $61 \pm 3$ & $11.1 \pm 0.6$ & - & - & - \\
0.9 & $30 \pm 2$ & $1.7 \pm 0.1$ & $3.7 \pm 0.2$ & $52 \pm 3$ & $12.2 \pm 0.6$ & - & - & - \\
1.2 & $28 \pm 1$ & $1.8 \pm 0.1$ & $3.8 \pm 0.2$ & $56 \pm 3$ & $10.7 \pm 0.5$ & - & - & - \\
1.5 & $29 \pm 1$ & $1.3 \pm 0.1$ & $3.3 \pm 0.2$ & $56 \pm 3$ & $9.9 \pm 0.5$ & - & - & - \\
1.8 & $17.5 \pm 0.9$ & $2.1 \pm 0.1$ & $2.9 \pm 0.1$ & $67 \pm 3$ & $10.7 \pm 0.5$ & - & - & - \\
2.7 & $18.2 \pm 0.9$ & $2.3 \pm 0.1$ & $3.4 \pm 0.2$ & $61 \pm 3$ & $14.9 \pm 0.7$ & - & - & - \\
3.1 & $11.7 \pm 0.6$ & $2.4 \pm 0.1$ & $3.4 \pm 0.2$ & $69 \pm 3$ & $13.9 \pm 0.7$ & - & - & - \\
3.7 & $18.8 \pm 0.9$ & $2.2 \pm 0.1$ & $3.0 \pm 0.2$ & $60 \pm 3$ & $16.2 \pm 0.8$ & - & - & - \\
4.3 & $24 \pm 1$ & $1.4 \pm 0.1$ & $3.7 \pm 0.2$ & $57 \pm 3$ & $14.3 \pm 0.7$ & - & - & - \\
4.9 & $18.1 \pm 0.9$ & $1.9 \pm 0.1$ & $3.0 \pm 0.1$ & $22 \pm 3$ & $15.2 \pm 0.8$ & - & & \\
5.5 & $18.7 \pm 0.9$ & $2.0 \pm 0.1$ & $2.9 \pm 0.1$ & $61 \pm 3$ & $15.2 \pm 0.8$ & - & - & - \\
6.4 & $19.0 \pm 0.9$ & $2.0 \pm 0.1$ & $2.4 \pm 0.1$ & $59 \pm 3$ & $17.2 \pm 0.9$ & - & - & - \\
7.0 & $16.7 \pm 0.8$ & $1.6 \pm 0.1$ & $3.9 \pm 0.2$ & $59 \pm 3$ & $18.7 \pm 0.9$ & - & - & - \\
7.6 & $19 \pm 1$ & $1.6 \pm 0.1$ & $3.5 \pm 0.2$ & $55 \pm 3$ & $21 \pm 1$ & - & - & - \\
8.2 & $14.3 \pm 0.7$ & $2.1 \pm 0.1$ & $3.2 \pm 0.2$ & $62 \pm 3$ & $18.4 \pm 0.9$ & - & - & - \\
8.5 & $25 \pm 1$ & $0.99 \pm 0.05$ & $2.3 \pm 0.1$ & $55 \pm 3$ & $17.3 \pm 0.9$ & - & - & - \\
9.0 & $33 \pm 2$ & $0.49 \pm 0.02$ & $1.9 \pm 0.1$ & $44 \pm 2$ & $11.0 \pm 0.6$ & $7.2 \pm 0.4$ & $2.4 \pm 0.1$ & - \\
$9.0 \mathrm{R}^{\mathrm{c}}$ & $74 \pm 4$ & 0 & $1.3 \pm 0.1$ & $7.1 \pm 0.4$ & $3.2 \pm 0.2$ & $7.7 \pm 0.4$ & $6.3 \pm 0.3$ & - \\
9.3 & $22 \pm 1$ & $0.48 \pm 0.02$ & $2.0 \pm 0.1$ & $46 \pm 2$ & $12.8 \pm 0.6$ & $12.1 \pm 0.6$ & $4.2 \pm 0.2$ & - \\
$9.3 \mathrm{R}$ & $63 \pm 3$ & 0 & $0.71 \pm 0.04$ & $7.4 \pm 0.4$ & $2.2 \pm 0.1$ & $17.8 \pm 0.9$ & $8.6 \pm 0.4$ & $0.10 \pm 0.01$ \\
\hline
\end{tabular}

${ }^{\mathrm{a}}$ Error estimated at $\pm 5 \%$ of the measured value.

${ }^{\mathrm{b}} \mathrm{K}$-spar $=$ orthoclase, Plag = plagioclase

${ }^{\mathrm{c}}$ Depths labelled R with shaded rows are weathered clasts from the given depth. 
Table 9. Weathering gradients ${ }^{\mathrm{a}}$ used to calculate weathering rates and fluxes in Eq. 8-11.

\begin{tabular}{|c|c|c|c|c|c|}
\hline \multirow{2}{*}{\multicolumn{2}{|c|}{$\begin{array}{cc}\text { Rio Icacos } \\
\text { LG1 }\end{array}$}} & \multicolumn{4}{|c|}{ Bisley } \\
\hline & & B1R & B1S1 & B1S2 & B1S4 \\
\hline \multicolumn{6}{|c|}{ Solid-state weathering gradients $b_{s}\left(\mathrm{~m} \mathrm{~kg} \mathrm{~mol}^{-1}\right)^{b}$} \\
\hline Mg (regolith) & $1.12 \pm 0.02(1.0)$ & - & $46 \pm 6(0.72)$ & $5.9 \pm 0.5(0.82)$ & $3.5 \pm 0.6(0.64)$ \\
\hline Mg (chlorite) & - & - & $6 \pm 1(0.69)$ & - & - \\
\hline $\mathrm{Si}$ & - & - & $2.6 \pm 0.7(0.67)$ & $1.1 \pm 0.5(0.49)$ & $0.4 \pm 0.1(0.99)$ \\
\hline $\mathrm{K}$ & $17 \pm 2(0.59)$ & - & $72 \pm 8(0.57)$ & - & $4.8 \pm 0.5(0.95)$ \\
\hline $\mathrm{P}$ & $44 \pm 8(0.75)$ & - & $110 \pm 20(0.93)$ & - & - \\
\hline Kaolinite & - & - & $7.5 \pm 0.6(0.76)$ & - & - \\
\hline Illite & - & - & $30 \pm 10(0.95)$ & - & - \\
\hline \multicolumn{6}{|c|}{ Solute weathering gradients $b_{f}\left(m \mathrm{~L} \mathrm{~mol}^{-1}\right)^{c}$} \\
\hline $\mathrm{Mg}$ & $1.1 \times 10^{5}(0.48)$ & $1.1 \times 10^{6} \pm 7 \times 10^{5}(0.63)$ & $7 \times 10^{5} \pm 4 \times 10^{5}(0.61$ & 1) & - \\
\hline $\mathrm{Si}$ & $3.6 \times 10^{4}(0.74)$ & $3.3 \times 10^{4} \pm 3 \times 10^{3}(0.56)$ & $5.8 \times 10^{4} \pm 3 \times 10^{3}(0.99$ & 9) & - \\
\hline K & $2.0 \times 10^{5}(0.82)$ & - & - & - & - \\
\hline \multicolumn{6}{|l|}{ Depth range and $\Delta z(m)^{d}$} \\
\hline Solid-state $\mathrm{Mg}$ (regolith) & $4.6-4.9(0.3)$ & - & $1.2-9.3(8.1)$ & $0.9-2.7(1.8)$ & $0.15-0.9(0.6)$ \\
\hline Solid-state $\mathrm{Mg}$ (chlorite) & - & - & $8.2-9.3(1.1)$ & - & - \\
\hline Solid-state $\mathrm{Si}$ & - & - & $1.8-9.3(7.5)$ & $0.9-2.7(1.8)$ & $0.15-0.9(0.6)$ \\
\hline Solid-state K & $0.15-4.9(4.8)$ & - & $1.8-9.3(7.5)$ & - & $0.15-0.9(0.6)$ \\
\hline Solid-state P & $4.0-4.9(0.8)$ & - & $8.2-9.3(1.1)$ & - & - \\
\hline Kaolinite & - & - & $0.9-4.6(4.3)$ & - & - \\
\hline Illite & - & - & $0.6-7.6(7.0)$ & - & - \\
\hline Solute Mg & $1.2-8.5(7.3)$ & $1.2-16.0(14.8)$ & $1.2-9.3(8.1)$ & - & - \\
\hline Solute $\mathrm{Si}$ & $1.2-8.5(7.3)$ & $1.5-16.0(14.5)$ & $1.8-9.3(7.5)$ & - & - \\
\hline Solute K & $1.2-8.5(7.3)$ & - & - & - & - \\
\hline
\end{tabular}

${ }^{\mathrm{a}}$ Errors reflect detection limits and SE of averages fully propagated through the calculations.

${ }^{\mathrm{b}}$ Solid state gradients are linear regressions over normalised concentrations (Figures 7-8) and $\mathrm{R}^{2}$ values are given in parentheses. Dashes for elemental gradients indicate absence of a measurable gradient for the given element in the given profile. Kaolinite and illite gradients are only shown for B1S1 because mineralogical analysis was not done for B1S(2-4), gradients were not detected for these minerals in B1R and Rio Icacos contains a different mineral assemblage.

${ }^{c}$ Solute gradients (Figure 2) only given for Bisley ridgetop profiles (B1R and B1S1) as the influence of lateral subsurface solute transport cannot be ruled out for slope sites B1S(2-4). Weathering solute concentrations of $\mathrm{K}$ were below detection at most depths in Bisley pore waters. Rio Icacos solute gradients are from White (2002) for $\mathrm{Mg}$ and $\mathrm{K}$ and Schulz and White (1999) for Si.

${ }^{\mathrm{d}}$ Depth ranges over which the weathering gradients were determined with $\Delta \mathrm{z}$ in parentheses. 
Table 10. Weathering rates and fluxes ${ }^{\mathrm{a}}$

\begin{tabular}{|c|c|c|c|c|c|}
\hline \multirow{2}{*}{\multicolumn{2}{|c|}{$\begin{array}{c}\text { Rio Icacos } \\
\text { LG1 }\end{array}$}} & & \multicolumn{3}{|c|}{ Bisley } \\
\hline & & $\mathrm{B} 1 \mathrm{R}$ & B1S1 & B1S2 & B1S4 \\
\hline \multicolumn{6}{|c|}{ Solid-state weathering fluxes, $Q_{L T}: \log \left(\mathrm{mol} \mathrm{m}^{-2} \mathrm{~s}^{-1}\right)$} \\
\hline $\mathrm{Si}$ & - & - & $-4.2(-4.3$ to -4.0$)$ & $-4.4(-4.7$ to -4.2$)$ & $-4.3(-4.5$ to -4.1$)$ \\
\hline $\mathrm{K}$ & $-9.0(-9.2$ to -8.9$)$ & - & $-5.5(-5.6$ to -5.5$)$ & - & $-5.4(-5.5$ to -5.3$)$ \\
\hline $\mathrm{P}$ & $-10.3(-10.5$ to -10.1$)$ & - & $-6.6(-6.7$ to -6.5$)$ & - & - \\
\hline $\mathrm{Mg}$ & -8.7 & $-9.4(-9.9$ to -9.1$)$ & $-9.5(-9.8$ to -9.3$)$ & - & - \\
\hline $\mathrm{Si}$ & -8.2 & $-7.9(-8.0$ to -7.8$)$ & $-8.4(-8.5$ to -8.4$)$ & - & - \\
\hline $\mathrm{K}$ & -8.9 & - & - & - & - \\
\hline \multicolumn{6}{|c|}{ Solute watershed-averaged weathering fluxes: $\log \left(\mathrm{mol} \mathrm{m} \mathrm{m}^{-2} \mathrm{~s}^{-1}\right)^{c}$} \\
\hline & $\underline{\text { Río Icacos }}$ & Río Mameyes & & & \\
\hline Chlorite & - & - & $-13.1(-13.2$ to -13.0$)$ & - & - \\
\hline Kaolinite & - & - & $-13.4(-13.5$ to -13.3$)$ & - & - \\
\hline Illite & - & - & $-13.7(-13.9$ to -13.5$)$ & - & - \\
\hline
\end{tabular}

Calculated from Eqns. 8-11 using parameters given in Table 9 and in the text. Ranges, shown in parentheses, reflect

\pm errors fully propagated through the calculations.

${ }^{\mathrm{b}}$ Solute weathering fluxes only given for ridgetop profiles (LG1, B1R, B1S1) as the influence of lateral subsurface solute transport cannot be ruled out for the slope sites B1S(2-4). Río Icacos Mg and K weathering fluxes were calculated from Eqn. 11 using gradients calculated by White (2002) and Schulz and White (1999) and $q_{h}$ and $\Gamma$ values (Table 6).

${ }^{c}$ Solute watershed-averaged weathering fluxes from Stallard (2012), determined from riverine and atmospheric fluxes over 1991-2005 in the Río Icacos and Río Mameyes (which the Bisley streams feed into).

${ }^{\mathrm{d}}$ Mineral weathering rates are only shown for B1S1 because mineralogical analysis was not done for B1S(2-4), gradients were not detected for these minerals in B1R and Rio Icacos contains a different mineral assemblage. 
Figure 1

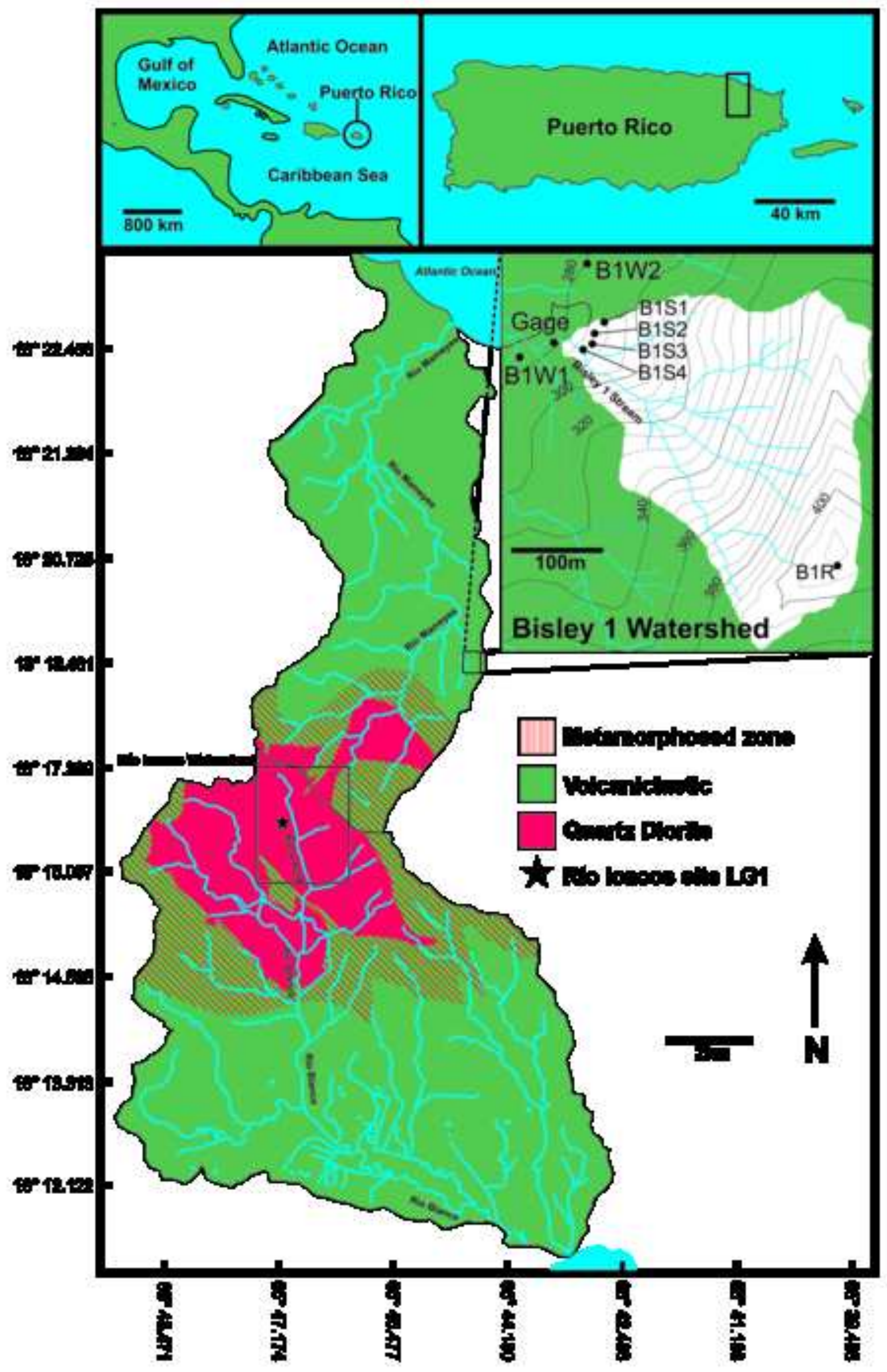



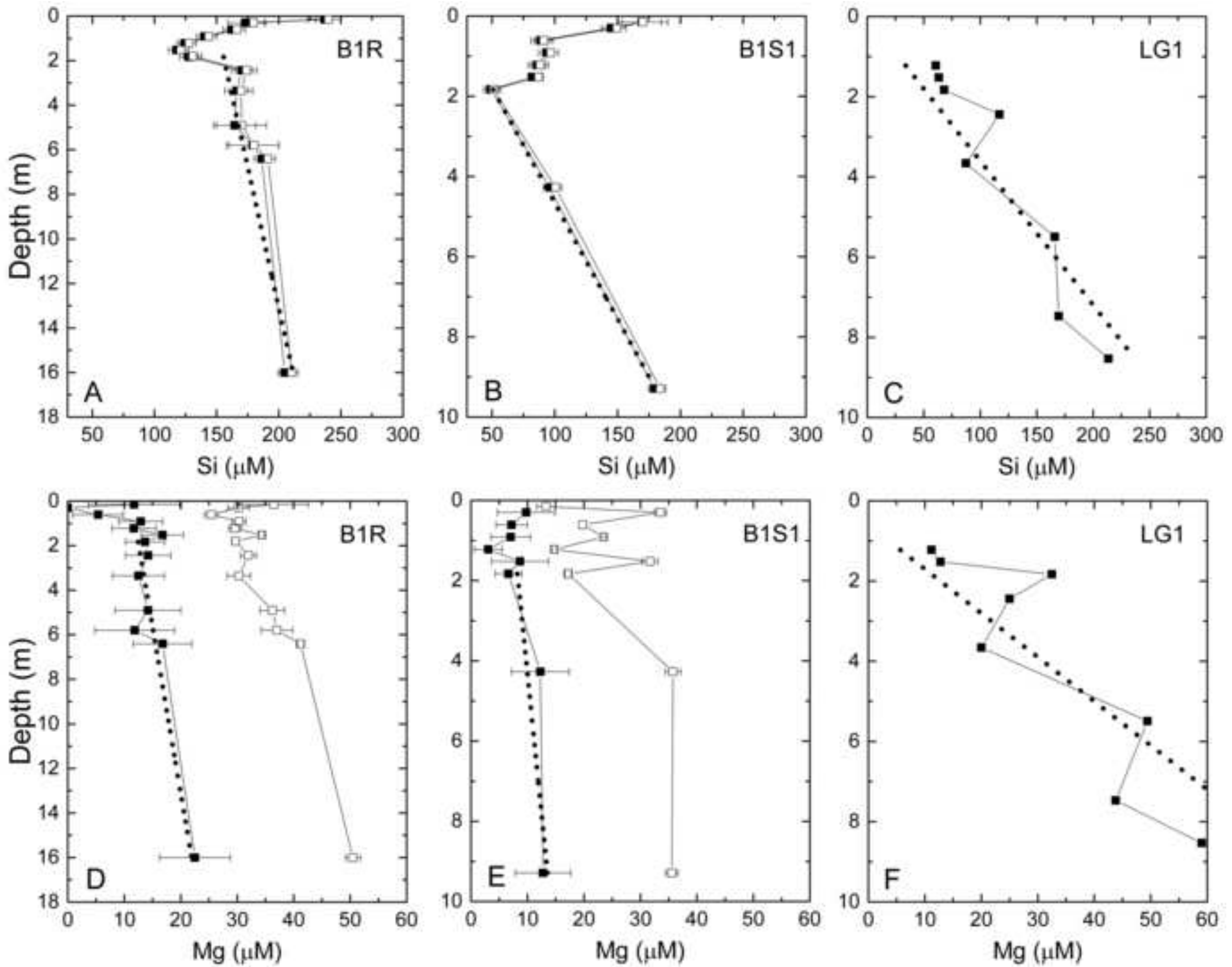

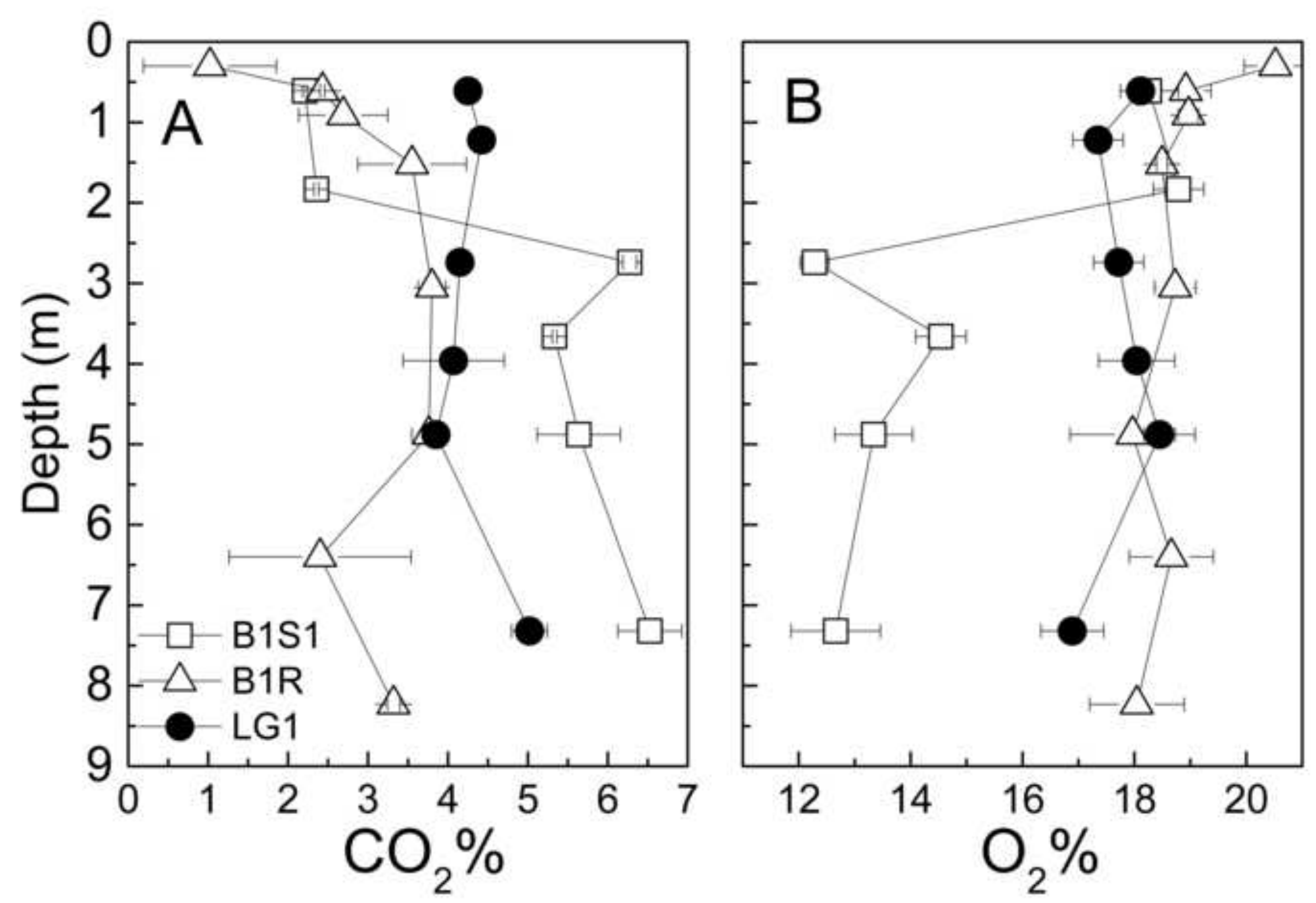

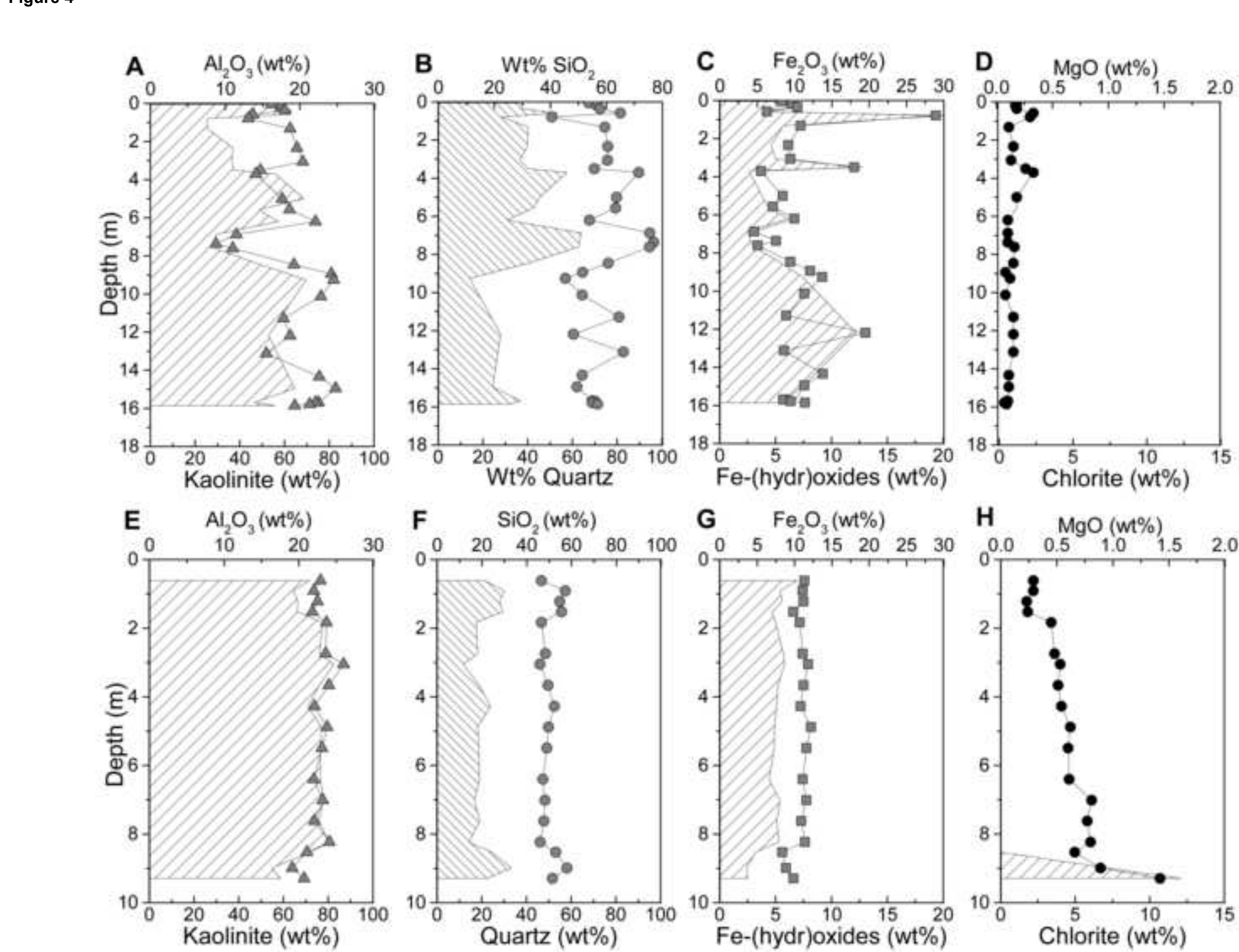

H $\quad \mathrm{MgO}(\mathrm{w} \%)$

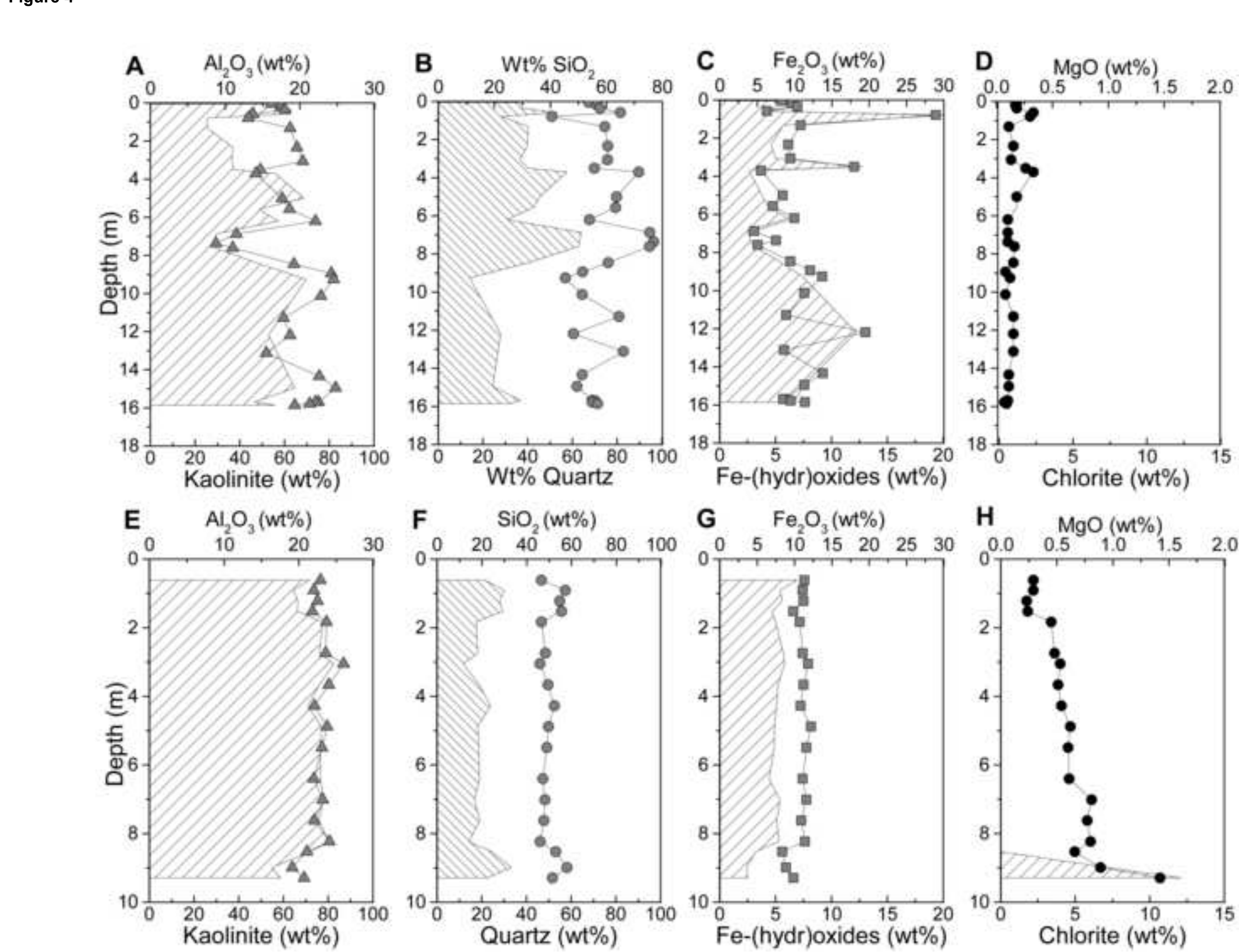



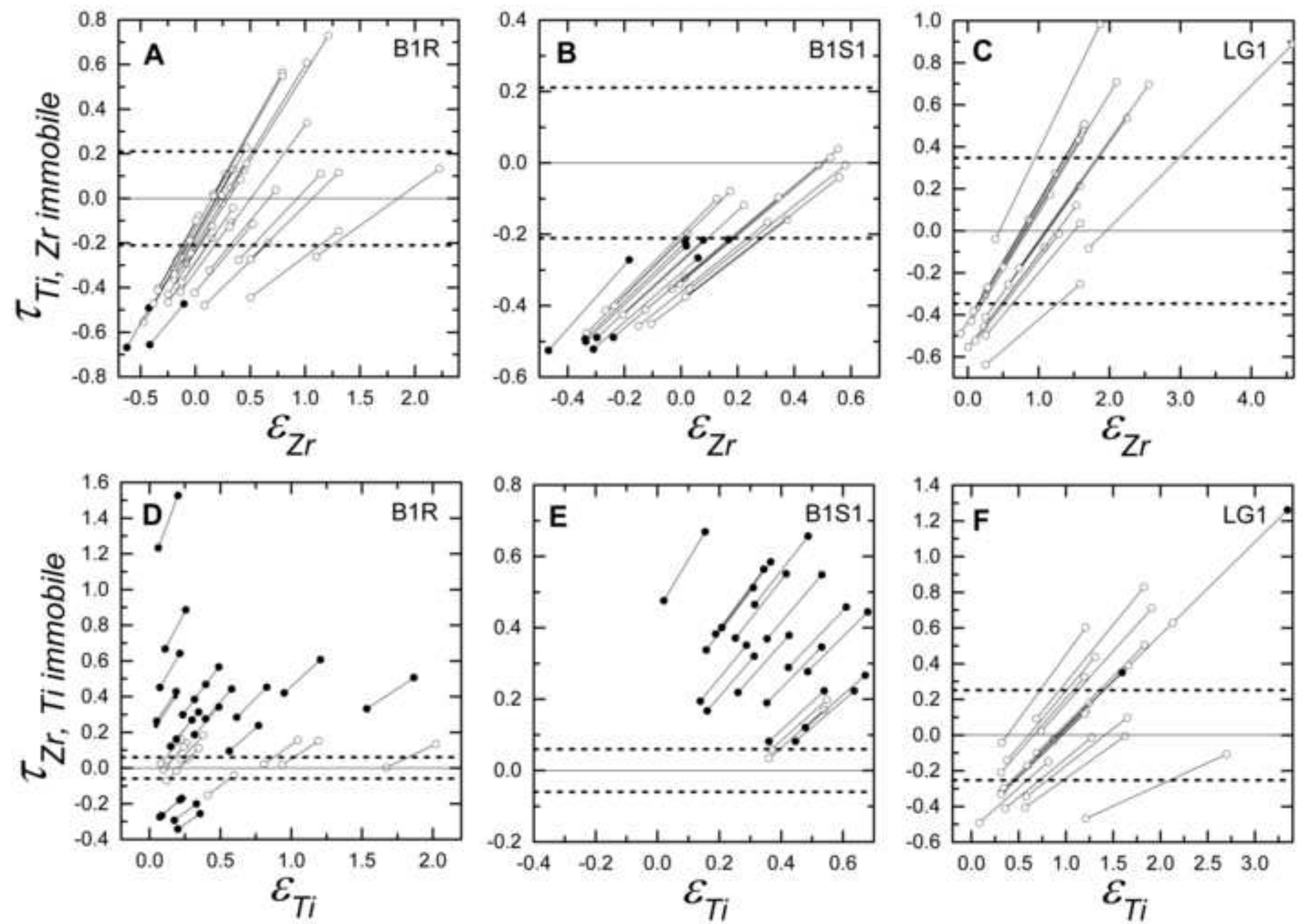

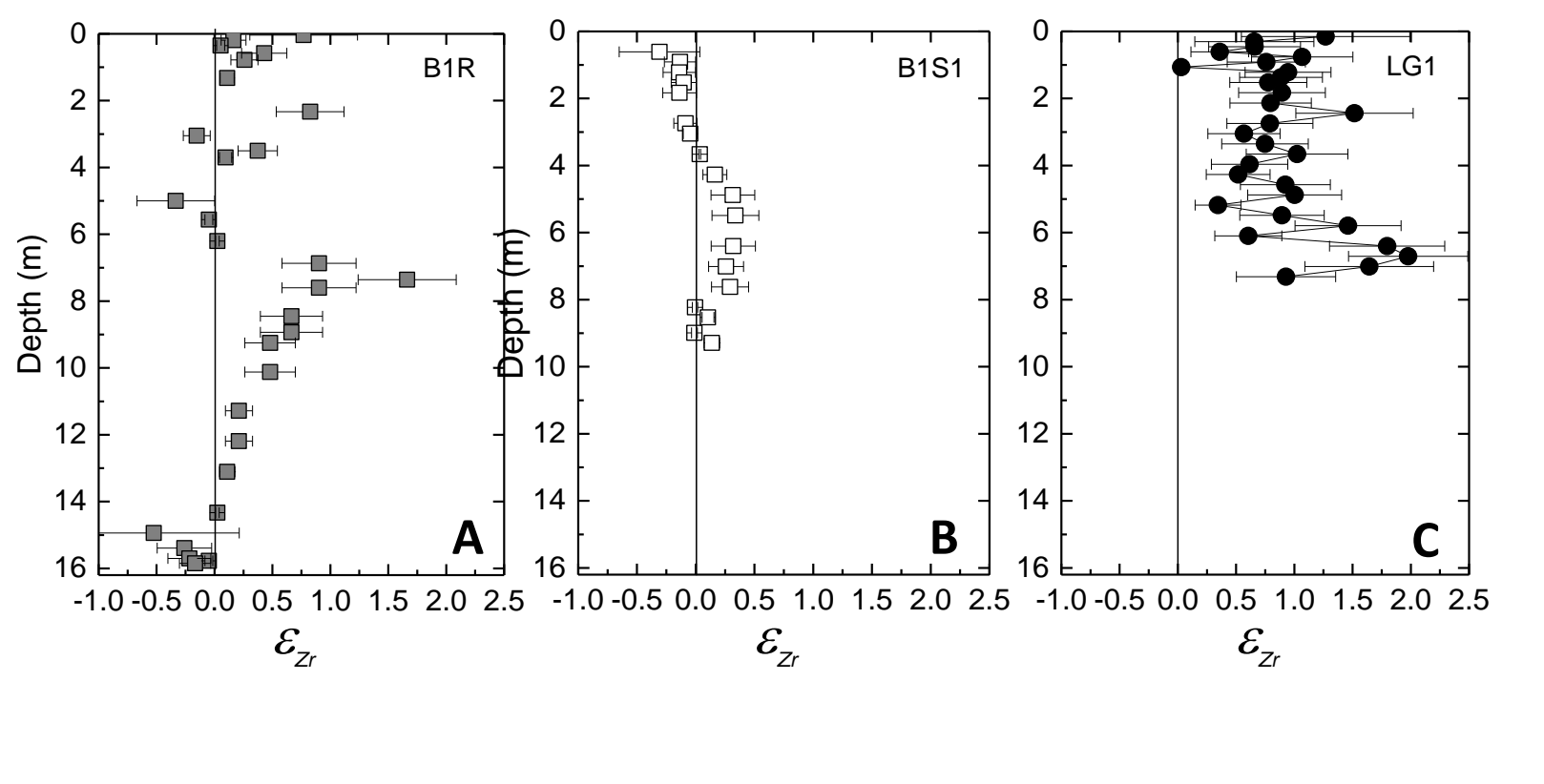

Figure 6

.

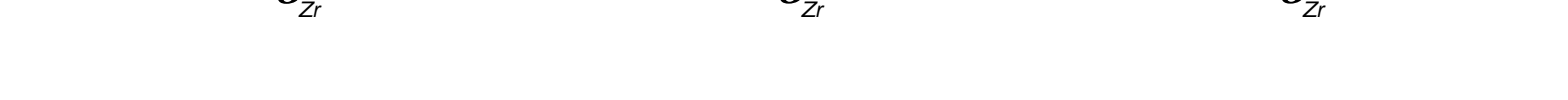

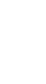

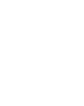

.

.
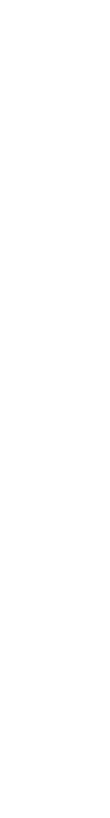

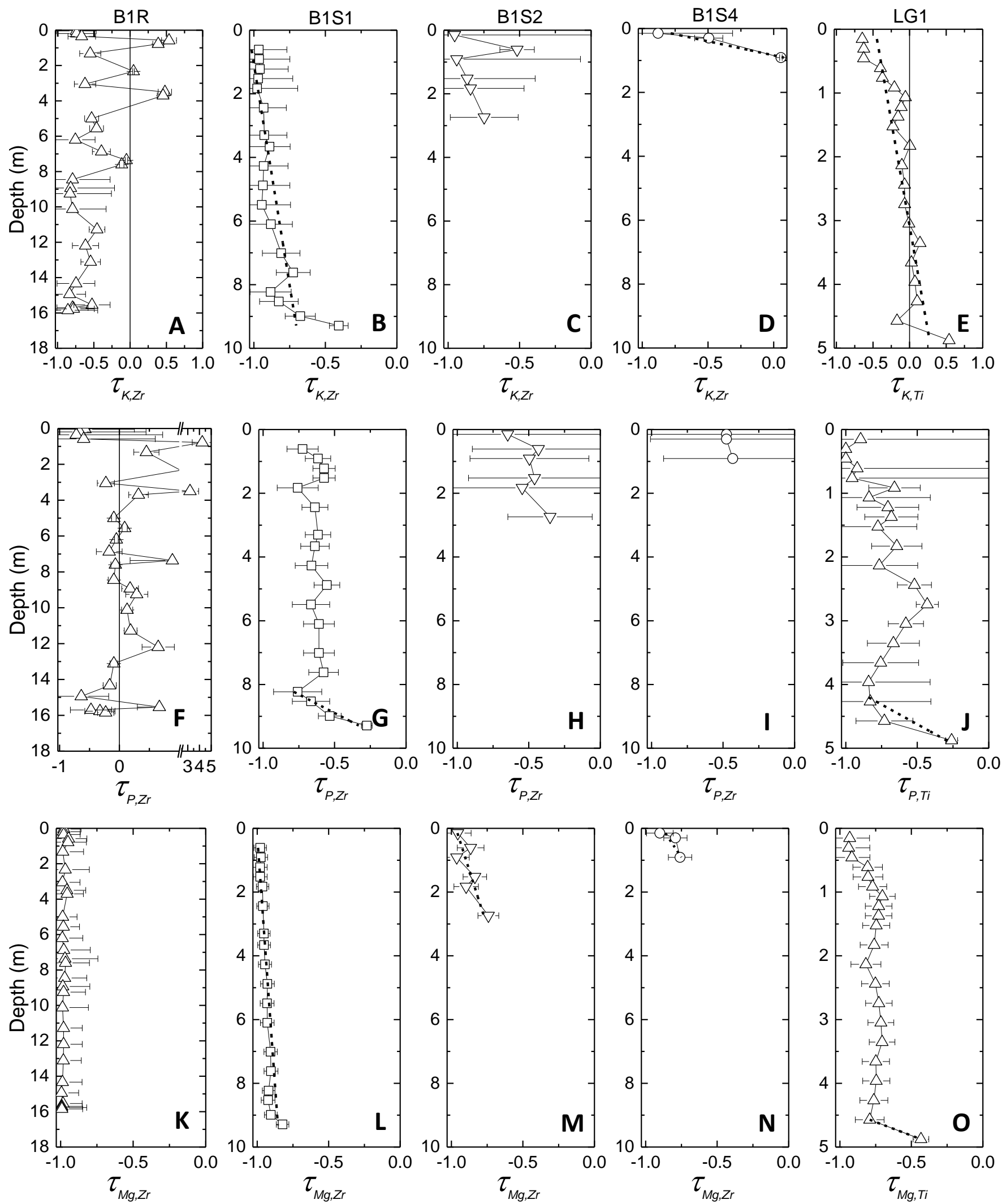
Figure 8
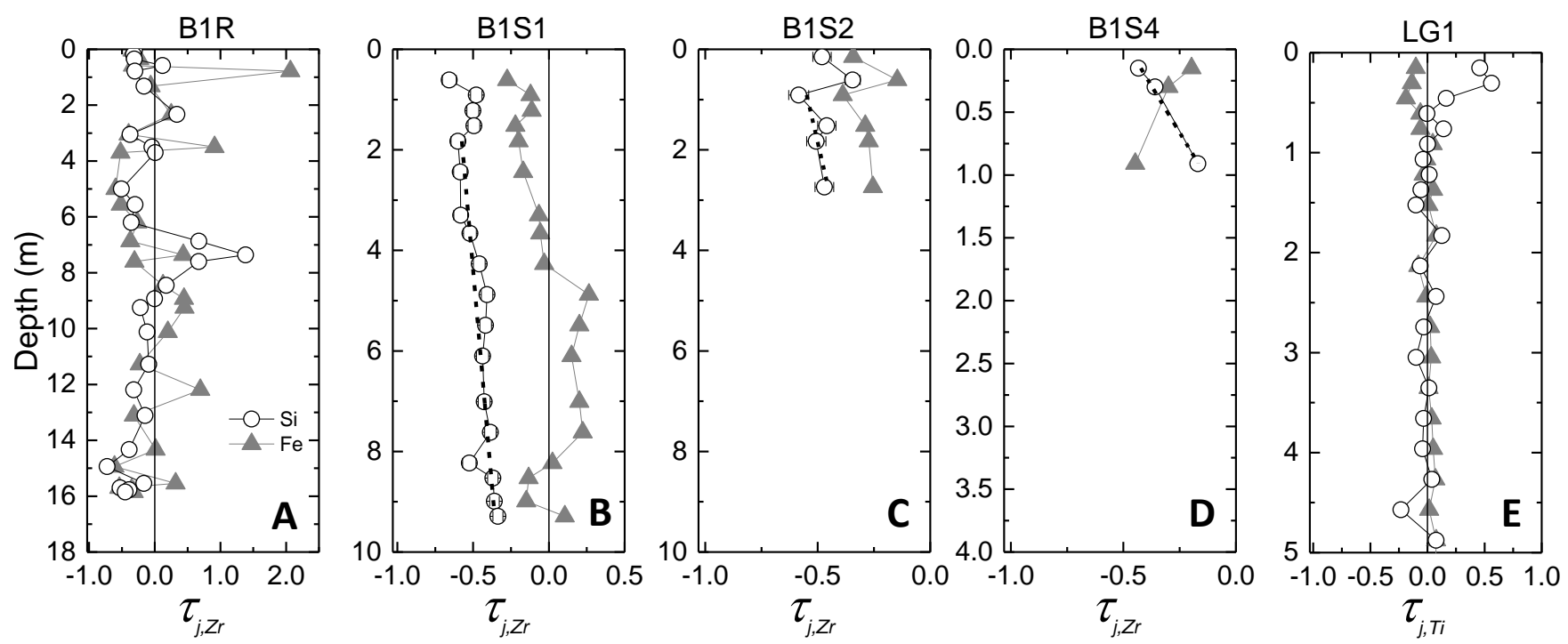
Figure 9
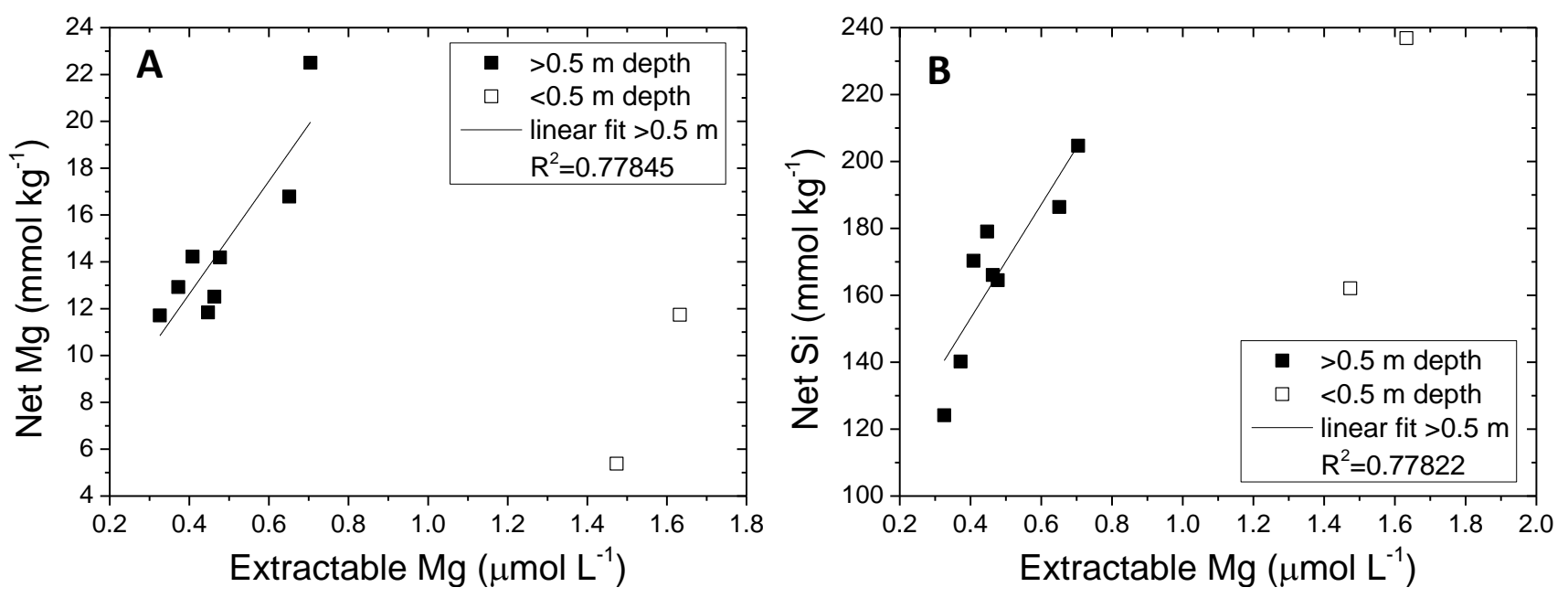

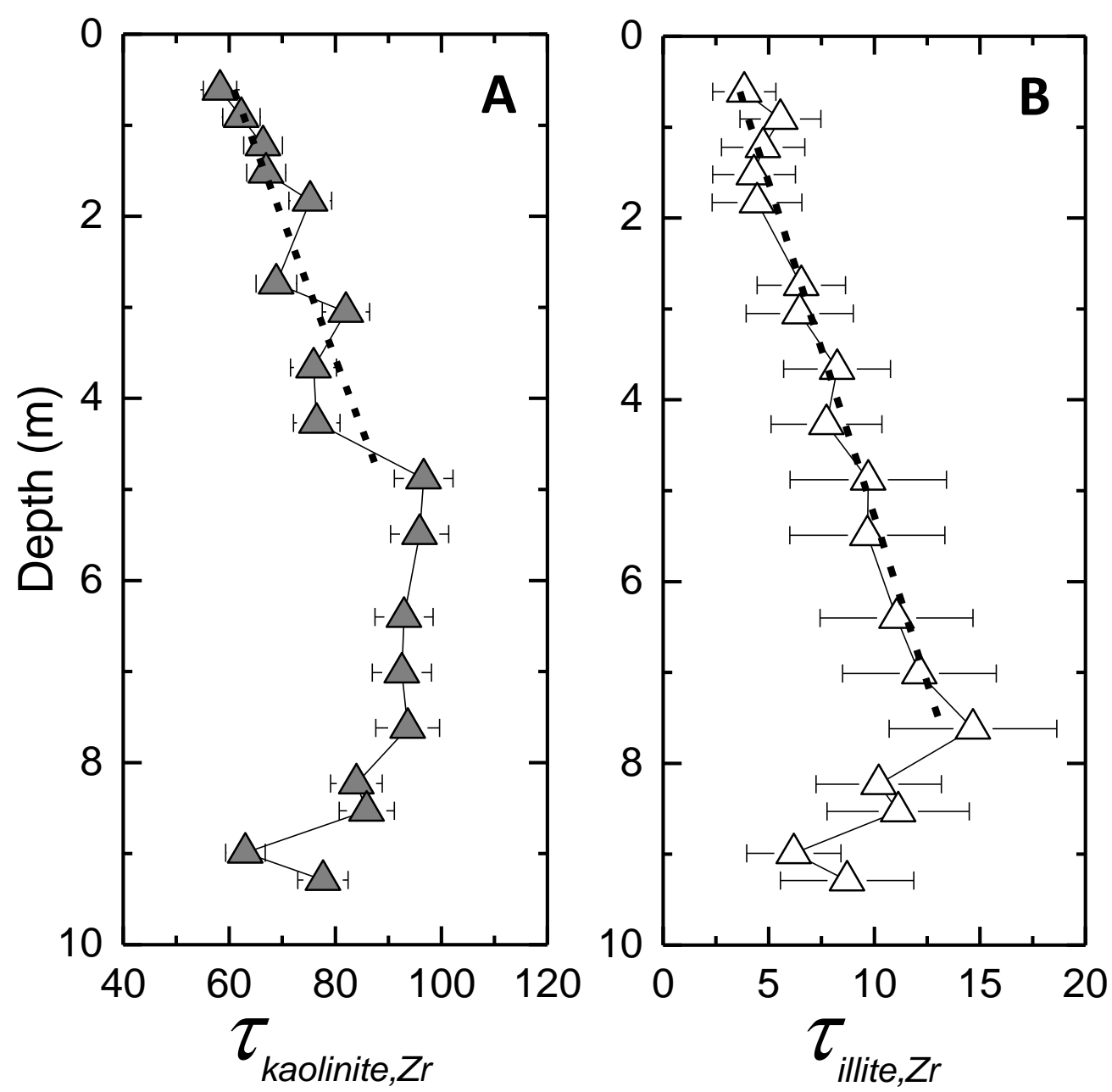